\title{
Modelagem de Usuários para Sistemas de auxílio à Escrita Técnica
}

Renato Correia de Barros

Orientadora: Profa. Dra. Sandra Maria Aluísio

Dissertação apresentada ao Instituto de Ciências Matemáticas e de Computação - ICMC-USP, como parte dos requisitos para obtenção do título de Mestre em Ciências - Área: Ciências de Computação e Matemática Computacional.

São Carlos

Janeiro/2000 
Dedicatória

Aos meus pais, José e Olinda. 


\section{Agradecimentos}

A Deus, por ser soberano sobre todas as coisas e ter me acompanhado em todos os momentos, principalmente nos mais dificeis sempre se fazendo presente, me consolando e dando novo animo.

A Profa. Dra. Sandra Maria Aluísio, por sua compreensão, carinho, amizade, e pelo excelente trabalho de orientação.

Ao Jorge, por sua amizade, pela disposição e pela ajuda na realização deste trabalho.

Ao Luciano pela dedicação, amizade e ajuda com sugestões, sem as quais, muitas coisas não seriam feitas.

À Maria Helena pelo carinho e companheirismo.

Aos meus amigos de curso e laboratório, pela amizade e pelos "bate-papos".

Aos meus companheiros de república, por serem verdadeiros amigos.

A Maria Lucia por ter insistido para que eu iniciasse o mestrado e pelos ótimos momentos que passamos juntos.

Aos amigos Francisco, Leslie, Maria Rita, Myrian, Daniela por suas sinceras amizades e carinho. Ao grande amigo Fábio Henrique que em muitos momentos me ajudou, principalmente nas últimas semanas.

Aos amigos e professores do Departamento de Computação da Unesp de Bauru pelas recomendações, dicas e amizade.

À minha familia, pelo apoio, amor e compreensão pelo tempo que estive ausente.

Às funcionárias da Pós-Graduação, Beth, Laura e Marília, por serem sempre tão educadas e prestativas.

Ao CNPq pelo apoio financeiro.

Àqueles que, de um modo ou de outro, contribuíram para a realização deste trabalho. 


\section{Índice}

1. INTRODUÇÃO.

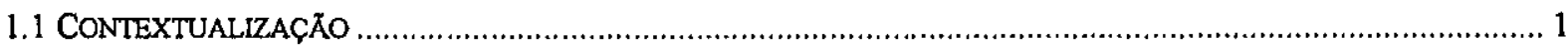

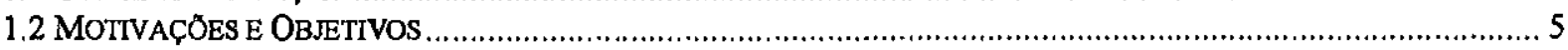

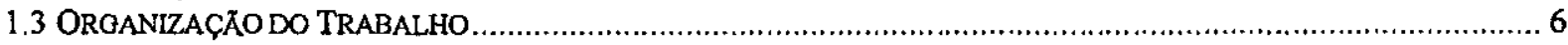

2. ESCRITA TÉCNICA EM INGLÊS COMO LÍNGUA ESTRANGEIRA .................................................. 7

2.1 ALGUNS ERROS COMETIDOS POR ESTUDANTES BRASILEIROS NA ESCRITA EM INGLES .............................. 7

2.2 AMBIENTES DE SOFTWARE E FERRAMENTAS PARA O AUXILIO E ENSINO DA ESCRITA TECCNICA ....................9

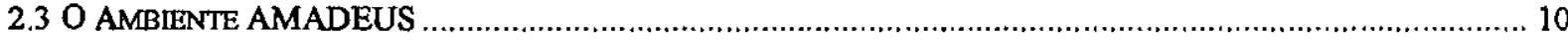

2.3.1 Ferramenta de Referência: Um assistente descritivo ............................................................

2.3.1.1 Arquitetura da Ferramenta de Referência............................................................................................................ 13

2.3.2 Ferramenta de Suporte: Um assistente cooperativo................................................................ 15

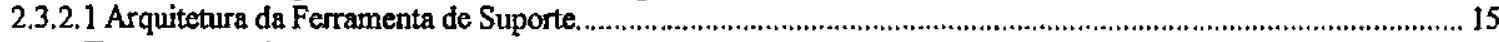

2.3.3 A Ferramenta de Critica: Um tutor colaborativo....................................................................... I8

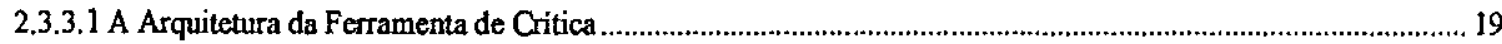

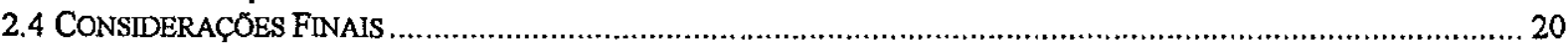

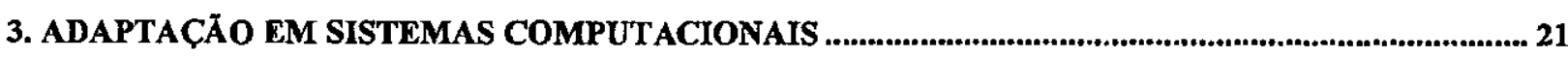

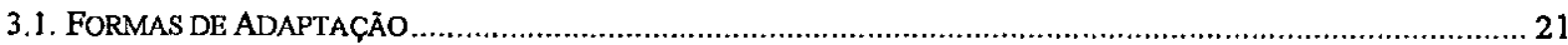

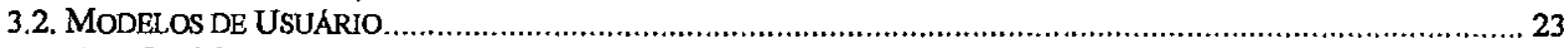

3.2.1. Os diferentes tipos de Modelos de Ustuário..........................................................................24

3.2.2. Métodos Adaptativos em Diferentes Áreas de Pesquisa ................................................................ 26

3.2.2.1. Modelo do estudante para sistemas tutores inteligentes (STIs) ....................................................................26

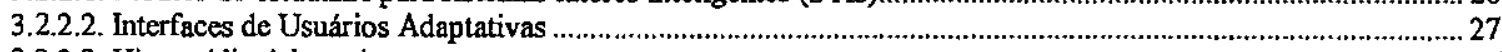

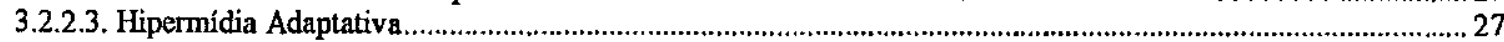

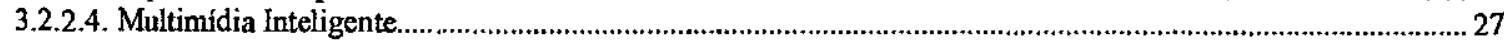

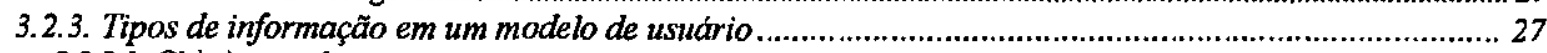

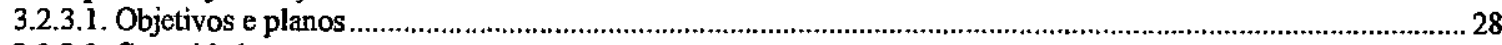

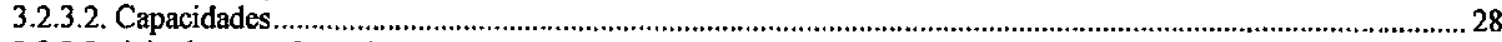

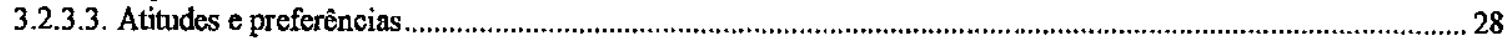

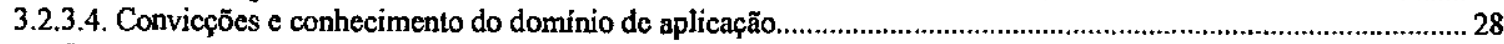

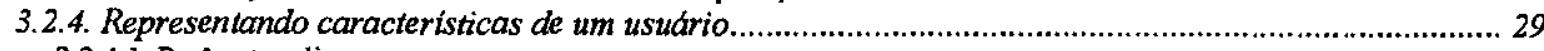

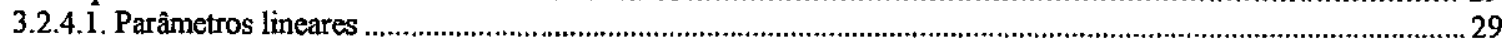

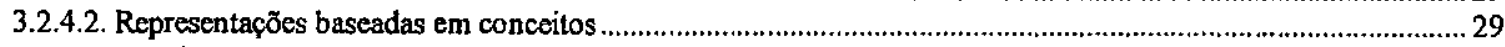

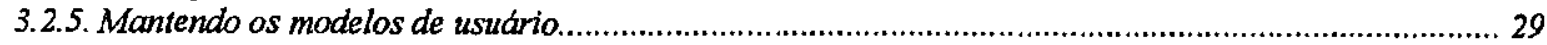

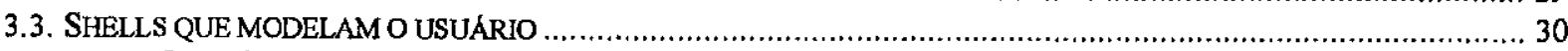

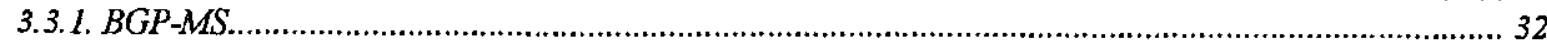

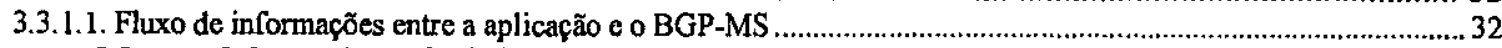

3.3.1.1.1. Informando o BGP-MS a respeito de crenças e objetivos do usuário .....................................................33

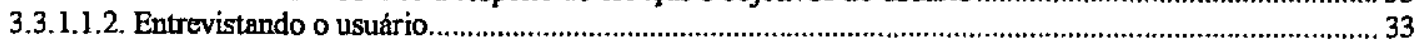

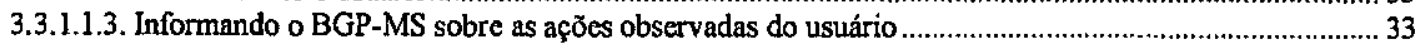

3.3.1.1.4. Questionando o BGP-MS sobre as suposições correntes sobre as crenças e metas do usuário ............... 34

3.3.1.1.5. Sinalizando importantes suposições deduzidas à aplicaçăo ....................................................................34

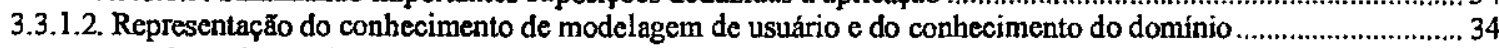

3.3.1.2.1. Hierarq̣uias de partị̂ão para a representação de modelos de usuários individuais e estereótipos ........... 35

3.3.1.2.1.1. Representação do conhecimento do domínio do BGP.MS ...................................................... 35

3.3.1 2.1.2. Representação do modelo de usuário individual ....................................................................35

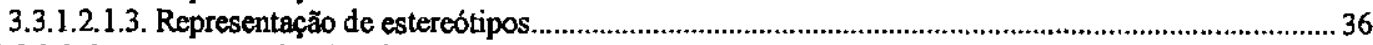

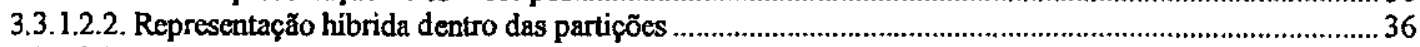

3.3.1.3. Aquisição do Modelo de Usuário e a manutenção da consistência no BGP-MS …............................................37

3.3.1.3.1. Inferências a partir de entrevistas com o usuário.............................................................................. 37

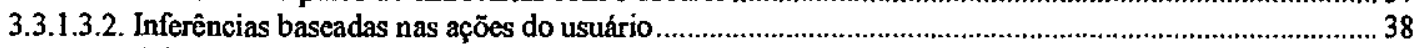

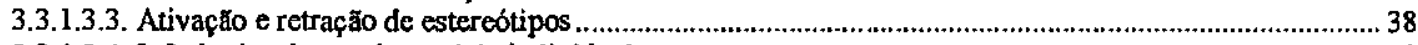

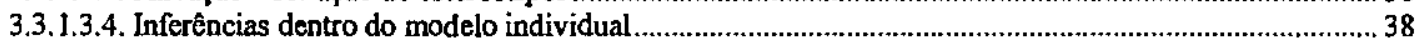

3.3.1.3.5. Dependências inferenciais e manutenção da consistência .................................................................. 39

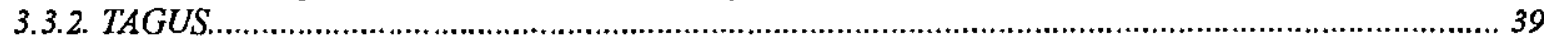

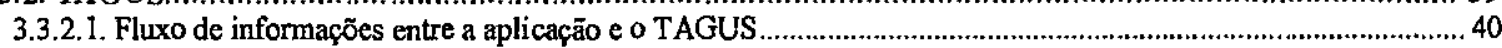

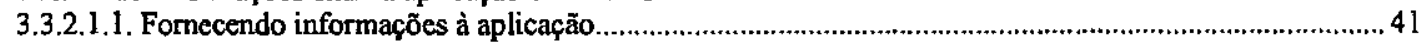




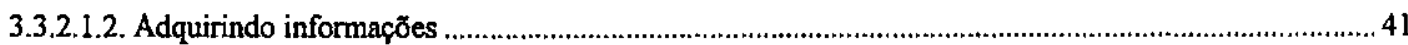

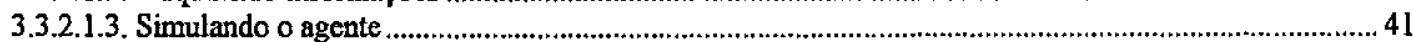

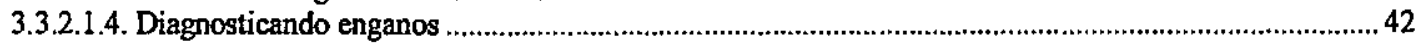

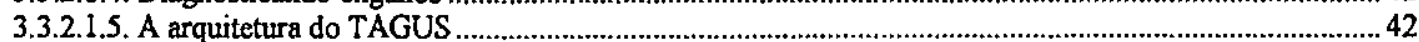

3.3.2.2. Representação do conhecimento de modelagem de usuário e do conhecimento do dominio ............................43

3.3.2.2.1. Conhecimentos e crenças de usuários e estudantes ................................................................................4

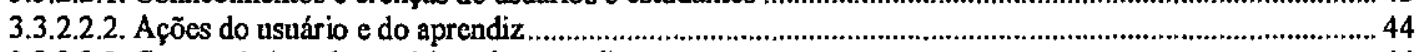

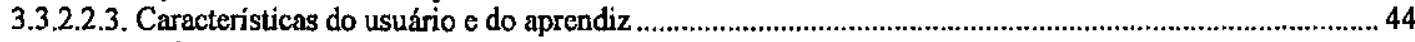

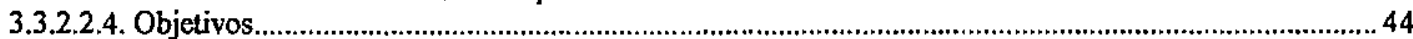

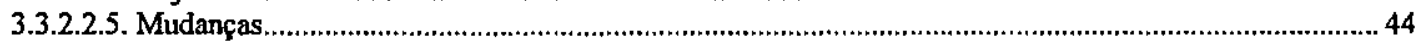

3.3.2.3. Aquisição do Modelo de Usuário e a manutençăo da consistência no TAGUS ................................................44

3.3.3. Comparação entre os Shells .............................................................................................45

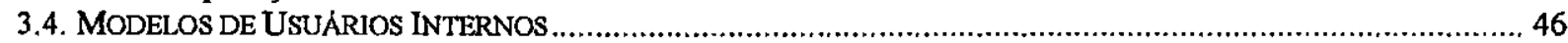

3.4. . Modelando os erros dos estudantes no tutor ELECTRE.......................................................46

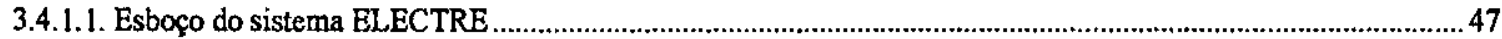

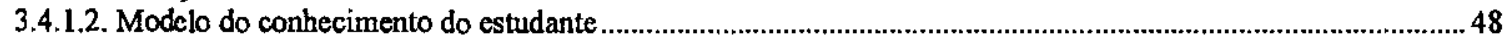

3.4.2. Uma interface de banco de dados adaptável .......................................................................... 50

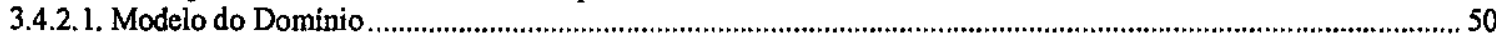

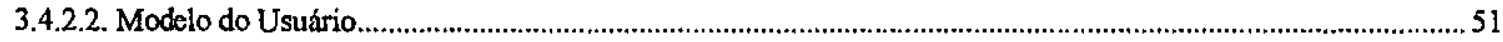

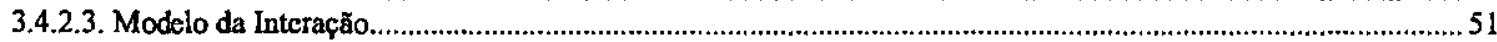

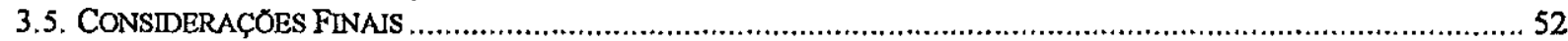

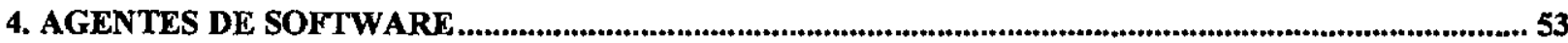

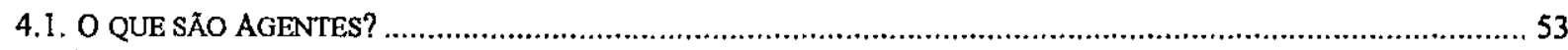

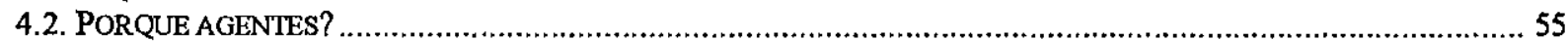

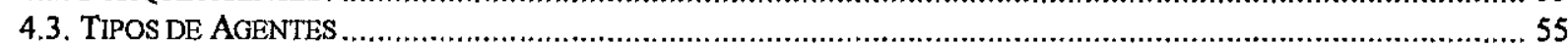

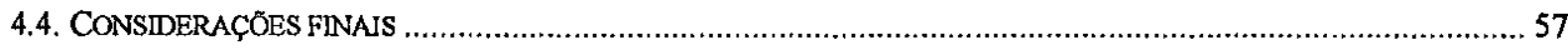

5. MODELANDO O USUÁRIO EM UM SISTEMA DE AUXÍLIO À ESCRITA TÉCNICA EM INGXÊS.. 58

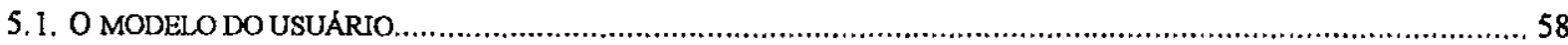

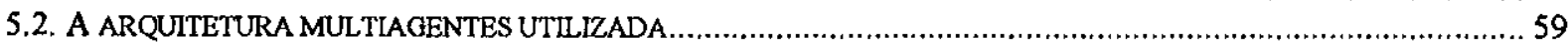

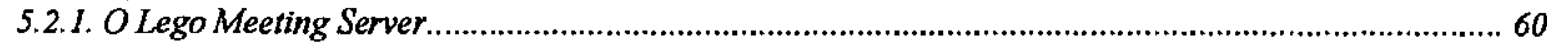

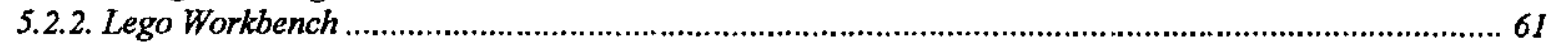

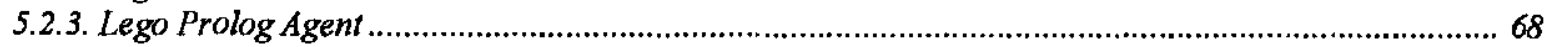

5.2.3.1. Mudanças na estrutura das ferramentas para reportarem o score do usuário....................................................69

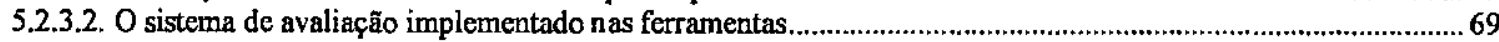

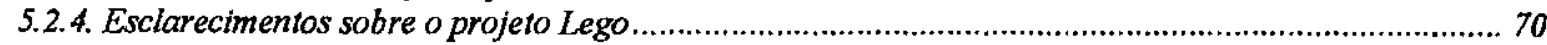

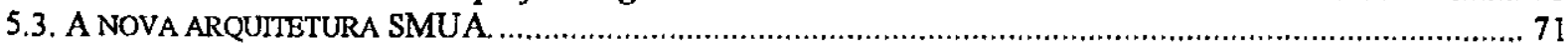

5.3.1. Fhoxo de informações entre a aplicação e o Shell SMUA ....................................................................73

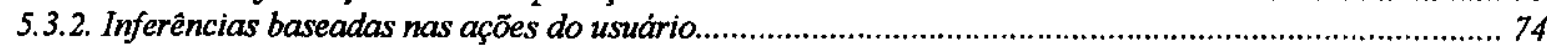

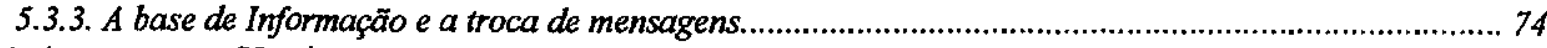

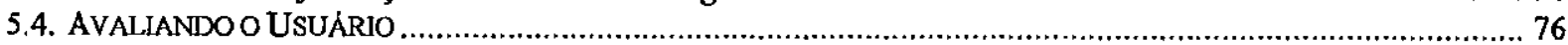

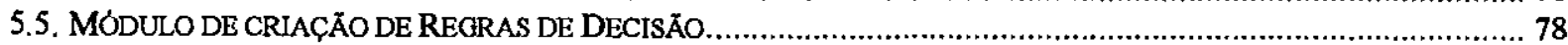

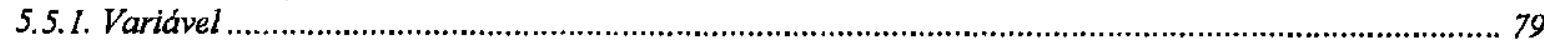

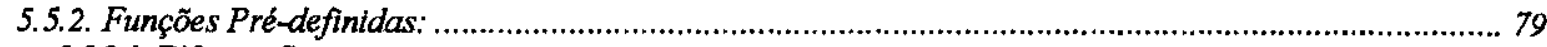

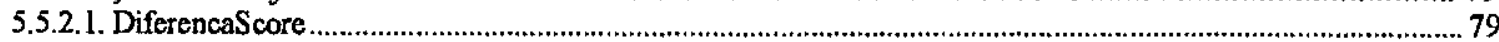

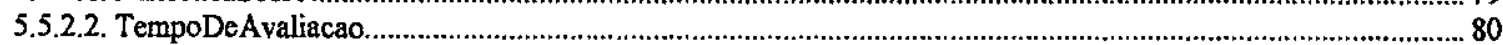

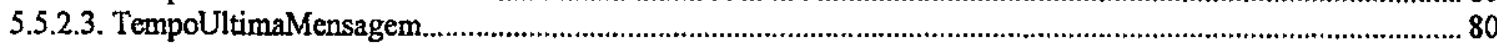

5.5.2.4. Funções de Manipulação da avaliação do usuário .........................................................................................8 81

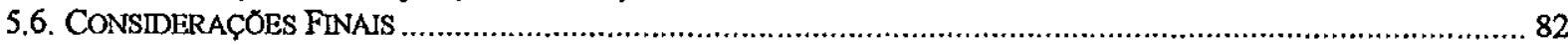

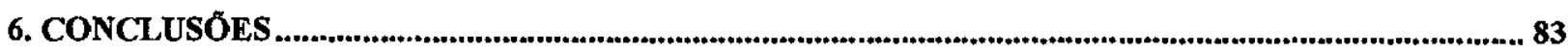

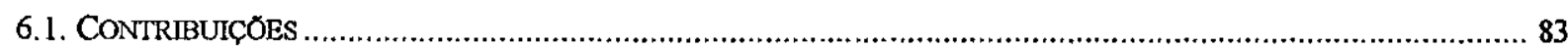

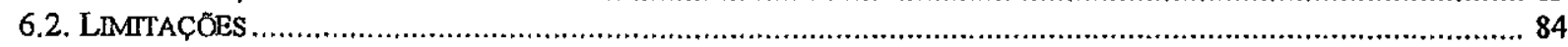

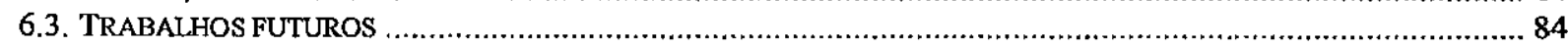

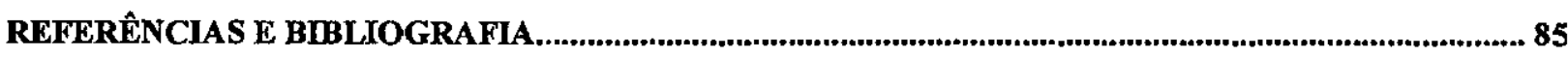

APÊNDICE - COMO UTILIZAR O SISTEMA ADAPTATIVO .......................................................... 94 


\section{Lista de Figuras}

Figura 1: Modelo do Ambiente AMADEUS enfatizando os tipos de conhecimento utilizados .3

Figura 2: A arquitetura da Ferramenta de Referência .................................................... 14

Figura 3: A arquitetura da Ferramenta de Suporte................................................................ 17

Figura 4: A abordagem de críticas [Fischer-91] ............................................................. 18

Figura 5: A arquitetura da Ferramenta de Crítica................................................................. 19

Figura 6: Um diagrama onde dois resistores estão conectados em série...................................49

Figura 7: Tipologia de agentes segundo Nwana. ...........................................................56

Figura 8: Classificação de Agentes de software......................................................................56

Figura 9: Modelo de Compartilhamento de Projetos..............................................................61

Figura 10: Interface Gráfica do Lego Workbench.............................................................62

Figura 11: Apoio Gráfico à Construção de Árvores..................................................................63

Figura 12: Aliviando a Memória com a Adição de uma Palette..............................................63

Figura 13: Três Momentos da Palette Dinâmica (Sensível a Contexto) em Ação......................64

Figura 14: Seqüência da Substituição de um Vocábulo Abstrato Quando de sua

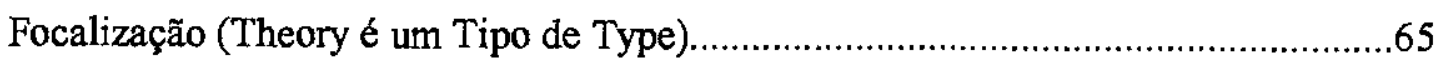

Figura 15: Seqüência da Substituição de um Vocábulo Abstrato quando de sua

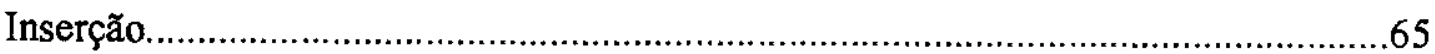

Figura 16: Lego Workbench: Ênfase em Anotaçð̃es de Revisão .................................................67

Figura 17: Lego Workbench: Ênfase em Notificaçø̃es..............................................................68

Figura 18: A nova arquitetura do AMADEUS com o SMUA ...............................................72

Figura 19: Representação da topologia de agentes híbridos utilizada.....................................73

Figura 20: Representação do fluxo das mensagens...............................................................75

Figura 21: Gráfico ilustrando os tipos de decisões.................................................................77

Figura 22: Avaliação do usuário usando a base temporal......................................................78

Figura 23: A Interface de criação de regras do modelo de usuário para cada ferramenta ...........79

Figura 24: Instalação do Lego Meeting Server....................................................................94

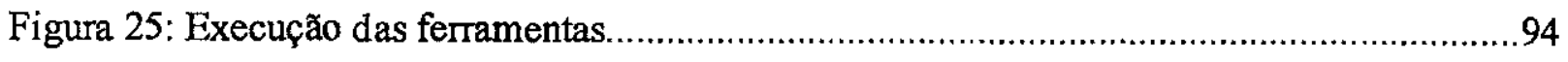

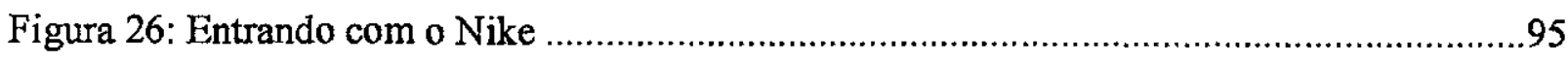

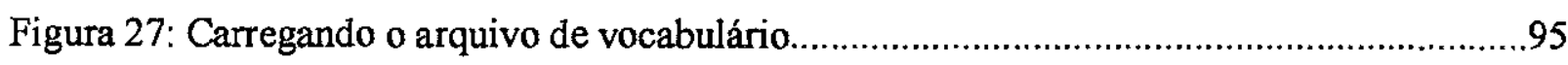

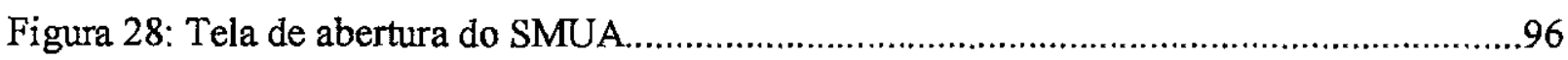




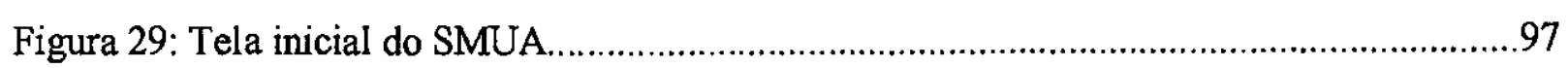

Figura 30: Iniciando a construção de um projeto.....................................................................97

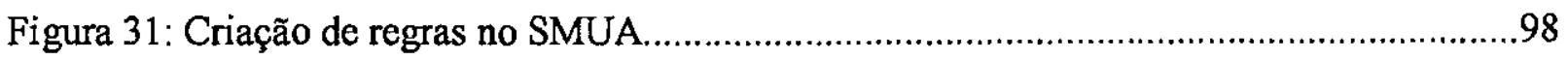

Figura 32: Um usuário leigo criando um outline................................................................99

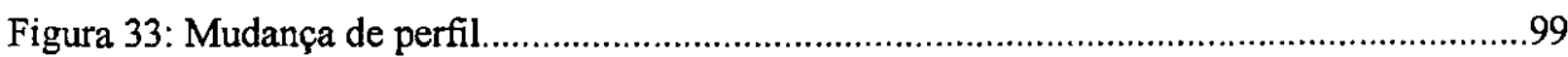

Figura 34: Erros e acertos do usuário reportados pelas ferramentas.........................................100 


\section{Lista de Tabelas}

Tabela 1: Exemplos de erros cometidos por estudantes brasileiros......................................8

Tabela 2: Adequabilidade do tipo de ferramenta quanto ao conhecimento do usuário..............11

Tabela 3: Diferenças entre os três modos de adaptatividade. ...............................................22

Tabela 4: Comparação de seis shells de acordo com nove critérios........................................31

Tabela 5: Comparação das características básicas dos shells: BGP x TAGUS .........................45

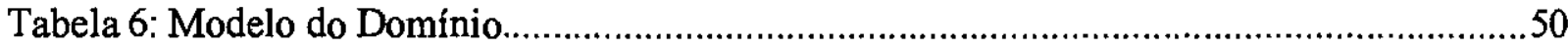

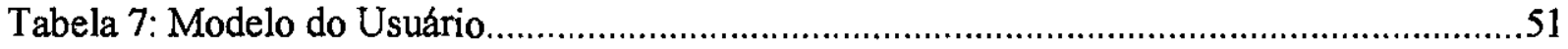

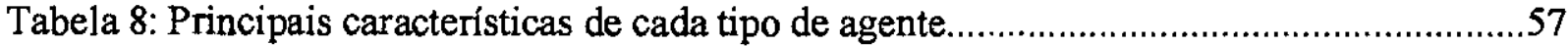

Tabela 9: O novo conjunto de instruções das ferramentas...............................................69

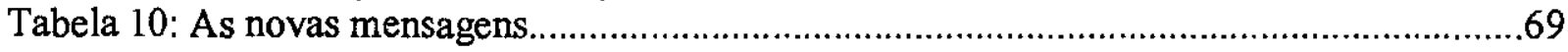




\section{Resumo}

Atualmente, o inglês é a língua dominante para a escrita e divulgação de pesquisas cientificas na forma de artigos científicos. Porém, existem muitos usuários da língua inglesa que sofrem interferência da língua materna quando escrevem este gênero de texto em inglês. Estes usuários se defrontam com problemas nas regras da gramática e estilo, e/ou se sentem incapazes de gerar expressões e orações padrões, e composiçðes linguísticas maiores que são convencionais neste gênero. Para amenizar os problemas desses usuários foi desenvolvido um ambiente modular de auxilio e ensino de escrita técnica chamado AMADEUS (Amiable Article Development for User Support). AMADEUS consiste de várias ferramentas inter-relacionadas - ferramenta de referência, ferramenta de suporte, ferramenta de crítica e ferramenta tutorial - e fornece o contexto que está inserido este trabalho de mestrado. O objetivo principal deste mestrado é implementar AMADEUS como uma arquitetura de agentes que se comunicam através da troca de mensagem com um agente especial que contém um modelo dinâmico do usuário interagindo com o ambiente. Para tanto, introduzimos o conceito de adaptatividade em sistemas computacionais e descrevemos vários shells para modelar o usuário. Também fornecemos detalhes sobre agentes inteligentes que foram usados para implementar o modelo de usuário para o ambiente AMADEUS. 


\begin{abstract}
Currently, the English is the language chosen to publish research. However, many non-natives of English face problems related to interference from their mother tongue (L1 interference) when writing scientific papers in English. These non-native users also face problems concerning several aspects of the English such as grammar and style, and/or have difficulties in choosing appropriate sentence and collocations which appear with high frequency in scientific texts. In order to overcome some of these difficulties we developed a learning environment for scientific writing named AMADEUS (Amiable Article Development for User Support). The overall architecture of AMADEUS embodies both advising and tutoring tools, which are called Reference, Support, Critic and Tutoring tools and provides the context of this research work. The main goal of this work is to implement AMADEUS as an agent-based architecture with collaborative agents communicating with a special agent embodying a dynamic user model. In order to do that we present the concept of adaptivity and describe several user model shells. We also provide details about intelligent agents which were used to implement the user model for the AMADEUS environment.
\end{abstract}




\section{Introdução}

\subsection{Contextualização}

Problemas com a escrita podem afetar o desempenho de profissionais de maneira marcante, principalmente no caso de pesquisadores e acadêmicos que precisam escrever com proficiência e desembaraço não apenas na língua materna, mas também em uma ou mais línguas estrangeiras.

Atualmente, o inglês é a língua dominante para a escrita e divulgação de pesquisas científicas na forma de artigos científicos. Porém, existem muitos usuários da língua inglesa que sofrem interferência da língua materna quando escrevem este gênero de texto em inglês. Estes usuários se defrontam com problemas nas regras da gramática e estilo, e/ou se sentem incapazes de gerar expressões e orações padrões, e composições lingüísticas maiores que são convencionais neste gênero. Para amenizar os problemas desses usuários foi desenvolvido um ambiente modular de aux́lio e ensino de escrita técnica chamado AMADEUS (Amiable Article Development for User Support) [Fontana-93; Aluísio-95a; Aluísio-95b; Aluísio-95c; Aluísio97a, Aluísio-97b].

AMADEUS consiste de várias ferramentas inter-relacionadas - ferramenta de referência, ferramenta de suporte, ferramenta de critica e ferramenta tutorial - que apresentam diferentes estilos de interação usuário-sistema (usuário dirigindo a interação, cooperação ${ }^{1}$ entre sistema e usuário, colaboração ${ }^{2}$ entre sistema e usuário e sistema dirigindo a interação, respectivamente) e diferentes tipos de conhecimento a respeito: (1) da estrutura de um artigo (expressões e orações, parágrafos e seções), (2) do propósito, e (3) do tipo de audiência dos diversos subtipos de textos científicos.

No modelo do ambiente AMADEUS, a primeira das ferramentas concebidas foi a ferramenta de referência que se caracteriza por conter o conhecimento enciclopédico do sistema,

\footnotetext{
${ }^{1}$ Cooperação utiliza a divisão de trabalho entre os participantes, com cada um sendo responsável por uma parte, não necessariamente mantendo o engajamento mútuo [Brandford-94; Burton-97].

${ }^{2}$ Colaboração é um processo $\mathrm{cm}$ que dois ou mais agentes trabalham juntos para resolver metas comuns. A colaboração, segundo Blandford [Blandford-94] e Burton [Burton-97], implica em uma atividade sincrona e coordenada, resultado da tentativa constante de construir e manter uma conccp̧ão compartilhada do problema.
} 
isto é, conhecimento das expressões e orações padrões que são utilizadas para descrever tabelas, figuras e procedimentos experimentais; comparar resultados; ou fornecer suporte para argumentações, por exemplo. Esta ferramenta descreve o conhecimento que possui pois mostra como a escrita é feita.

A segunda das ferramentas desenvolvidas foi a ferramenta de suporte, um assistente cooperativo responsável pela divisão de trabalho entre sistema e usuário com cada um sendo responsável por uma parte do problema: o assistente faz o que máquinas fazem melhor indexar e organizar adequadamente uma grande quantidade de informações que resolveram problemas no passado para apresentação ao usuário da informação mais similar àquela necessária a uma situação atual - enquanto que o usuário faz o resto. Esta ferramenta contém o conhecimento de estratégias retóricas necessárias para montar um parágrafo, assegurando coesão e coerência em pequenos pedaços de texto.

A ferramenta de crítica, por sua vez, provê conhecimento estrutural em um nivel textual maior que um parágrafo; conhecimento que indica as sequêencias mais apropriadas de estratégias retóricas para cada uma das várias seções de um artigo. Essa ferramenta permite a escrita de textos apropriados a um propósito e audiência específicos (por exemplo, a escrita de um artigo sobre uma pesquisa experimental para uma comunidade de pesquisa específica dentro da Computação) e possui um estilo colaborativo para a resolução de problemas se utilizando de críticas a um trecho de texto ou outline gerado pelo usuário.

Finalmente, a ferramenta tutorial familiariza o escritor com o vocabulário das três ferramentas descritas até então e com o processo de escrita utilizando material reusável de textos de nativos do inglês, guiando-o através da escrita de uma seção de um artigo. Esta última ferramenta prescreve o conhecimento da escrita para o usuário, mostrando como a escrita de um artigo deve ser feita. Uma caracterização dessas ferramentas quanto ao conhecimento utilizado é mostrada na Figura 1. 


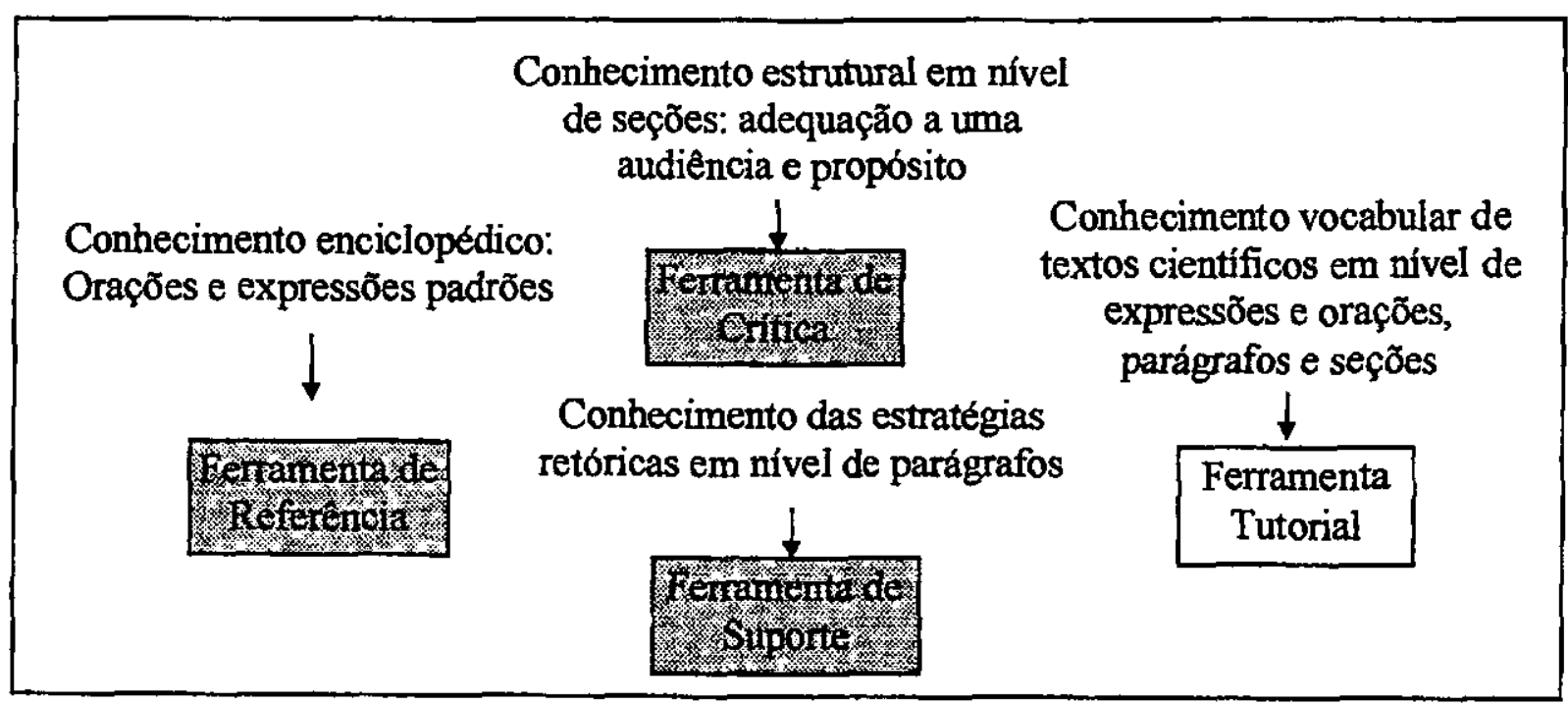

Figura 1: Modelo do Ambiente AMADEUS enfatizando os tipos de conhecimento utilizados

A figura acima fornece o contexto que está inserido este trabalho de mestrado. As ferramentas de referência e de suporte já foram desenvolvidas para auxiliar a escrita de artigos curtos em inglês para o domínio de Física Experimental e para auxiliar a escrita de Introduções para o mesmo domínio, respectivamente. A ferramenta de crítica foi desenvolvida como um trabalho de mestrado no ICMS [Silva-99] e trata do ensino da escrita técnica para uma comunidade de pesquisa especifica, a $\mathrm{CHI}$ (Conference on Human Factors in Computing Systems), sendo que a seção escolhida para a análise nesse trabalho foi a Introdução.

A ferramenta tutorial, ainda não desenvolvida, será capaz de guiar o usuário através dos passos de uma tarefa, como por exemplo, a escolha da melhor expressão para escrever o propósito de um determinado artigo, dado um contexto específico. O modelo desta ferramenta segue os tutoriais de utilização de processadores de texto, planilhas e softwares de apresentação, por exemplo, que guiam o usuário através da funcionalidade do software dando exemplos e permitindo algum treinamento para as funções.

Cada uma das ferramentas apresentadas acima é direcionada a um conjunto de problemas específicos, caracterizado pelos níveis diferentes de facilidade de escrita na segunda língua e conhecimento da escrita técnica de cada usuário, correspondendo a quatro estereótipos de usuários ${ }^{3}$.

3 Modelos de grupos de usuários que servem como fonte para inferências "default" sobre o usuário, no caso deste ser um membro do grupo [Pohl-96]. 
Através da Figura 1, poderia se imaginar que a utilização do ambiente AMADEUS por um usuário leigo na escrita técnica e língua inglesa começaria pela ferramenta tutorial, sendo seguida pela ferramenta de crítica, depois suporte, e finalmente este utilizasse sempre a ferramenta de referência, pois ela fornece uma variedade de expressões de uma forma rápida e é adequada para usuários que possuem um bom domínio de língua e escrita técnica.

Entretanto, é fácil antever uma situação na qual um usuário com boa recepção do inglês e boa experiência de escrita que é capaz de articular uma argumentação com destreza, descrever facilmente tabelas e figuras, comparar resultados, etc., ainda escreva uma contextualização de seu trabalho de uma forma que não é apropriada para uma audiência não especialista em uma dada área de pesquisa. Este usuário teria um problema especifico que não seria significativo o bastante para colocá-lo em outro grupo de usuários, porém, trabalhando com a ferramenta de referência não conseguiria ajuda desta para superá-lo. Ou ainda, é fácil imaginar outra situação na qual um usuário cujo estereótipo indique o uso da ferramenta de crítica tenha preferência pelo estilo de interação cooperativo em vez do colaborativo.

Para satisfazer as diferentes necessidades e exigências dos usuários os sistemas computacionais podem ser adequados manualmente pelo usuário ou então devem, eles mesmos, reconhecer a necessidade de adaptação através de suposições sobre os usuários. Os sistemas que permitem que o usuário mude, manualmente, certas características suas para adaptar o seu comportamento para as preferências individuais são chamados adaptáveis. A segunda solução para adaptação possui duas variantes: o sistema orienta o usuário para a adaptação necessária, explica as razões, mas deixa o usuário decidir se uma dada adaptação deve ser realizada (são os chamados sistemas com suporte para a adaptação controlada pelo usuário), ou o sistema muda seu comportamento automaticamente de acordo com as necessidades (possivelmente antecipadas) do usuário. Estes últimos são chamados sistemas adaptativos.

Este último tipo de sistema é de interesse neste trabalho, pois com a adaptatividade implementada no ambiente AMADEUS resolveríamos os problemas levantados nas duas situações acima.

Para fornecer comportamento adaptativo a um sistema, um modelo de usuário precisa ser implementado e mantido durante a interação com o usuário. Ele contem suposições explícitas sobre todos os aspectos do usuário que podem ser relevantes para a adaptação do sistema, como por exemplo, conhecimento necessário para operar no dominio, preferências, interesses e habilidades [Chin-93].

$\mathrm{Na}$ próxima seção, discutiremos melhor esta motivação para o trabalho de mestrado e a relevância da escolha dos tópicos teóricos que tendem a resolver o problema de tornar $o$ 
ambiente AMADEUS um ambiente adaptativo tanto ao conhecimento de escrita e da língua inglesa que possui um usuário, quanto à preferência de estilo de interação com um sistema computacional.

\subsection{Motivações e Objetivos}

O domínio de aplicação deste trabalho de mestrado traz desafios para a área de modelagem de usuários, pois o modelo do usuário a ser utilizado no ambiente descrito acima deve integrar e ativar quatro ferramentas de escrita independentes ${ }^{4}$ que diferem no conhecimento sobre a escrita e língua inglesa utilizada em artigos, e na forma de interação usuário-sistema, isto é, na estratégia de auxilio ou ensino que cada ferramenta utiliza. Este contexto único privilegia também a pesquisa sobre agentes inteligentes que se comunicam com um modelo de usuário externo a cada uma das ferramentas e que auxilie e ensine o usuário na tarefa da escrita técnica. Como veremos no Capítulo 3, modelar as preferências de um usuário quanto à forma de interação ainda é um tópico de pesquisa aberto.

O objetivo principal deste mestrado é implementar uma arquitetura de agentes que se comunicam através da troca de mensagem com um agente especial que contém um modelo dinâmico do usuário interagindo com o ambiente.

$O$ conceito de um agente tem se tornado importante nas pesquisas de Computação em geral e em Inteligência Artificial (IA), em particular. A idéia de integrar as quatro ferramentas num ambiente único vem de encontro com estas pesquisas.

Agentes são componentes de software que se comunicam com seus pares pela troca de mensagens utilizando uma linguagem de comunicação. Embora eles possam ser tão simples como subrotinas, geralmente eles são modelados como entidades maiores contendo algum tipo de controle persistente $e$, principalmente, autonomia. O que caracteriza agentes é a sua habilidade de comunicação e cooperação com outros agentes [Moreira-95, Tambe-95].

Os agentes de software podem ser vistos como pequenos programas cooperando entre si para realizar grandes tarefas, e por serem formados por pequenas partes facilitam a manutenção. Com o uso de técnicas de IA, conseguem também se adaptar a novas situações. Grandes programas seqüenciais que realizavam várias tarefas estão perdendo seu lugar porque são mais sensiveis ao ataque de vírus, não podem adaptar-se a novas situações, geralmente possuem muitos "bugs" e contam com partes de seu código incompreensíveis, e devido ao tamanho do código fonte e da complexidade, acabam por dificultar a sua manutenção.

\footnotetext{
${ }^{4}$ Embora a ferramenta tutorial não esteja ainda implementada, a arquitetura do sistema adaptativo foi projetada para facilitar a sua fácil integração com as outras três ferramentas já desenvolvidas.
} 
A tecnologia de agentes vem também facilitar a criação de software capaz de interoperar em ambientes heterogêneos. Além das vantagens apresentadas acima, temos uma maior flexibilidade e adequação para uso em um modelo de implementação cliente/servidor. Do ponto de vista de IA, Guha and Lenat [Guha-94] declaram a existência de dois paradigmas de agentes de software nos dias atuais, sendo que um deles diz que a competência e capacidade emergem de um grande número de agentes integrados por uma arquitetura inteligentemente construída. Resumindo, os objetivos deste mestrado são:

- Descrever com detalhes o domínio de aplicação e salientar os desafios de pesquisa para a área de agentes de software e modelos de usuário;

- Propor um modelo dinâmico do usuário baseado no nível de conhecimento a respeito da escrita e da língua inglesa técnica e da preferência por uma determinada forma de interação usuário-sistema.

- Implementar o ambiente integrado e adaptativo de escrita.

\subsection{Organização do Trabalho}

O Capítulo 2 apresenta com detalhes o projeto AMADEUS no qual este mestrado está inserido, apresentando as arquiteturas de suas ferramentas integrantes. O Capítulo 3 introduz o conceito de adaptatividade e descreve vários shells para modelar o usuário. No Capítulo 4 são fornecidos mais detalhes sobre agentes inteligentes. No Capítulo 5 abordamos as decisões de projeto para a construção do protótipo de um Sistema Adaptativo para a Escrita Técnica em Inglês e, finalmente, no Capítulo 6 apresentamos as conclusões deste trabalho e as considerações sobre os trabalhos futuros. 


\section{Escrita Técnica em Inglês como Língua Estrangeira}

As dificuldades que não nativos enfrentam quando estão preparando textos em uma língua estrangeira, mesmo considerando-se que eles possuam um conhecimento operacional daquela língua, surgem principalmente de dois fatores. O primeiro é devido à diversidade sóciolinguística, pois línguas diferem em nível léxico, sintático e pragmático [Wolfson-89]. Conseqüentemente, diferentes línguas utilizam diferentes padrões retóricos para organizar o discurso. O segundo fator causador de dificuldades para não nativos está relacionado aos processos de compreensão e produção de uma língua. Sabe-se que a compreensão é mais facilmente alcançada do que a produção.

Abaixo, mostramos um estudo que apresenta as dificuldades de não nativos da língua inglesa na atividade de escrita de teses, artigos e trabalhos acadêmicos.

\subsection{Alguns Erros Cometidos por Estudantes Brasileiros na Escrita em Inglês}

Um estudo das dificuldades mais comuns enfrentadas por estudantes brasileiros de pósgradução foi realizado em 1989 por Fontana [Fontana-91; Fontana-93]. Foram colhidos amostras de erros cometidos por estudantes brasileiros de pós-graduação no Reino Unido, na produção de teses, artigos e trabalhos acadêmicos. Após o levantamento, os itens considerados errados foram categorizados de acordo com o procedimento chamado "Análise de Erros" usado em Linguística Aplicada.

Segundo Carl James [James-89], os erros podem ser analisados a partir de dois eixos, o linguístico e o comportamental. No eixo linguístico estão às categorias em nível da língua: gramática, texto, fonologia/ortografia, léxico, pragmática/semântica, que permitem a identificação da área em que os erros ocorrem. No eixo comportamental estão colocadas quatro categorias, que descrevem os principais procedimentos do usuário: omissão, redundância, escolha inadequada, e ordenação inadequada. Alguns exemplos são fornecidos na Tabela 1. 
Tabela 1: Exemplos de erros cometidos por estudantes brasileiros.

\begin{tabular}{|c|c|c|}
\hline Forma Utilizada & Forma Correta/Pretendida & Categoria do Erro \\
\hline $\begin{array}{l}\text { Posterior } \\
\text { Incentived } \\
\text { Experimentator }\end{array}$ & $\begin{array}{l}\text { Subsequent } \\
\text { Encouraged } \\
\text { Experimenter }\end{array}$ & $\begin{array}{l}\text { Escolha lexical inadequada (por } \\
\text { transferência da lingua materna) }\end{array}$ \\
\hline Informations & bits of information & $\begin{array}{l}\text { Redundância gramatical (inclusão } \\
\text { de material supérfluo) }\end{array}$ \\
\hline $\begin{array}{l}\text { the literature's sources } \\
\text { more new }\end{array}$ & recent literature souces & $\begin{array}{l}\text { gramatical e lexical } \\
\text { (ordenação inadequada, } \\
\text { redundância) e (escolha } \\
\text { inadequada) }\end{array}$ \\
\hline in this area & qual área? & textual (omissão da referência) \\
\hline $\begin{array}{l}\text { The third misconception } \\
\text { claims that every language } \\
\text { is (...) used and understood } \\
\text { by all its practitioners (...), } \\
\text { but there are dialect-users } \\
\text { in each (..) country (...), } \\
\text { that may have serious } \\
\text { problems understanding } \\
\text { but all the people have } \\
\text { somewhat in common. }\end{array}$ & $\begin{array}{l}\text { The third misconception } \\
\text { claims that every language is } \\
\text { (...) used and understood by all } \\
\text { its practitioners (...). As a matter } \\
\text { of fact there are dialect-users in } \\
\text { each (...) country (...), that may } \\
\text { have serious problems } \\
\text { understanding each other. } \\
\text { However, in spite of this the } \\
\text { people have somewhat in } \\
\text { common. }\end{array}$ & $\begin{array}{l}\text { textual (escolha inadequada de } \\
\text { relações lógicas entre orações, } \\
\text { omissão da referência e escolha } \\
\text { inadequada de pontuação) }\end{array}$ \\
\hline
\end{tabular}

As constatações da análise de erros são:

- Erros localizados, isto é, aqueles que podem ser tratados isoladamente não causam tantos danos à comunicação como aqueles que afetam o significado global do texto ou o significado de várias orações.

- Erros dentro dos limites de uma oração podem ser corrigidos facilmente com uso de um dicionário, uma gramática ou suas correspondentes ferramentas de software.

As deficiências dos textos não se restringiam ao uso de vocabulário inadequado ou estruturas gramaticais incorretas, mas também eram dadas pelo mau uso ou omissão de expressões convencionais para desempenhar funções específicas do texto acadêmico, como, por exemplo, expor a importância de um trabalho, área ou autor; argumentar, introduzir um tópico ou dar exemplos, comparar e contrastar resultados. Estas funções exigem o conhecimento de expressões padronizadas e dos conectivos lógicos adequados que são utilizados nas relações inter-orações. James, em [James-84] ilustra muito bem as dificuldades de não nativos em tornar 
explf́cito o fluxo de informações antecedente a uma oração de forma a fortalecer a coesão entre elas. Na análise da escrita de não nativos do inglês, o autor nota a falta de expressões do tipo:

Still on the subject of $X, \ldots$ As far as $X$ is concerned, ... In the light of $X, \ldots$

A further point about $Y, \ldots$ As regard $Y, \ldots \quad$ Viewed from the angle $Y$

Erros, ou omissões dessa natureza afetam a coerência do texto e podem ser tratados mais adequadamente com uma ferramenta para a escrita que forneça material lingüístico como ilustrado nas expressões acima.

\subsection{Ambientes de software e ferramentas para o auxilio e ensino da escrita técnica}

Várias ferramentas e ambientes de software [Cherry-82; Smith-86; Dale-90; WTG-91; RSI-92; Sharples-94; Pemberton-96] têm sido criados para auxiliar o processo de escrita, muitos dos quais já estão disponíveis comercialmente. A grande maioria deles é dedicada ao pósprocessamento do texto visando corrigí-lo tanto do ponto de vista gramatical, como da clareza, estilo, e concisão das idéias apresentadas. Apesar de serem extremamente úteis para usuários com dificuldades linguísticas, essas ferramentas são limitadas quanto à escrita numa língua estrangeira, pois proporcionam somente mecanismos de correção de um texto acabado. Entretanto, muitas vezes o usuário não é capaz de gerar um texto passível de ser apenas melhorado. Existem outras ferramentas dedicadas ao ensino de uma língua, seja ela a língua nativa do usuário ou não. As ferramentas geralmente se dividem em ensino do vocabulário [Bos94; Goodfellow-95; Renié-95; Segalowitz-95], da gramática [Bolt-91; Yazdani-91], e de gêneros de texto - por exemplo, textos comerciais [Beeken-92] e textos técnicos [Andeweg-92].

Existem dois ambientes de software especificamente devotados para a escrita técnica de não-nativos do inglês: o sistema Composer [Pemberton-96; Shurville-97] e o ambiente AMADEUS [Aluísio-95a; Aluísio-97a]. Composer foi fortemente baseado na ferramenta Writer's Assistant [Sharples-90], um ambiente composto de ferramentas para o planejamento e composição de textos que foi fundamentado em teorias cognitivas do processo de escrita. Atualmente, Composer apresenta inovações que focalizam problemas de não-nativos do inglês escrevendo artigos técnicos. Entretanto, Composer é um sistema de auxílio à escrita enquanto que o ambiente AMADEUS prevê ferramentas de auxílio e também de ensino. 
Como comentado na Seção 2.1, AMADEUS foi fundamentado nos estudos de Fontana [Fontana-91; Fontana-93] que mostraram que algumas das deficiências de alunos brasileiros, realizando cursos de pós-graduação no exterior, estão relacionadas ao mau uso ou omissão de expressões mais ou menos convencionais que desempenham funções específicas do texto acadêmico. Uma solução para este problema consiste na utilização de expressões aprendidas com a prática adquirida na leitura de artigos - acreditamos ser essa estratégia largamente difundida entre estrangeiros que precisam escrever em inglês. Ou seja, numa situação de dúvida, o escritor recorre a textos escritos por pessoas de reconhecida competência. Para otimizar o uso desta estratégia, foi feita uma compilação de expressões e orações extraídas de artigos e livros científicos. Uma verificação surpreendente foi que um número relativamente pequeno de expressões e orações pode ser suficiente para cobrir uma grande proporção das expressões e orações usadas numa certa área do conhecimento. Isto ocorre porque as expressões e orações são empregadas de maneira sistemática, quando se descrevem tabelas, figuras e procedimentos experimentais; quando se comparam resultados; ou se empregam argumentos para dar suporte a afirmações. Anteviu-se, a partir dessa constatação, a possibilidade de se criar ferramentas de software que utilizem essa estratégia de reutilização de trechos de textos.

\subsection{O Ambiente AMADEUS}

Como comentado na Introdução, AMADEUS é um ambiente modular de auxílio e ensino da escrita técnica, que conta com várias ferramentas inter-relacionadas — ferramenta de referência, ferramenta de suporte, ferramenta de crítica e ferramenta tutorial. Cada uma das ferramentas possui a característica comum de ser aplicada a usuários com interferência da língua materna quando escrevem em inglês, porém cada uma se aplica especificamente a um conjunto de problemas caracterizado por diferentes níveis de facilidade na segunda língua (inglês) e grau de experiência na escrita técnica, como ilustra a Tabela 2. 
Tabela 2: Adequabilidade do tipo de ferramenta quanto ao conhecimento do usuário

\begin{tabular}{l|l|l|l}
\multicolumn{1}{r|}{$\begin{array}{l}\text { Escrita } \\
\text { Técnica }\end{array}$} & $\begin{array}{l}\text { Boa } \\
\text { Experiência }\end{array}$ & $\begin{array}{l}\text { Alguma } \\
\text { Experiência } \\
\text { Experiência }\end{array}$ \\
\hline Boa recepção & Ferramenta de Referência & & \\
\hline $\begin{array}{l}\text { Problemas de coesão em } \\
\text { nivel de parágrafo }\end{array}$ & & Ferramenta de Suporte & \\
\hline $\begin{array}{l}\text { Problemas na escrita para } \\
\text { um propósito e audiência } \\
\text { específicos }\end{array}$ & & Ferramenta de Crítica & \\
\hline $\begin{array}{l}\text { Problemas de coesão em } \\
\text { vários niveis }\end{array}$ & & & \\
\hline
\end{tabular}

Das quatro ferramentas do ambiente AMADEUS citadas acima, as duas primeiras são dedicadas ao auxílio da escrita e foram implementadas para o domínio da Física Experimental. A ferramenta de crítica foi desenvolvida como um trabalho de mestrado no ICMS e segue abordagem colaborativa dos sistemas baseados em crítica [Fischer-91; Silverman-92; Fischer-93; Rankin-93; Fischer-95].

Finalmente, a última ferramenta de ensino proposta no ambiente AMADEUS - a ferramenta tutorial - difere da de crítica pois esta não é adequada quando o usuário é completamente novato ou quando existe algum tópico que ele desconheça inteiramente. Neste momento, é desejável uma interação tutor/aprendiz, pois o sistema tem mais conhecimento que o usuário.

As próximas seções apresentam com detalhes o contexto de uso e a arquitetura das ferramentas de referência, suporte e crítica.

\subsubsection{Ferramenta de Referência: Um assistente descritivo}

Diante das dificuldades apontadas na Seção 2.1, como o problema da interferência da língua materna e todos os outros que afetam a coerência de textos escritos por não nativos, Oliveira em [Oliveira-92], propôs um recurso empírico que consiste em fornecer ao escritor material lingüístico na forma de expressões-padrão alocadas em uma base de expressões. Este recurso constitui uma resposta alternativa à necessidade de ajuda técnica, configurada na estratégia de solicitação de ajuda [Huckin-91], cujo emprego parece ser consensual na produção escrita.

Expressões autênticas foram compiladas de artigos científicos das áreas de Física e Informática e apresentam lacunas (para indicar a falta de palavras) que devem ser preenchidas 
com o material factual da pesquisa do escritor. Elas estão agrupadas de acordo com os componentes da estrutura esquemática ${ }^{5}$ de um artigo da área experimental: resumo, introdução, revisão da literatura, metodologia (materiais e métodos), resultados, discussão (inferências). A estrutura esquemática foi novamente subcategorizada, e de acordo com [Deyes-82] a seção Introdução, por exemplo, apresenta os componentes mostrados abaixo.

a) Importance of the field, general interests, etc.

There has been substantial interest in the fabrication of ...

b) Description of an effect, phenomenon, etc.

The phenomenon of ... induced by ... has not only provided a sensitive and convenient probe for monitoring ... (membrane breakdown) but has also revealed the irreversible changes that can occur during...

c) Previous reports on related work.

Several papers have reported measurements aimed at obtaining evidence for, and insight into, ... processes in ...

d) What is lacking in the field.

Although significant advances have been made in the understanding of how ...

(something) influences ... (another), very little further attention appears to have been given to the ...

e) Difficulties faced in a particular analysis

Further difficulties arise from the limited ... available and the requirement for a ...

f) Improvements on previous works, models, etc.

This is an improvement over the existing practice of simply inserting (calculating, determining, etc) ...

g) What the present work does.

The purpose of the work reported here was to study the influence of ... on the ...

h) Relevance of this work to the field or other areas

The surface properties of ... apart from the pure physical chemical interest will help to elucidate the role of ...in many ... phenomena.

i) Layout or Outline of the paper

The organisation (outline) of the (this) paper is as follows. In Section II we describe ...

The ... is presented in section III. In Sec. II we solve the ... equation giving expressions for ... This is necessary for the work of Sec. III, in which the extended ... equation is derived. Numerical results of the theory are given in Sec. IV, together with a comparison with .... and... calculations.

\footnotetext{
5 Estruturas esquemáticas ou superestruturas foram definidas por van Dijk e Kintsch [Kintsch-78] como sendo os componentes do discurso que definem sua forma e ajudam a identificar alguns discursos como sendo um artigo cientifico, uma estória, uma novela e outros.
} 
Como podemos ver acima, as expressões indexadas variam em tamanho, de períodos simples (entrada a)) e compostos (entrada d)) a vários períodos como ilustrado na entrada i). A idéia subjacente é fornecer, para alguns casos, os conectivos lógicos necessários para a conexão entre períodos.

Uma outra característica do recurso é que as expressões não contêm apenas a forma adequada de certas funções retóricas, mas fornecem também substantivos, adjetivos e verbos adequados para a descrição de processos, comparação de dados e figuras e outros. Esta característica sugere que talvez o recurso possa ser melhor explorado em uma ferramenta para a escrita que mantenha bases de expressões específicas a cada área de pesquisa/conhecimento, como o faz a ferramenta de crítica (Veja Seção 2.3.3).

Um dos objetivos principais desse recurso é fornecer uma grande variedade de expressões para que o escritor possa (a) ter um input lingüístico adequado às suas necessidades, (b) adaptar as expressões que julgar adequada ao seu texto e (c) reproduzir fórmulas ou expressões fixas quando estiver escrevendo sobre determinados aspectos do seu trabalho. Uma consequeência de seu uso é a familiarização com a retórica do gênero artigo científico e diminuição da sobrecarga cognitiva na fase de tradução das idéias em texto (no caso especial, em texto de uma língua não nativa ou estrangeira).

\subsubsection{Arquitetura da Ferramenta de Referência}

Os recursos utilizados na implementação da Ferramenta de Referência são:

- Uma lista de componentes e subcomponentes da estrutura funcional/retórica para artigos proposta por [Deyes-82] com ponteiros para a Base de Padrões;

- Uma lista de funções retóricas como causas, comparações, definições e exemplificações que também apontam para suas respectivas entradas na Base de Padrões;

- Uma lista de palavras-chave características do gênero (report, paper, model, technique, methodology, figure, section, etc.) que permite o acesso às expressões padrão da Base de Padrões através de um processo simples de busca capaz de mostrar todas as orações que satisfazem a busca de uma dada palavra-chave; e expressões padrões tomadas de artigos autênticos da área de fisica experimental e informática.

Como mostrado na Figura 2, existem dois grandes processos na arquitetura da Ferramenta de Referência: aquisição de material lingüístico e composição de texto. 


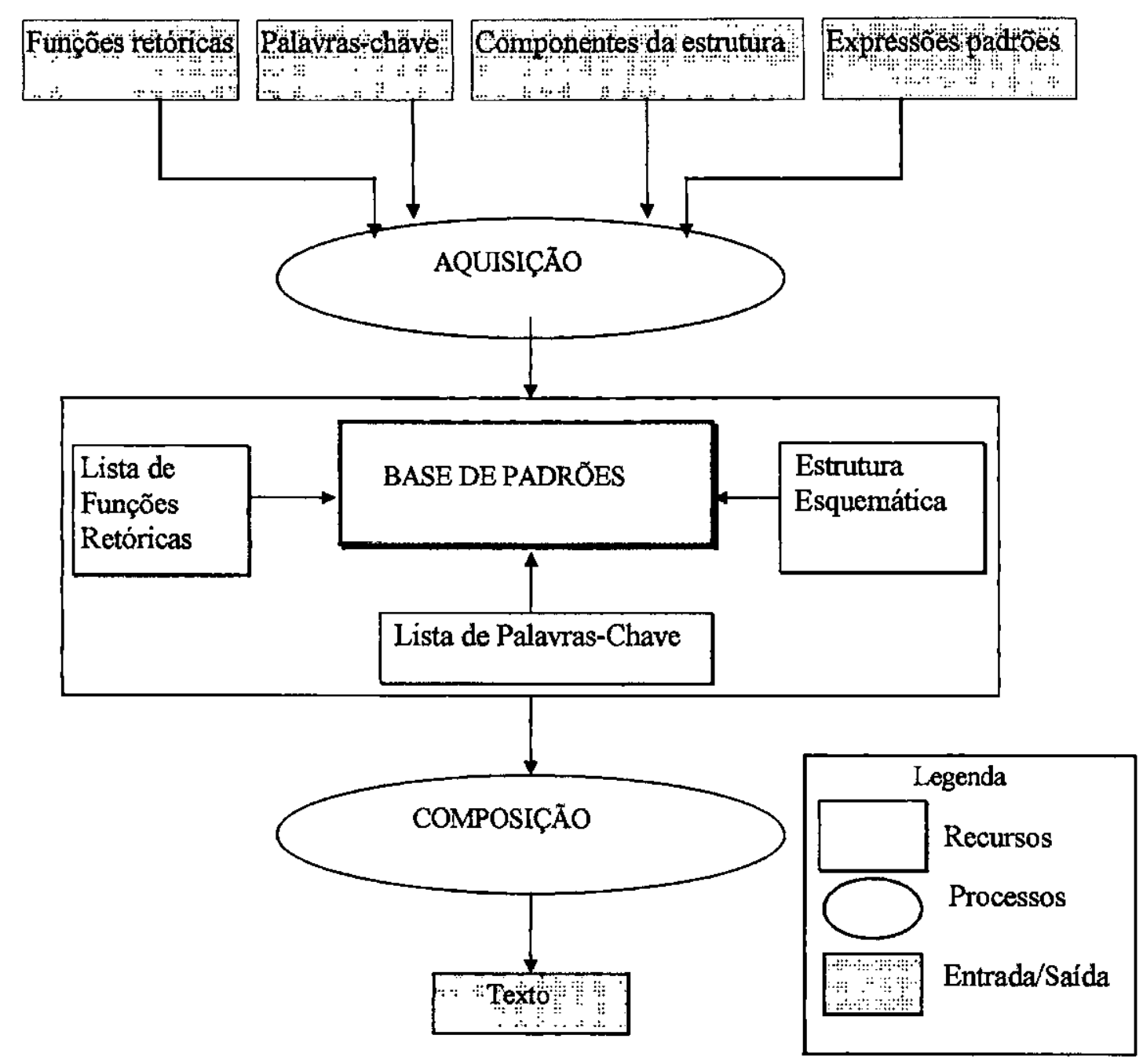

Figura 2: A arquitetura da Ferramenta de Referência

O processo de aquisição toma como entrada as palavras-chave, as funções retóricas ${ }^{6}$, expressões padrões de artigos e os componentes/subcomponentes da estrutura esquemática de artigos e os transforma em recursos para serem utilizados no processo de composição. $\mathrm{Na}$ aquisição, novos padrões podem ser inseridos para cada componente/subcomponente da estrutura esquemática e podem também ser associados às suas funções retóricas se são representativos de alguma. Novas palavras-chave e outras funções podem também ser anexadas, bem como alguma nova subdivisão para a estrutura esquemática. Com esse processo, a Ferramenta de Referência pode ser totalmente personalizada, e inclusive pode servir à escrita de outros gêneros correlatos como os relatórios técnicos, artigos de revisão (review articles), artigos argumentativos (position papers), etc. As palavras-chave também podem representar itens léxicos que são problemáticos

\footnotetext{
6 Trimble e co-autores introduziram e desenvolveram a idéia da estrutura retórica de artigos científicos. Desenvolveram o conceito de funçốes retóricas (gerais: indicar propósito, revisar literatura, etc. ou especificas: definição, descrição, etc.) que podem ser vistas em um gráfico do processo retórico em [Trimble- 85], juntamente com as técnicas retóricas de que são feitas.
} 
para não nativos do inglês, como as palavras homófonas; as quase homógrafas e os falsos cognatos (stationary/stationery; real/royal; principal/principle; actually/really, por exemplo); conectivos de discurso (because, therefore, as a result, etc.) fornecendo um meio alternativo de acesso às funções retóricas.

O processo de composição permite o acesso às expressões padrões através da seleção de um componente ou subcomponente da estrutura esquemática, da seleção de uma dada função retórica ou de uma dada palavra-chave.

\subsubsection{Ferramenta de Suporte: Um assistente cooperativo}

Nesta seção, apresentamos as decisões de projeto tomadas para a construção de uma ferramenta de suporte à escrita para não nativos que possuem conhecimento deficitário da língua inglesa e/ou da escrita científica, principalmente na hora de compor um parágrafo de texto. Esta ferramenta é destinada à escrita da seção introdutória de artigos curtos (Letters) da área de pesquisa experimental e utiliza o método de resolução de problemas chamado raciocínio baseado em casos [Mantaras-95].

\subsubsection{Arquitetura da Ferramenta de Suporte}

Como mostrado na Figura 3, existem três fontes de conhecimento na Ferramenta de Suporte:

- A Base de Casos;

- A Base de Regras de Revisão;

- As Regras e Medidas de Similaridade.

A Base de Casos e parte da Base de Regras (a Estrutura Esquemática) foram obtidas do processo de Análise de Corpus de introduções de artigos da área de Física Experimental. Os textos das Introduções foram obtidos através do processo de Digitalização das Introduções. As Regras de Adaptação são genéricas, pois servem para adaptar qualquer uma das trinta estratégias e suas quarenta e cinco mensagens associadas. As Regras e Medidas de Similaridade também são genéricas, pois são baseadas em regras de similaridade entre listas e na medida de similaridade conceitual chamada nearest neighbours matching, bastante conhecida na área de Raciocínio Baseado em Casos. 
A interação com o usuário é realizada pelos processos: Coleta de Features, Seleção Dirigida pelo Usuário e Adaptações Interativas. A entrada inicial de dados (ou requisição) fornecida pelo usuário alimenta o processo de Recuperação de Casos. Este processo toma: as Features Retóricas fornecidas para a Introdução a ser escrita, as Estruturas Retóricas de cada caso da base e as Regras e Medidas de Similaridade, e devolve ao usuário os casos mais próximos à sua requisição. Dentre estes casos, o usuário escolhe o melhor, e através do processo de Adaptações Interativas e da entrada de material linguístico relativo à sua pesquisa/trabalho compõe o Texto da Introdução. Entretanto, é possível também que o usuário escreva seu texto a partir dos vários casos recuperados, isto é, sem a ajuda do processo de adaptações interativas, produzindo assim o Texto da Introdução a partir dos casos. Finalmente, o usuário pode iterar dois processos: a Seleção Dirigida pelo Usuário e as Adaptações Interativas durante o processo de composição de seu texto da introdução. 


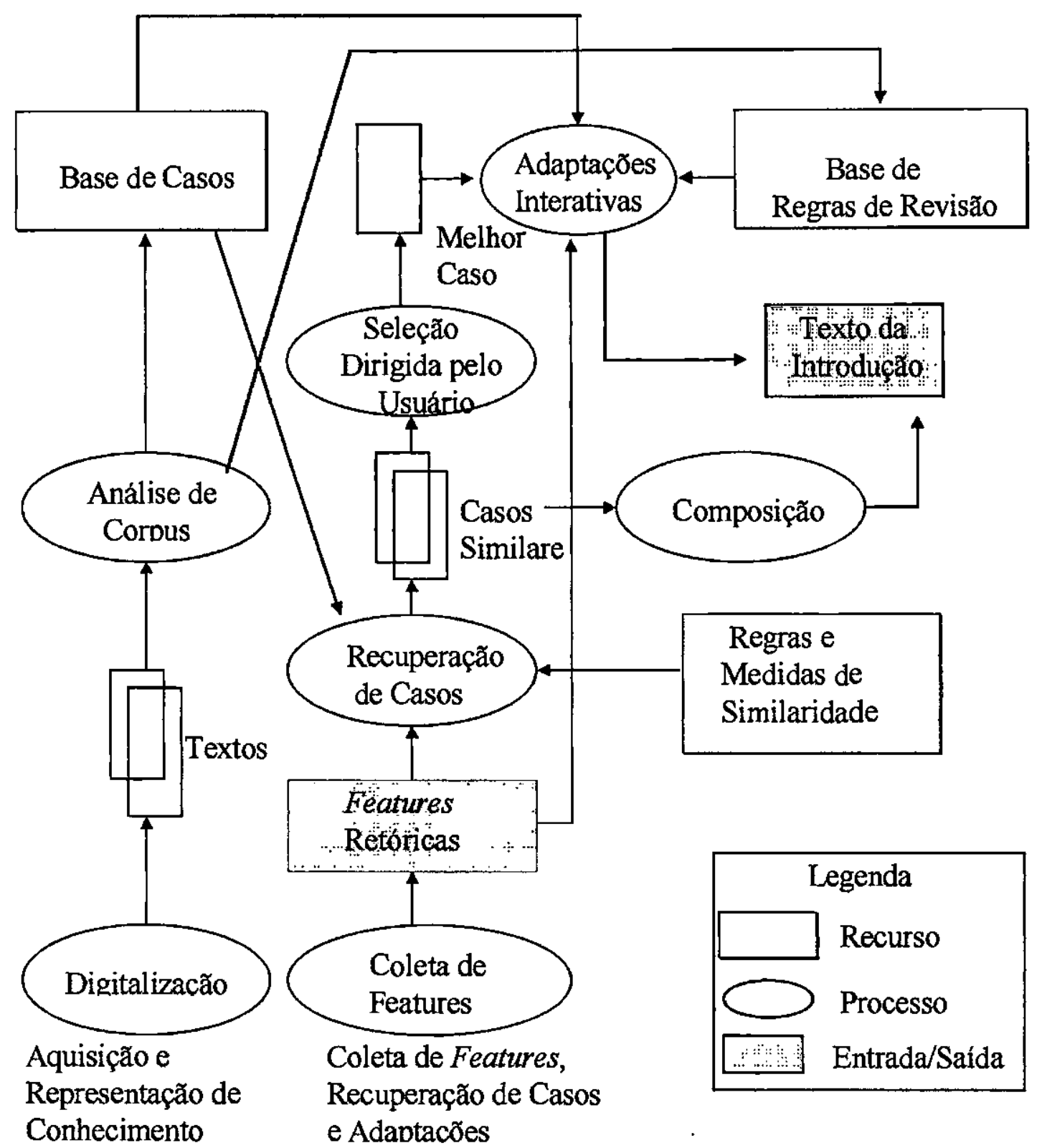

Figura 3: A arquitetura da Ferramenta de Suporte

A Base de Casos contém cinqüenta e quatro instâncias de Introduções autênticas, sendo que cada caso é representado em um formalismo computacional e tem associado o texto da introdução correspondente. A ferramenta interage com o usuário em três estágios:

- Para a coleta de informaçб̃es sobre a estrutura retórica de introduçбes,

- Para a seleção do melhor caso dentre os vários recuperados, e

- Durante fase de adaptações do melhor caso. 


\subsubsection{A Ferramenta de Crítica: Um tutor colaborativo}

Um sistema de critica apresenta uma opinião racional sobre um produto ou uma ação gerada por um usuário, além de prover uma forma efetiva de interação entre usuário-computador auxiliando o usuário no desenvolvimento de produtos. Um produto pode ser, por exemplo, um programa de computador, um projeto de uma cozinha ou um plano de tratamento médico enquanto que uma ação pode ser uma sequêencia de teclas pressionadas em um editor de textos para corrigir um erro, ou uma seqüência de comandos de um sistema operacional, entre outras. Um agente que é capaz de criticar neste sentido é classificado como um crítico, e pode ser uma máquina ou um ser humano [Fischer-91; Silverman-92; Fischer-93; Rankin-93; Fischer-95].

Um sistema de crítica é composto por dois agentes, um computador e um usuário, trabalhando em colaboração. Ambos os agentes contribuem com o que conhecem sobre o domínio do problema a ser solucionado. A tarefa básica do sistema é o reconhecimento e a indicação de deficiências no produto ou ação do usuário e não necessariamente a resolução do problema - a maioria dos sistemas de crítica fazem sugestões de como melhorar o produto. Com estas sugestões, o usuário pode consertar o problema ou procurar obter explicações adicionais. O papel do usuário é inicialmente gerar um produto/solução e depois fazer mudanças nele, participando juntamente com o sistema do processo de resolução do problema. A tarefa do sistema é analisar os produtos/soluções, produzindo uma crítica que permite ao usuário iniciar a próxima iteração deste processo, como ilustra a Figura 4.

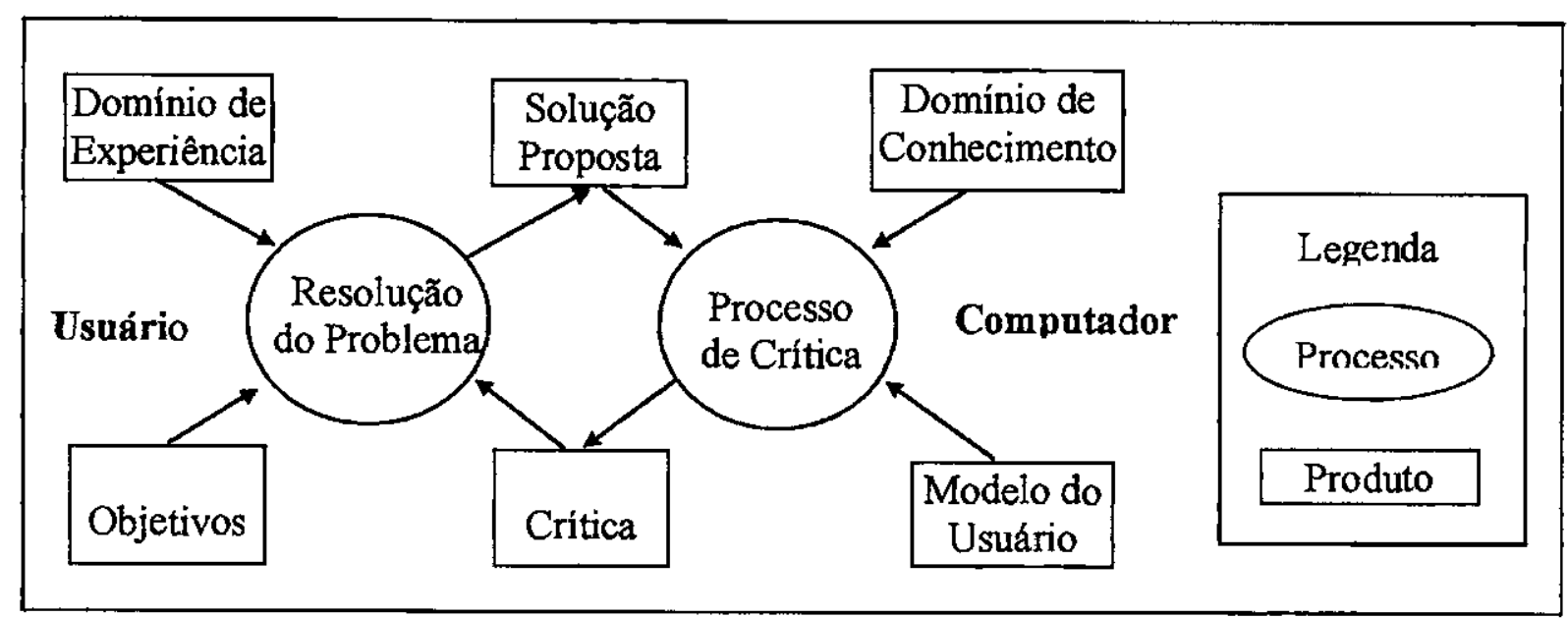

Figura 4: A abordagem de críticas [Fischer-91] 


\subsubsection{A Arquitetura da Ferramenta de Crítica}

Na Figura 5, mostramos a arquitetura da ferramenta, como proposta por Silva em [Silva-99].

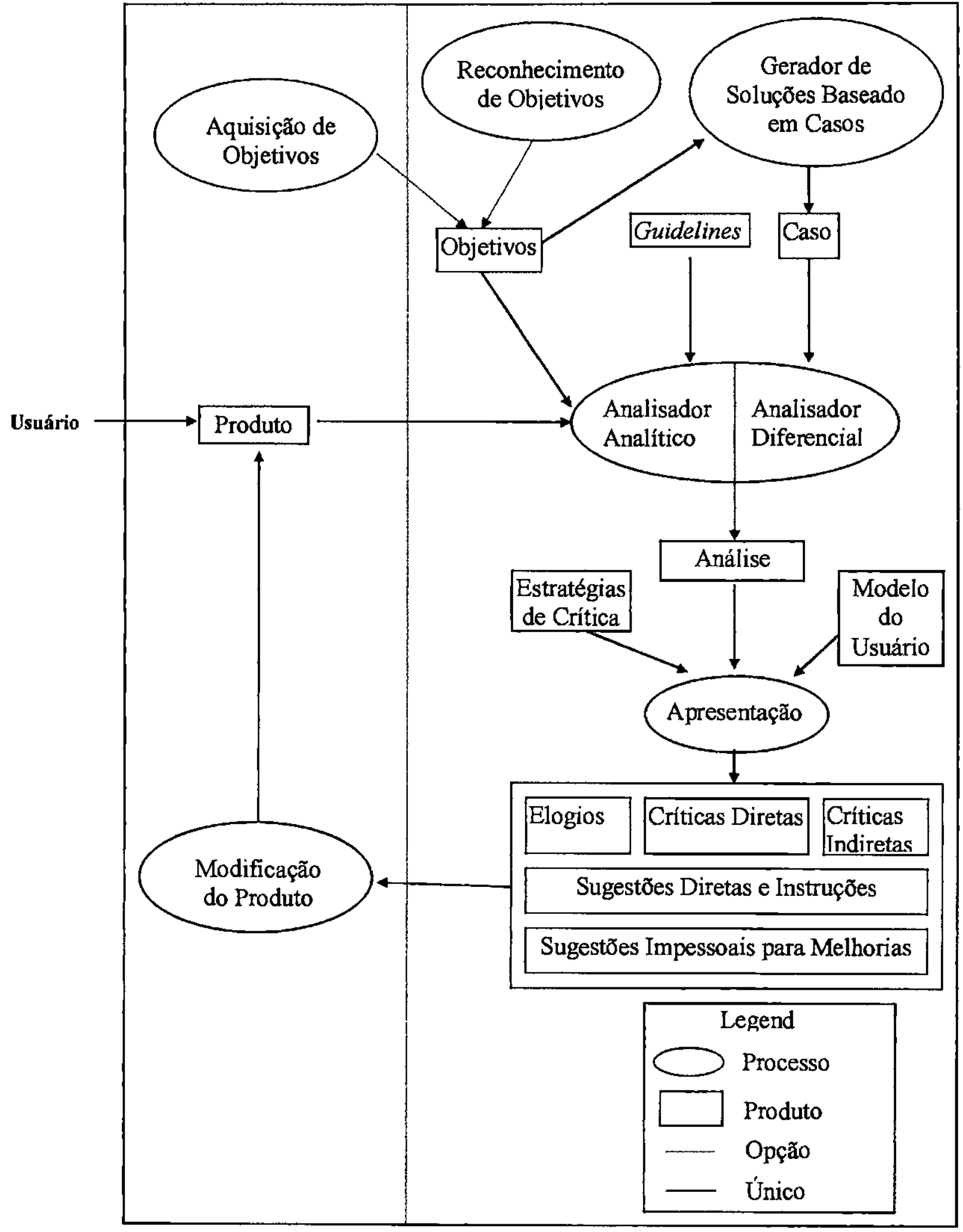

Figura 5: A arquitetura da Ferramenta de Crítica. 
$\mathrm{O}$ processo de crítica se inicia assim que o usuário apresenta um produto para a ferramenta. Para criticá-lo, a ferramenta deve obter o(s) objetivo(s) do usuário. Isto pode ser feito através de 2 processos mutuamente exclusivos: (1) Reconhecimento de Objetivos, que reconhece o objetivo do usuário através das escolhas utilizadas no produto, ou (2) Aquisição de Objetivos que utiliza informações explícitas fornecidas pelo usuário. Tendo os objetivos do usuário, o modelo utiliza dois tipos de analisadores para avaliar o produto: Analítico e Diferencial. O Analítico analisa o produto através de guidelines enquanto que o Diferencial utiliza o caso gerado através da abordagem de Raciocínio Baseado em Casos (RBC) como modelo para ser comparado com o produto do usuário. O módulo Gerador de Soluçóes segue as especificações do trabalho de Aluísio [Aluísio-95b] (sendo que os casos são agora representados pelas duas estruturas: retórica e de critérios específicos) e recupera o caso mais similar ao produto do usuário. $O$ analisador Analítico é responsável por checar o conteúdo - quais componentes devem estar presentes no artigo - , e o Diferencial, a organização - a ordem mais provável desses componentes, se alguns dos componentes podem ser opcionais, ou aparecer mais de uma vez - pois ele trabalha com uma base de artigos aceitos para publicação na CHI'96. Os analisadores de produto geram fatos a respeito das diferenças contra o caso recuperado, e da análise do produto contra guidelines. O componente Apresentação vai então mostrar estes fatos ao usuário da forma mais adequada possível se baseando nas Estratégias de Crítica e no Modelo do Usuário. Baseado em cinco formas possíveis de críticas (elogios, críticas diretas, indiretas, sugestões diretas e instruções e sugestões impessoais para melhorias), o usuário gera uma nova versão do produto e o ciclo se repete.

\subsection{Considerações Finais}

Neste Capítulo abordamos a natureza do problema de escrita técnica em inglês como língua estrangeira e os ambientes e ferramentas da literatura desenvolvidas para torná-lo menor. O Ambiente AMADEUS foi descrito com detalhes salientando-se o conhecimento que cada ferramenta utiliza para auxiliar ou ensinar a escrita técnica de artigos. No próximo capítulo, veremos como os conceitos de adaptatividade e modelos de usuário podem ajudar na tarefa de integrar as ferramentas do AMADEUS. 


\section{Adaptação em Sistemas Computacionais}

Freqüentemente, encontramos situações nas quais um sistema computacional não satisfaz as exigências ou necessidades atuais de um usuário, por exemplo, sua operação é muito complicada, o nome ou colocação de funções ou objetos não corresponde às idéias do usuário. Além disso, tais sistemas exibem o mesmo comportamento para todos os usuários.

Segundo Grunst [Grunst-96], uma solução para estes problemas é a extensão da fase de desenvolvimento até a fase de utilização. Isto deveria reduzir a distância entre desenvolvimento $\mathrm{e}$ aplicação. Acreditamos que, atualmente, poucos usuários estão suficientemente preparados para projetar seus próprios sistemas (mas veja [Barbosa et al.-97]). Deveríamos então, procurar outras soluções para estes sistemas interativos rígidos.

\subsection{Formas de Adaptação}

Um sistema capacitado a se adaptar ao usuário deve se basear em conhecimento sobre o sistema, sua interface, o domínio de tarefa, e o usuário [Norcio-89].

Para satisfazer as diferentes necessidades e exigências dos usuários temos duas soluç̃̃es: os sistemas computacionais podem ser adequados manualmente pelo usuário ou então devem, eles mesmos, reconhecer a necessidade de adaptação através de suposiç̃̃es sobre os usuários [Kobsa-94].

Os sistemas que permitem que o usuário mude, manualmente, certas características suas para adaptar o seu comportamento para as preferências individuais são chamados adaptáveis. Neste caso, o usuário ou administrador inicia e seleciona a adaptação necessária, através de menus de preferências ou da edição de "profiles". O único inconveniente é que esta forma de adaptação requer do usuário conhecimento considerável do sistema, tendo, assim, um escopo limitado de uso. A segunda solução para adaptação possui duas variantes: o sistema orienta o usuário para a adaptação necessária, explica as razões, mas deixa o usuário decidir se uma dada adaptação deve ser realizada (são os chamados sistemas com suporte para a adaptação controlada pelo usuário), ou o sistema muda seu comportamento automaticamente de acordo 
com as necessidades (possivelmente antecipadas) do usuário. Estes últimos são chamados sistemas adaptativos.

Em sistemas com suporte à adaptação encontramos: 1) meios para o usuário ativar e desativar a adaptação para o sistema global ou partes individuais do sistema; e 2) a adaptação na forma de sugestões que o usuário pode aceitar ou rejeitar, ou permissão para selecionar entre várias possibilidades de adaptação. Esta alternativa é preferida se a adaptação não ocorre freqüentemente, mas é muito importante (por exemplo, alterações na interface que oferecem funcionalidade adicional). Quando, porém, as adaptações ocorrem freqüentemente e não são tão relevantes, os sistemas que se adaptam automaticamente são mais indicados. As adaptações automáticas e controladas pelo usuário podem, também, aparecer combinadas em um sistema. Kobsa, em [Kobsa-94], apresenta os valores de seis critérios para determinar o grau de autonomia da adaptação (Tabela 3).

Tabela 3: Diferenças entre os três modos de adaptatividade.

\begin{tabular}{|c|c|c|c|}
\hline & $\begin{array}{l}\text { Sistemas } \\
\text { Adaptáveis }\end{array}$ & $\begin{array}{l}\text { Sistemas com Suporte para a } \\
\text { Adaptação Controlada }\end{array}$ & $\begin{array}{l}\text { Sistemas } \\
\text { Adaptativos }\end{array}$ \\
\hline $\begin{array}{l}\text { Freqüência do } \\
\text { comportamento adaptativo }\end{array}$ & Baixa & Baixa & Alta \\
\hline $\begin{array}{l}\text { Relevância do efeito da } \\
\text { adaptação }\end{array}$ & Muita & Muita & Pouca \\
\hline $\begin{array}{l}\text { Efeitos Negativos de falsa } \\
\text { adaptação }\end{array}$ & Fortes & Intermediários & Mínimos \\
\hline $\begin{array}{l}\text { Violação da constância visual } \\
\text { e motora }\end{array}$ & Forte & Forte & Mínima \\
\hline $\begin{array}{l}\text { Aceitação da adaptação } \\
\text { automática pelo usuário }\end{array}$ & Baixa & Intermediária & Alta \\
\hline $\begin{array}{l}\text { Aceitação do usuário do fato } \\
\text { de ser modelado }\end{array}$ & Baixa & Intermediária & Alta \\
\hline
\end{tabular}

O módulo que contém suposições explícitas sobre todos os aspectos do usuário que podem ser relevantes para a adaptação do sistema é chamado modelo do usuário, e será explorado na próxima seção. 


\subsection{Modelos de Usuário}

Um assistente humano ideal, por exemplo, adota a perspectiva do cliente: o assistente aprende sobre o cliente e sabe sobre as suas necessidades, preferências, e intenções. $\mathrm{Na}$ comunicação entre humanos, ambos os participantes podem adaptar-se de acordo com as características do outro. O processo de comunicação enriquece e refina o conhecimento de ambos. Este conhecimento permite aos dois melhorar o processo de comunicação, e assim aumentar a satisfação com a interação.

Segundo Mctear [McTear-93], para que um sistema possa interagir eficientemente com outras pessoas, ele precisa saber alguma coisa sobre elas. Surgiu, então, a idéia que computadores pudessem se comportar mais cooperativamente, como sugerido acima sobre o comportamento de assistentes humanos, se eles tivessem conhecimento das características dos usuários. Como os sistemas atuais estão se tornando cada vez mais complexos, é importante que o sistema ajude o usuário a fazer bom uso de toda a funcionalidade disponível. Além disso, dado que diferentes usuários não têm os mesmos problemas ou necessidades, e que o nível de habilidade de um usuário muda com o passar do tempo, torna desejável que as interfaces de sistemas complexos adaptem-se e apoiem as exigências de usuários individuais.

Modelar um usuário significa adquirir e representar as suposições sobre usuários de sistemas computacionais, e explorar estas suposições para conseguir um sistema individualizado. Existem várias terminologias adotadas para modelos de usuário. Uma das mais aceita é usada por Mctear [McTear-93]: o termo modelo do usuário normalmente se refere ao projeto do modelo do usuário no sistema, ou grosso modo, como podem ser os procedimentos envolvidos quando se está interagindo com o sistema.

Todos os sistemas têm um modelo de usuário, que pode estar implícito no projeto do sistema ou representado explicitamente: todos os sistemas são projetados com algum usuário em mente e o tipo de usuário imaginado para um sistema especifico usualmente afeta o projeto do sistema e a forma de sua interação com seus usuários. Atualmente, cada vez mais pesquisadores tem explorado o uso de modelagem de usuário explicita, onde o conhecimento sobre o usuário é explicitamente representado e modificável, e o sistema possui mecanismos para explorar esta informação explicita para adaptar-se a um usuário especifico dinamicamente. 


\subsubsection{Os diferentes tipos de Modelos de Usuário}

Nos últimos vinte anos, muitos pesquisadores de diversas áreas reconheceram o potencial que um modelo de usuário tem na melhoria da interação do sistema com seus usuários. Como existem diversas aplicações para modelos de usuário, não é surpreendente que existam vários tipos diferentes de modelos de usuário [Rich-83; Kass-88; Kok-91]. Uma classificação bastante típica, segundo Mctear [McTear-93], pode ser vista abaixo. Ela possui quatro parâmetros/critérios:

\section{Individual contra canônico}

Normalmente, o modelo de usuário se refere a um modelo da pessoa que usa o sistema. Porém, um sistema também pode modelar outras pessoas ao mesmo tempo [Sparck-89], com cada usuário possuindo um modelo individual.

O sistema pode ter modelos múltiplos do mesmo usuário, por exemplo, modelagem das características de um usuário por papéis diferentes (canônico), como perito em um domínio, mas talvez novato em outro.

\section{Estático contra dinâmico}

Uma segunda característica se preocupa se o modelo de usuário pode ser alterado ou não. Um modelo dinâmico seria alterado durante o curso da interação ou ao término de uma sessão, considerando que um modelo estático, uma vez construído, permaneceria inalterado. Modelos dinâmicos deveriam ser, assim, mais úteis, adaptando-se às características variáveis dos usuários. Realmente, no caso de algumas aplicações, como sistemas tutores inteligentes, tal modelo é essencial para modelar o estado de conhecimento variável de um estudante durante o curso de interação com o sistema.

\section{Curto prazo contra longo prazo}

Esta característica se refere ao armazenamento da informação do modelo do usuário: se for descartada ao término de uma sessão (curto prazo) ou se é mantida para uso futuro (longo prazo). Modelos de usuário estáticos valem a pena se eles podem ser retidos durante um certo tempo e reutilizado. Pela natureza dos modelos dinâmicos (são de curto prazo) eles mudam com o passar do tempo e envolvem informação que é substituída. 
Aquisição explícita contra implícita

Em modelos explícitos, o usuário provê a informação a pedido do sistema que o apoiará. Já em modelos implícitos, as informações são adquiridas pelo sistema sem consultar o usuário. A informação explicitamente adquirida tem menos probabilidade de mudar em curto prazo, considerando que informação implícita é mais dinâmica, adquirida durante o curso de uma sessão. Aquisição de informação explícita se tefere à adição de informação nova ao modelo de usuário de uma fonte externa. Esta fonte externa pode ser o usuário que está interagindo com o sistema. A aquisição de informação implicita se refere a deduzir para o usuário informações com base conhecimento disponivel dentro do modelo de usuário e nas regras de inferência que são aplicadas a este conhecimento.

Um método para aquisição implícita envolve regras de inferência. Por exemplo: um sistema de ajuda poderia deduzir que, se o usuário usa um comando complexo, então o usuário provavelmente entende bem os comandos mais simples.

Modelos de usuário dinâmicos permitem o sistema reagir a uma nova informação sobre um usuário. A aquisição implícita de modelos de usuário economiza tempo do usuário e evita sessões longas de interrogação de usuário, evitando os problemas de perda de controle do usuário, como comentado na Seção 3.1. Porém, sistemas que constroem implicitamente o modelo para um usuário também têm que lutar seriamente com as informações incorretas ou contraditórias. Geralmente, o uso para o qual um modelo de usuário será posto determinará o tipo de modelagem envolvida. Por exemplo, em um sistema que não é usado freqüentemente seria impróprio envolver o usuário em uma sessão inicial longa de interrogatório para construir um modelo de usuário, particularmente se a informação não será retida para uso futuro.

Pelo fato do ambiente AMADEUS possuir três tipos diferentes de ferramentas, este trabalho traz semelhanças com a arquitetura LaboUr, proposta por Pohl, [Pohl-97] que trata modelos de usuário como um processo de aprendizado aberto, utilizando para isto aprendizado de máquina. Enquanto que este trabalho não pretende utilizar algoritmos de aprendizado de máquina para realizar o aprendizado, ele se assemelha à arquitetura LaboUr pelo fato dela considerar a avaliação dinâmica de usuários utilizando várias ferramentas, para conseguir um modelo mais preciso do usuário.

Modelagem de usuário é uma área aberta em que existem muitos assuntos a serem pesquisados. Encontramos muitos sistemas com modelos de usuários que possuem as seguintes deficiências [Pohl-97]: 
1. Suposições sobre atitudes mentais como conhecimento e objetivos são modeladas, enquanto que suposições orientadas a comportamento, por exemplo, preferências da forma de interação ou padrões de comportamento, ainda estão faltando;

2. Suposiç̃̃es são geralmente adquiridas a partir de heurísticas especializadas, que fazem inferência baseando-se em observações isoladas sem levar em conta o contexto de interação;

3. O comportamento do usuário, preferências, e atitudes mentais são sujeitos a mudanças, que, freqüentemente, não são tratadas adequadamente;

4. Modelos de usuário são construídos e explorados em grande parte dentro dos limites de uma aplicação.

As deficiências acima sugerem tópicos de pesquisa a serem explorados. O modelo do usuário do ambiente AMADEUS explora todos os itens acima. Para 0 item 1) exploramos a preferência a três estilos de interação, que variam de acordo com cada ferramenta de AMADEUS. Devemos observar que as interfaces das três ferramentas foram padronizadas. Para o item 2), mantemos um descritor bastante elaborado e completo da situação que gerou determinada ação do usuário, ou do contexto que resultou em um texto criado pelo usuário. Para o Item 3), estamos adotando um modelo de usuário dinâmico. No item 4), teremos três ferramentas se comunicando com o modelo de usuário sendo responsáveis por criar e manter um modelo mais aprimorado do usuário. Optamos por projetar o modelo do usuário na forma de um shell para que ele possa ser reaproveitado por sistemas de escrita semelhantes ao AMADEUS.

\subsubsection{Métodos Adaptativos em Diferentes Áreas de Pesquisa}

Um modelo de usuário só é útil se a quantidade e tipos de informação que contém são relevantes a uma aplicação em particular. Cada aplicação em particular se preocupa com diferentes tipos de informação. Segundo Specht [Specht-96] existem quatro grandes áreas que utilizam modelos de usuários para criar Ambientes Inteligentes de Aprendizado: Sistemas Tutores Inteligentes (STI), Interfaces de Usuários Adaptativas (IUA), Hipermídia Adaptativa (HA) e Multimídia Inteligente (MI).

\subsubsection{Modelo do estudante para sistemas tutores inteligentes (STIs)}

Modelar um usuário para STIs envolve criar um modelo de estudante no qual é representado o conhecimento de um estudante e o entendimento do material que está sendo ensinado. Uma técnica de modelagem comum é representar o conhecimento do estudante como um subconjunto do conhecimento do sistema de domínio. Pode-se manter apenas uma lista de conferência do que o estudante sabe e não sabe. Porém, está técnica não apura o conhecimento 
incorreto de um estudante. Em um nivel mais sofisticado o modelo poderia envolver reconhecimento de planos. O nivel de conhecimento de um estudante muda freqüentemente no decorrer de uma lição, de forma que um STI tem que atualizar seu modelo do estudante continuamente. Além disso, é freqüente o caso em que um estudante não possui conhecimento sobre um determinado assunto ou tem pequenas dúvidas sobre o que está sendo ensinado. Por isto, o modelo de estudante tem que levar em consideração a representação e a argumentação do conhecimento.

\subsubsection{Interfaces de Usuários Adaptativas}

A área de IUA está normalmente preocupada com o estilo cognitivo do usuário e fatores de personalidade. A ênfase em IUA está em prover um diálogo adaptado às exigências do usuário e para a tarefa particular na qual o usuário está atualmente comprometido. Assim, além de um modelo de usuário, é requerido um modelo de tarefa que descreve os aspectos físicos como também conceituais de um domínio [Benyon-87]. Enquanto o modelo de tarefa é relativamente estável, o modelo de usuário que inclui o modelo mental do usuário e sua estrutura de tarefa, pode mudar dinamicamente quando o usuário interage com o sistema. Uma exigência de modelagem de usuário em IUA é que eles deveriam ser psicologicamente pertinentes, sendo este aspecto geralmente validado empiricamente.

\subsubsection{Hipermídia Adaptativa}

Hipermídia Adaptativa trabalha com métodos para adaptar o conteúdo e forma de apresentação para várias características de um usuário. As técnicas mais populares são a apresentação adaptável e o apoio à navegação adaptável [Brusilovsky-96].

\subsubsection{Multimídia Inteligente}

A Multimídia Inteligente tenta aumentar a quantidade do fluxo de informação em uma comunicação com computador, através da escolha da mídia de apresentação apropriada para uma certa informação [Maybury-93] e da integração adequada.

\subsubsection{Tipos de informação em um modelo de usuário}

As características de usuários geralmente modeladas são as metas e planos, capacidades/habilidades, atitudes e preferências, conhecimento (sobre o domínio e sobre o sistema) e convicções de usuários [Kass-88; Paris-88; Kobsa-94]. Elas são detalhadas abaixo. 


\subsubsection{Objetivos e planos}

Muito do trabalho mais teórico em modelagem de usuário converge com a pesquisa de IA a reconhecimento de planos. Metas ou objetivos se referem a um estado que o usuário deseja alcançar, enquanto planos descrevem que passos podem ser tomados para alcançar uma meta. Reconhecimento de planos é um problema dificil, particularmente se as metas do usuário estão baseadas em convicções enganosas. [Quilici-89; Cohen-91; Eller-91]. O objetivo do usuário pode modificar os planos, como por exemplo, uma pergunta apropriada pode ser feita ao usuário em um determinado ponto da interação.

\subsubsection{Capacidades}

Muitos sistemas de modelagem de usuário se preocupam com as capacidades do sistema para apresentar informação para o usuário dentro de seu nível de compreensão. Por exemplo, no sistema de KNOME [Chin-89] o nível de perícia de um usuário usando o sistema operacional Unix é deduzido do diálogo do usuário com o sistema e as explicações oferecidas ao usuário pelo sistema são construídas em um nível que o usuário entenda. Semelhantemente, o sistema TAILOR [Paris-88] provê tipos diferentes de explicações que variam de acordo com o conhecimento do usuário, isto é, se o usuário é considerado como novato ou especialista com respeito ao conhecimento de domínio em questão.

\subsubsection{Atitudes e preferências}

Há vários sistemas que podem modelar e adaptar-se às atitudes, preferências e estilos de um usuário. GRUNDY [Rich-83] possui regras para automatizar uma biblioteca com base nas preferências de um modelo de usuário, usando estereótipos predeterminados, que são ativados no curso de um diálogo. Estes estereótipos podem sofrer modificações particulares para um usuário particular. O modelo de usuário resultante é então usado como uma base para a recomendação de livros.

\subsubsection{Conviç̧̃̃es e conhecimento do domínio de aplicação}

Modelar o conhecimento de um usuário e suas conviç̧̃̃es são importantes para um sistema adaptativo. Nos casos mais simples pode-se registrar no sistema se um usuário sabe ou não um conceito particular. Especialmente quando lidamos com domínios técnicos, o usuário 
pode não saber todos os termos técnicos referenciados no conceito do domínio. Em muitos casos, entretanto, estes conceitos podem ser referidos por palavras não técnicas. O modelo deve então indicar as palavras conhecidas e desconhecidas pelo usuário. Também deve indicar os tipos de estruturas sintáticas preferidas pelo usuário, quando for o caso.

\subsubsection{Representando características de um usuário}

Muitos sistemas de modelagem de usuários e shells usam estereótipos para representar características dos usuários. Exemplos incluem: GRUNDY [Rich-79, Rich-83], KNOME [Chin 89], GUMS [Finin-89] e BGP-MS [Kobsa-90a]. Estereótipos fornecem um modo de reduzir o problema de modelar cada usuário individualmente. Podemos usar estereótipos para preencher informações iniciais sobre uma pessoa quando nós sabemos poucos detalhes sobre ela [Rich-79; McLoughlin-87]. Dado que um usuário pode ser classificado com um tipo particular, então o usuário individual pode herdar as características daquele tipo. Este processo permite o sistema adquirir informação do usuário de forma implícita. De acordo com a complexidade da informação mantida em um modelo de usuário, podemos utilizar parâmetros lineares ou representações baseadas em conceitos.

\subsubsection{Parâmetros lineares}

Parâmetros lineares são um modo simples para representar informação sobre características de usuário. Valores podem ser numéricos ou simbólicos. Por exemplo, uma escala entre 0 e 1 ou valores simbólicos como "conhecido" e "não conhecido".

\subsubsection{Representações baseadas em conceitos}

Tratar as suposições do sistema sobre o conhecimento do usuário, convicções, metas, planos e preferências pode requerer uma representação mais expressiva, como as fórmulas do cálculo de predicado de primeira-ordem.

\subsubsection{Mantendo os modelos de usuário}

Um das características principais dos modelos de usuários é que eles tendem a estar incompletos. Além disso, a informação em um modelo de usuário pode ser incerta se, por exemplo, estiver baseada em suposições padronizadas. Finalmente, dado que um modelo de usuário pode ser incremental, informações recentemente adquiridas podem se mostrar incompatíveis com uma informação previamente armazenada. 
Um segundo problema consiste em assumir suposições padronizadas dentro de um estereótipo, quando, por exemplo, uma pessoa pode ter características que são típicas de um estereótipo, mas outras que não são. Uma dificuldade adicional envolve as avaliações de confiança associadas com informação de usuário e como estes valores podem ser mudados.

O método de resolução mais simples envolve distinguir entre as informações padronizadas do estereótipo e as que foram providas explicitamente pelo usuário [Rich-89]. Se há um conflito entre estes dois tipos de informação, o conflito deveria ser solucionado em favor da informação definida pelo usuário, que é a mais provável de ser verdadeira.

\subsection{Shells que modelam o usuário}

Um dos objetivos deste mestrado é o desenvolvimento de um modelo de usuário para o ambiente AMADEUS. Porém, em vez de projetá-lo para funcionar somente com o ambiente em questão, projetamos de uma maneira independente e flexível, para poder ser utilizado em outras aplicações afins, isto é, como um Shell de modelagem de usuário. Este Shell é um programa que tem a capacidade de organizar informações sobre o usuário e disponibilizá-las para as aplicações de forma que a interação entre o usuário e a aplicação se torne o mais eficiente possível. A idéia básica de um Shell é a sua independência em relação ao sistema que o utiliza, o que pode ser alcançado graças ao fornecimento de uma linguagem em que o modelo de usuário (ou aprendiz) é definido.

A Tabela 4 abaixo mostra as características de seis shells da literatura que funcionaram como um ponto de partida para o projeto do Shell para um ambiente de escrita. 
Tabela 4: Comparação de seis shells de acordo com nove critérios.

\begin{tabular}{|c|c|c|c|c|c|c|}
\hline & Gums & UMT & $\mathbf{U m}$ & Protum & Tagus & BGP-MS \\
\hline $\begin{array}{l}\text { Desenvolvido } \\
\text { em }\end{array}$ & Prolog & - & - & - & Prolog & Lisp \\
\hline Autor & [Fmin-89] & [Brajnik-92] & [Kay-90] & [Vergara-94] & [Paiva-94] & [Kobsa-92] \\
\hline Caracteristicas & $\begin{array}{l}\text { Manutenção } \\
\text { de } \\
\text { suposições } \\
\text { sobre as } \\
\text { crenças do } \\
\text { usuário }\end{array}$ & $\begin{array}{l}\text { Permite ao } \\
\text { administrador } \\
\text { definir } \\
\text { estereótipos de } \\
\text { usuários }\end{array}$ & $\begin{array}{l}\text { Possui a } \\
\text { arquitetura } \\
\text { mais simples } \\
\text { dos shells } \\
\text { comparados }\end{array}$ & $\begin{array}{l}\text { Semelhante ao } \\
\text { UMT, mas } \\
\text { com um } \\
\text { mecanismo de } \\
\text { representacão } \\
\text { de estereótipos } \\
\text { mais } \\
\text { sofisticado. }\end{array}$ & $\begin{array}{l}\text { Usado para } \\
\text { modelar } \\
\text { sistemas } \\
\text { interativos, } \\
\text { sistemas } \\
\text { tutores } \\
\text { inteligentes e } \\
\text { ambientes de } \\
\text { aprendizado. }\end{array}$ & $\begin{array}{l}\text { Usado para } \\
\text { modclar sistemas } \\
\text { interativos. } \\
\text { Mantem } \\
\text { suposiços sobre } \\
\text { conhecimento, } \\
\text { crenças e metas } \\
\text { do usuário. }\end{array}$ \\
\hline $\begin{array}{l}\text { Representaça } \\
\text { do } \\
\text { Conhecimento } \\
\text { utilizado }\end{array}$ & $\begin{array}{l}\text { Armazena } \\
\text { fatos novos } \\
\text { sobre o } \\
\text { usuário }\end{array}$ & $\begin{array}{l}\text { Armazena } \\
\text { características } \\
\text { de um } \\
\text { subgrupo } \\
\text { através do par } \\
\text { Atributo - } \\
\text { valor }\end{array}$ & $\begin{array}{l}\text { Fonte de } \\
\text { evidência, seu } \\
\text { tipo e o tempo } \\
\text { são registrados } \\
\text { através da } \\
\text { tripla: } \\
\text { atributo-valor- } \\
\text { como }\end{array}$ & $\begin{array}{l}\text { Semelhante ao } \\
\text { Um }\end{array}$ & $\begin{array}{l}\text { Logica de } \\
\text { primeira } \\
\text { ordem }\end{array}$ & $\begin{array}{l}\text { Logica de } \\
\text { Primeira Ordem c } \\
\text { Represcntagáo } \\
\text { Conceitual }\end{array}$ \\
\hline $\begin{array}{l}\text { Origem dos } \\
\text { dados (como os } \\
\text { dados são } \\
\text { adquiridos) }\end{array}$ & $\begin{array}{l}\text { Sistema de } \\
\text { Aplicação }\end{array}$ & $\begin{array}{l}\text { Sistema de } \\
\text { Aplicação }\end{array}$ & $\begin{array}{l}\text { Sistema de } \\
\text { Aplicação }\end{array}$ & $\begin{array}{l}\text { Sistema de } \\
\text { Aplicação }\end{array}$ & $\begin{array}{l}\text { Sistema de } \\
\text { Aplicação. }\end{array}$ & $\begin{array}{l}\text { Sistema de } \\
\text { Aplicação, } \\
\text { entrevista com o } \\
\text { usuário, ações do } \\
\text { usuário, } \\
\text { conhecimento do } \\
\text { estereótipo. }\end{array}$ \\
\hline $\begin{array}{l}\text { Consistência de } \\
\text { dados }\end{array}$ & $\begin{array}{l}\text { Verifica a } \\
\text { consistência } \\
\text { de um fato } \\
\text { novo com as } \\
\text { suposições } \\
\text { atuais } \\
\text { (Através da } \\
\text { negação do } \\
\text { fato) }\end{array}$ & $\begin{array}{l}\text { Resolvida } \\
\text { através de } \\
\text { regras } \\
\text { explicitas. }\end{array}$ & $\begin{array}{l}\text { Verifica a } \\
\text { consistência } \\
\text { dos dados à } \\
\text { procura de } \\
\text { incoerências. }\end{array}$ & $\begin{array}{l}\text { Verifica a } \\
\text { consistência } \\
\text { dos dados à } \\
\text { procura de } \\
\text { incoerências. }\end{array}$ & - & $\begin{array}{l}\text { Verifica a } \\
\text { consistência dos } \\
\text { dados à procura } \\
\text { de incoerências. }\end{array}$ \\
\hline Aprendizado & $\begin{array}{l}\text { Não registra } \\
\text { os resultados } \\
\text { de } \\
\text { infcręncias }\end{array}$ & $\begin{array}{l}\text { Não recupera } \\
\text { suposições }\end{array}$ & - & $\begin{array}{l}\text { Não recupera } \\
\text { suposições }\end{array}$ & - & $\begin{array}{l}\text { Consegue } \\
\text { recuperar } \\
\text { resultados } \\
\text { anteriores. }\end{array}$ \\
\hline Hierarquia & $\begin{array}{l}\text { Definição de } \\
\text { hierarqquia de } \\
\text { estereótipo }\end{array}$ & $\begin{array}{l}\text { Ordenado em } \\
\text { hierarquia } \\
\text { arbitrária } \\
\text { (herança de } \\
\text { conteúdo de } \\
\text { estereótipos) }\end{array}$ & $\begin{array}{l}\text { Acesso por um } \\
\text { browser } \\
\text { gráfico à } \\
\text { hierarquia, } \\
\text { dividida em } \\
\text { tópicos e sub- } \\
\text { tópicos. }\end{array}$ & $\begin{array}{l}\text { Semelhante ao } \\
\text { Um }\end{array}$ & $\begin{array}{l}\text { Permite dcfinir } \\
\text { uma hierarquia } \\
\text { de } \\
\text { esterestipos. }\end{array}$ & $\begin{array}{l}\text { Permite definir } \\
\text { uma hierarquia de } \\
\text { estereotipos. }\end{array}$ \\
\hline $\begin{array}{l}\text { Regras de } \\
\text { Inferência }\end{array}$ & $\begin{array}{l}\text { Regras } \\
\text { dcfinidas; } \\
\text { Regras } \\
\text { default }\end{array}$ & $\begin{array}{l}\text { Cada } \\
\text { estereótipo } \\
\text { possui uma } \\
\text { condição de } \\
\text { ativação }\end{array}$ & $\begin{array}{l}\text { Condição de } \\
\text { ativaçăo }\end{array}$ & $\begin{array}{l}\text { Condição de } \\
\text { ativação }\end{array}$ & - & $\begin{array}{l}\text { Bascadas em } \\
\text { metas e crenças } \\
\text { observadas; } \\
\text { entrevistas com o } \\
\text { usuário; ações; e } \\
\text { conteúdo do } \\
\text { modelo atual. }\end{array}$ \\
\hline
\end{tabular}

Como visto na tabela acima, BGP-MS se sobressai em alguns critérios: permite a representação de mais de um tipo de suposição ao mesmo tempo (sobre conhecimento e objetivo, por exemplo); suporta entrevistas bem como inferências que são baseadas nas ações do usuário adquiridas da aplicação. Além disso, ele permite que as inferências sobre o usuário sejam 
executadas concorrentemente com a operação da aplicação e é independente da linguagem de programação em que a aplicação foi escrita. Outro shell que se sobressai é o Tagus, pois consegue modelar tanto o usuário como o estudante. Também é capaz de adquirir o modelo através de observações do agente, gerar hipóteses para explicar seu comportamento, modificar o modelo de acordo com a aquisição de novas informações, prover informações sobre o agente ao exterior e simular o comportamento do agente. Nas próximas seções serão vistos maiores detalhes sobre estes dois shells e também dois sistemas que possuem um modelo de usuário interno, isto é, não são implementados como shells.

\subsubsection{BGP-MS}

O shell BGP-MS (Belief, Goals and Plans Maintenance System) captura as informações da aplicação de vários modos (observaçðes ou entrevistas) e faz deduções a partir dessas informações, através de regras de inferência. Além dos processos de aquisição, representação, e manutenção do modelo de usuário, quando tratamos de shells se sobressai um outro processo: o fluxo de informações entre aplicação e shell. Este último processo está detalhado abaixo.

\subsubsection{Fluxo de informações entre a aplicação e o BGP-MS}

O BGP-MS é um programa independente que pode se comunicar com um sistema de aplicação através de mensagens, como por exemplo:

1) A aplicação pode informar o BGP-MS sobre crenças e objetivos observados do usuário.

2) O BGP-MS pode mandar à aplicação questionários que devem ser mostrados ao usuário.

3) A aplicação pode mandar ao BGP-MS as respostas do usuário.

4) A aplicação pode informar o BGP-MS sobre as ações observadas do usuário.

5) A aplicação pode questionar o BGP-MS a respeito das suposições correntes sobre o usuário.

6) O BGP-MS pode responder as questões da aplicação.

7) O BGP-MS pode sinalizar à aplicação eventos importantes no modelo de usuário mesmo quando não solicitado.

A comunicação entre a aplicação e o BGP-MS é feita via KN-IPCMS, um protocolo de comunicação orientado a mensagens que permite comunicação sincrona e assíncrona. As mensagens da aplicação são transferidas assincronamente, enquanto que as questões feitas ao 
BGP-MS sobre o conteúdo corrente do modelo são transmitidas sincronamente, isto é, a aplicação irá esperar pela resposta. Alguns detalhes da comunicação são fornecidos abaixo.

\subsection{Informando o BGP-MS a respeito de crenças e objetivos do usuário}

O BGP-MS aceita informações vindas da aplicação referente a crenças e metas do usuário e as armazena como uma informação primária. Estas e todas as outras informações que fazem parte do fluxo entre a aplicação e o shell são transmitidas utilizando-se uma linguagem de descrição de crenças e objetivos (BGDL). Nesta linguagem, temos B e W como operadores modais significando "believe" e "want", respectivamente. Os símbolos para os agentes são: U para $o$ usuário, $\mathrm{S}$ para o sistema e $\mathrm{M}$ quando ambos os agentes compartilham a mesma expressão. $O$ conteúdo da crença ou objetivo é expresso em cálculo de predicado de primeira ordem.

\subsection{Entrevistando o usuário}

A maior fonte de informações sobre um usuário é a entrevista inicial. As informações fornecidas pelo usuário podem ser diretamente incorporadas pelo modelo de usuário e podem ativar um processo inferencial que dará entrada a suposições adicionais. O BGP-MS oferece um componente de entrevista que cuida de determinar as questões que devem ser perguntadas, fazer inferências baseadas nas respostas dessas questões e entrar essas suposições no modelo de usuário. A aplicação se encarrega apenas de requisitar o próximo bloco de questões, bem como as possiveis respostas que podem ser dadas pelo usuário, mostrá-las ao usuário e informar ao shell suas respostas. O componente de entrevista infere as suposições resultantes e entra com os resultados no modelo de usuário.

\subsection{Informando o BGP-MS sobre as açōes observadas do usuário}

Para o shell, não faz diferença a maneira pela qual a aplicação obteve as informações. Em alguns casos, elas podem ser fornecidas diretamente pelo usuário. Na maioria das vezes, entretanto, a aplicação deve inferir as informações a partir das entradas do usuário. Para livrá-la dessa tarefa, o BGP-MS permite que a aplicação informe apenas as ações observadas do usuário (ou melhor, o conteúdo comunicativo por trás dessas ações), e o próprio shell fará as suposições possíveis sobre as crenças e metas do usuário baseadas em tipos de ações fornecidas pelo construtor do sistema. 
3.3.1.1.4. Questionando o BGP-MS sobre as suposiçôes correntes sobre as crenças e metas do usuário

A aplicação pode questionar o BGP-MS sobre alguma suposição especifica a respeito das crenças e metas correntemente contidas no modelo de usuário. A fim de responder à aplicação, o BGP-MS verificará se a informação requisitada está explicitamente disponível no modelo de usuário corrente. Adicionalmente, o construtor do sistema pode especificar que um processo de inferência deve ser inicializado se a informação requisitada não estiver explicitamente contida no modelo corrente. Deste modo, informações implícitas também podem ser levadas em consideração. A resposta à questão da aplicação será positiva se a informação estiver entre as armazenadas no modelo ou puder ser deduzida a partir destas.

\subsection{Sinalizando importantes suposiçōes deduzidas à aplicação}

Normalmente, quem dirige o fluxo de informações do BGP-MS para a aplicação é a demanda desta última. Em casos excepcionais, entretanto, pode ser de muita utilidade para a aplicação ser informada imediatamente sobre certos eventos, que podem ser cruciais para o comportamento adaptativo do sistema.

\subsubsection{Representação do conhecimento de modelagem de usuário e do conhecimento do dominio}

O BGP-MS oferece um conjunto integrado de mecanismos de representação de conhecimento para representar as suposições sobre o usuário corrente, o conhecimento específico do domínio e, opcionalmente, o conhecimento geral sobre o domínio da aplicação. A representação mais externa consiste em partições ordenadas em hierarquias. Dentro de cada partição o conhecimento pode ser representado tanto como um esquema conceitual (uma hierarquia de conceitos) como em cálculo de predicado de primeira ordem. Essa representação em dois níveis permite a representação de crenças e objetivos do usuário em relação ao domínio da aplicação, do conhecimento do sistema sobre o domínio da aplicação e de suposições a respeito caracteristicas relevantes à aplicação de subgrupos de usuários (chamados estereótipos). As regras de inferência que são baseadas em crenças e objetivos observados, respostas do usuário em entrevistas, ações do usuário, etc., também podem ser representadas. 
3.3.1.2.1. Hierarquias de partição para a representação de modelos de usuários individuais e estereótipos

O mecanismo de partições do BGP-MS, chamado KN-PART, permite tanto a coleta de diferentes tipos de suposições sobre o usuário como do conhecimento do domínio do sistema em partições separadas.

\subsection{Representação do conhecimento do domínio do BGP-MS}

O conhecimento do domínio de que o BGP-MS necessita para cuidar das tarefas de modelagem do usuário devem ser armazenadas em uma partição separada chamada SB (System Believes). Essa partição pode estar vazia se o BGP-MS não necessita desse tipo de conhecimento ou conter parte ou todo o conhecimento do dominio da aplicação.

\subsection{Representação do modelo de usuário individual}

No BGP-MS, o modelo de usuário individual contém todas as suposições e informações correntes sobre o usuário. Dependendo da aplicação podemos distinguir vários tipos diferentes de suposições. As mais freqüientemente empregadas são:

- As suposições "privadas", que contém as suposições do sistema sobre as crenças do usuário sobre o domínio da aplicação (SBUB), inclusive aquelas das quais o sistema não compartilha (enganos do usuário).

- As crenças mútuas do sistema e do usuário sobre as crenças do usuário a respeito do domínio da aplicação (SBMBUB), incluindo os enganos do usuário.

- As crenças mútuas do sistema e do usuário sobre o domínio da aplicação (SBMB).

- As suposições privadas do sistema sobre os objetivos do usuário a respeito do domínio da aplicação (SBUW).

- As crenças mútuas do sistema e do usuário sobre os objetivos do usuário a respeito do domínio da aplicação (SBMBUW).

- As suposições do sistema sobre "fatos objetivos" a respeito do usuário (que são parte da partição SB).

No BGP-MS, cada uma dessas suposições é coletada em uma partição separada. 


\subsection{Representação de estereótipos}

$\mathrm{Na}$ abordagem de estereótipos para a aquisição de modelos de usuário, o construtor da aplicação deve identificar subgrupos dentro da população esperada de usuários cujos membros possuem certas características homogêneas relevantes à aplicação. As características do subgrupo identificadas podem ser formalizadas em um sistema de representação apropriado. A coleção de todas as características de um subgrupo de usuários representadas é chamada de estereótipo do subgrupo. Para cada estereótipo, cabe ao construtor do sistema definir um pequeno número de chaves que identifiquem se o usuário é ou não pertencente a determinado subgrupo.

Para cada estereótipo temos uma partição separada no BGP-MS. Se as características se aplicam a um determinado usuário, o estereótipo é ligado ao modelo individual, e o conteúdo do estereótipo passa a ser automaticamente inerente ao modelo.

Se os conteúdos de dois ou mais estereótipos se sobrepõem, as hierarquias de partições podem ser usadas para se criar uma hierarquia de estereótipos.

As condições que as partições devem satisfazer para que sejam declaradas partições de estereótipos são:

- As partições de estereótipos devem ser folhas da hierarquia de estereótipos ou possuir ao menos duas partições de estereótipos como filhas.

- A propagação ascendente de uma partição não - estereótipo para uma partição de estereótipo é proibida.

Essas restrições existem para evitar propagações ascendentes incorretas.

\subsection{Representação híbrida dentro das partiçōes}

Como já foram citadas acima, as suposições dentro das partições podem ser representadas de uma forma híbrida que consiste de dois componentes. A linguagem de representação de conhecimento conceitual SB-ONE pode ser usada para formular suposições a respeito de conceitos do domínio da aplicação. A linguagem do cálculo de predicados é empregada para expressar as suposições que não podem ser representadas em SB-ONE, como expressões que incluem disjunções, negações, quantificações e implicações.

O poder de expressão do cálculo de predicados excede o da linguagem SB-ONE. Assim, toda expressão em SB-ONE é, em princípio, possivel de ser expressa nas fórmulas do cálculo de predicados. As vantagens dessa dupla representação são: 
- SB-ONE é um formalismo especializado para a representação de taxonomia de classes de objetos e de relações binárias entre essas classes. Um grande número de aplicações provavelmente precisará representar esse tipo de conhecimento terminológico.

- Muitas inferências que podem ser feitas na base de conhecimento que é representável em SB-ONE já são amarradas a esse sistema de representação de conhecimento. Assim, a parte terminológica do conhecimento do usuário modelado deve ser mais bem representada em SB-ONE, mesmo quando o cálculo de predicados é necessário.

Particularmente pela última razão, é preferível que as crenças e metas reportadas devem ser preferencialmente representadas em SB-ONE. Mecanismos de integração cuidam para que o conhecimento representado em SB-ONE seja levado em consideração nas inferências utilizando cálculo de predicados.

\subsubsection{Aquisição do Modelo de Usuário e a manutenção da consistência no BGP-MS}

O BGP-MS proporciona vários métodos de inferências para fazer suposições sobre o usuário baseado em mensagens da aplicação e em suposições feitas previamente. É possível que uma mesma mensagem acione mais de um método de inferência. Adicionalmente, os construtores de aplicações podem definir funções Lisp que o BGP.MS executará ao receber mensagens do BGP-MS.

\subsection{Inferências a partir de entrevistas com o usuário}

Uma entrevista consiste de blocos de questões onde cada um pode conter uma ou mais questões. Um bloco é apresentado ao usuário de uma só vez, e as respostas do usuário são mandadas de volta ao BGP.MS.

A definição de uma questão dentro de um bloco inclui seu nome, 0 texto da questão, 0 seu tipo e a parte de conclusões. O tipo da questão especifica o conjunto de possiveis respostas, 0 que pode ser levado em consideração quando a questão é visualizada. Neles estão inclusas as questões do tipo sim/não, questões com um conjunto pré-definido de respostas (onde mais de uma podem ser selecionadas) e questões com um intervalo numérico de respostas. Finalmente, na parte de conclusão, o construtor pode definir as suposições que serão feitas a partir de questões especificas usando BGDL. 
As conclusões sobre o usuário são tomadas assim que as respostas a um bloco de questões retornam ao BGP-MS, e se tornam partes do modelo. O componente de entrevistas pode levar essas conclusões em consideração quando compõe o novo bloco de questões e quando tira conclusões de novas respostas. Portanto, o BGP-MS permite que se definam expressões condicionais na seqüência da entrevista ou na parte de conclusões da definição da questão.

\subsection{Inferências baseadas nas ações do usuário}

Para se fazer suposições sobre o usuário, heurísticas de aquisição têm sido freqüentemente utilizadas na literatura de modelagem de usuário. Essas regras são

freqüentemente especificas do domínio, mas existem também algumas independentes, que descrevem as suposições que podem ser feitas quando o usuário realiza ações específicas na sua interface. Muitas dessas suposições podem ser consideradas como pré-requisitos para a correta execução das respectivas ações. Por exemplo, a utilização correta de um objeto presume que o usuário conhece o objeto. Então, pode ser pressuposto que o usuário conheça o objeto se ele o utilizar corretamente.

\subsection{Ativação e retração de estereótipos}

A ativação e retração de estereótipos são feitas automaticamente pelo BGP-MS. Condições de ativação ou retração de um estereótipo devem ser definidas pelo construtor da aplicação, levando em conta apenas às suposições obtidas diretamente do usuário. Estas suposições incluem as crenças e objetivos que foram reportadas pela aplicação, assim como suposições baseadas nas respostas das entrevistas. As suposições obtidas por processos de inferência ou através a ativação de outros estereótipos não devem ser consideradas.

Uma série de esquemas de condições de ativação e retração de estereótipos pré-definidas são fornecidas pelo BGP-MS, e incluem condições onde o estereótipo é ativado ou retraído se uma lista de itens de conhecimento é conhecida, ou se os itens são desconhecidos, se $\mathrm{n} \%$ do conteúdo de um estereótipo é conhecido, ou ainda se pelo menos n\% dos itens de uma lista é conhecido, etc.

\subsection{Inferências dentro do modelo individual}

Os formalismos de representação do BGP-MS oferecem uma variedade de possibilidades de inferência que são deixadas a cargo de dois processos de inferência principais. A representação SB-ONE oferece numerosas inferências predefinidas. O demonstrador de teoremas 
baseado em resoluções OTTER é encarregado das inferências no cálculo de predicados. Como o poder expressivo do SB-ONE é consideravelmente mais fraco que o do cálculo de predicados, o OTTER foi escolhido como o processador de inferências central, consultando o SB-ONE em relação ao conhecimento conceitual se isso for prometedor.

A computação automática da propriedade transitiva das relações de subordinação e a classificação são exemplos das inferências predefinidas do SB-ONE. Entre os exemplos de inferência na base do FOPC inclui-se a execução de regras de inferência que o usuário presumivelmente emprega. Essas regras não podem ser expressas em SB-ONE, devido a sua generalidade, e não têm necessariamente que ser válidas, mas representam enganos do usuário e podem ser usadas para simular o raciocínio (potencialmente enganoso) deste último.

\subsection{Dependências inferenciais e manutenção da consistência}

As suposições em um modelo de usuário individual podem ser contraditas por novas suposições, não importando o momento em que elas são reportadas ou inferidas pelo BGP-MS. Nesses casos pode ser necessário retrair uma suposição em favor de outra. Um problema adicional surge quando suposições prévias são feitas em função de outra que deve ser retraída. Então, todas as suposiçðes derivadas da que foi retraída devem ser retraídas também. Para tanto, os shells utilizam componentes de manutenção do raciocínio, que guardam e dão manutenção nas dependências entre as inferências. Se uma suposição é retraída, ela não é apagada literalmente do modelo, mudando apenas de status. Então, todas as outras inferências a partir dela são recalculadas e, como consequêencia, algumas ou todas as suposições dependentes também podem ser retraídas.

Atualmente, um componente de manutenção do raciocínio está sendo implementado para o BGP-MS, que deve empregar estratégias para resolução de conflitos. Essas estratégias incluirão a associação de prioridades às suposições, baseadas em como e quando elas foram derivadas. Retrações de estereótipos também devem ser incluidas no algoritmo de manutenção do raciocínio.

\subsubsection{TAGUS}

O TAGUS (Theory and Aplication of General User Modeling Systems) integra mecanismos das áreas de modelagem de usuários e estudantes ${ }^{7}$.

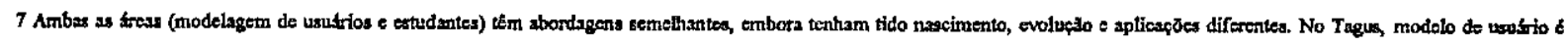
mais direcionado so entendimento da lingungern natural, enquanto o modelo do estudante (aprendiz) 6 majs wolado a diagróstico de enganot o aprendizado do "zhunos". 
O TAGUS é capaz de cuidar de algumas das funções básicas da modelagem, tais como: adquirir o modelo através de observações do agente, gerar hipóteses para explicar seu comportamento, modificar o modelo de acordo com a aquisição de novas informações, prover informações sobre o agente ao exterior e simular o comportamento do agente.

Porém, o TAGUS não pode ser visto propriamente como um shell, mas antes como uma implementação de um framework e um workbench para testar mecanismos e situações da modelagem de usuários e estudantes. Mesmo assim, algumas das funcionalidades dos shells, tais como independência e uma representação para modelagem de usuário e aprendiz (MUA) independente podem ser nele encontradas.

\subsubsection{Fluxo de informações entre a aplicação e o TAGUS}

Considerando sua arquitetura, a principal característica que se pode evidenciar é a independência. Apesar dessa ser uma caracteristica comum aos sistemas de modelagem de usuário, poucas vezes ela foi atingida na modelagem de estudantes. Entre outras razões que apoiam essa suposição está o fato de que há alguns mecanismos que todo sistema de modelagem deve realizar e que podem ser definidos de uma maneira geral, podendo, portanto ser utilizado por outras aplicações.

O grande problema, entretanto é a transferência de informações entre a aplicação e o sistema de modelagem de usuário e aprendiz (SMUA). Cada aplicação tende a ter uma representação de conhecimento particular, bem como uma linguagem particular para representálo. Neste caso, o problema de termos um SMUA independente do domínio se torna também um problema de comunicação entre os sistemas. Esse problema foi parcialmente solucionado através da imposição de uma linguagem de comunicação entre a aplicação e o MUA e uma linguagem de domínio para o conteúdo. Então, a arquitetura global do sistema é constituída de duas partes: a aplicação e o TAGUS, que são parcialmente independentes e que podem se comunicar via uma linguagem de comunicação. Logo, o agente realiza um diálogo (interação) com a aplicação e essa provê os detalhes dessa interação ao TAGUS.

As principais funções do TAGUS são: 1) fornecer informações à aplicação; 2) adquirir informações; 3) simular o agente; 4) diagnosticar enganos. Abaixo expressamos estas funções mais detalhadamente: 
O TAGUS é responsável por manter o modelo do agente e, deste modo, disponibilizar essas informações para o exterior. A aplicação pode utilizar duas funções para requisitar informações:

- $\quad$ Ask_ULM : $<$ TAGUS_sentence $>\rightarrow$ (yes, no, don'tknow)

- Inquire_ULM : $<$ TAGUS_sentence $>\rightarrow(($ yes, no, don'tknow), $<$ justification $>)$

nas quais $<$ TAGUS_sentence $>$ é especificada como uma tarefa na linguagem em que ULM é definido no TAGUS, (yes, no, don'tknow) são as respostas que o TAGUS pode retornar e $<$ justification> é um conjunto de fatos que justificam o resultado da tarefa.

A diferença entre as funções é que enquanto a função ask apenas verifica se o fato está presente no modelo, a função inquire checa sua justificativa.

\subsection{Adquirindo informaçōes}

O TAGUS adquire informações à medida que a aplicação as forece ao TAGUS. As funções para isso são:

- Add_ULM : <situation $><$ observation $>$

- Update_ULM: <situation> <observation> $\rightarrow$ ((suceed, fail), $<$ changesJustification $>$ )

onde <situation> é um conjunto de ações realizadas pela aplicação, <observation> é o conjunto de ações realizadas pelo agente e (suceed, fail) são as respostas que o TAGUS pode informar à aplicação. O tipo de aquisição mais comum utilizando é a função add, através da qual o fato é apenas adicionado ao modelo. Já a função update fornece as justificativas das mudanças feitas no modelo para incluir uma nova crença e os resultados dessa inclusão no modelo.

\subsection{Simulando o agente}

A simulação do agente feita pelo TAGUS pode ser de dois tipos: simulação para resolução de problemas e simulação de mudanças.

- $\quad$ SimulateProblemSolving_ULM: $<$ situation $>\rightarrow<$ TAGUS_Proof $>$

- Simulate Change_ULM: <situation $>$, <observation $>\rightarrow(<$ result>, $<$ hypothesesOfChange>) 
onde o "resultado" e as "hypothesesOfChange" descrevem as mudanças que ocorreram no modelo (tanto mudanças do sistema quanto do agente).

\subsection{Diagnosticando enganos}

Diagnosis_ULM: <situation $>$, <observation $>\rightarrow<$ hypotheses $>$

Até agora o TAGUS pode apenas fazer diagnósticos baseados em regras implícitas para gerar hipóteses que justificam um engano (se a aplicação solicitar).

\subsection{A arquitetura do TAGUS}

O TAGUS propriamente dito é composto de três partes principais: o modelo do agente, $o$ módulo de aquisição e o módulo de manutenção. Dentro do módulo de aquisição, vários componentes podem ser encontrados de acordo com as várias estratégias de aquisição: o módulo baseado em estereótipos, o módulo de diagnóstico, o módulo de aquisição implícita e o de

aquisição explícita. À parte de manutenção tem dois módulos: o AMMS (agent model reason maintenance system) e o meta-argumentador. Detalhadamente, temos:

- A aplicação: Pode ser um Sistema Tutor Inteligente (STI) ou Um Ambiente de Aprendizado Interativo (AAI), um Sistema de Consultas ou até mesmo um Sistema de Realidade Virtual. A aplicação é o componente que modifica o que é apresentado ao agente ou ao ambiente em que o agente está colocado. A aplicação também pode realizar a interpretação das ações do agente que serão fornecidas ao TAGUS. Também podemos encontrar na aplicação o modelo do agente ideal que na verdade é o Modelo do Domínio.

- O modelo de usuário e aprendiz (MUA): Representa o que é conhecido pelo TAGUS a respeito do agente e usa uma linguagem interna baseada em PROLOG, onde as atitudes do agente (tais como crenças, objetivos, capacidade de raciocínio) são representadas explicitamente como meta - operadores.

- O subsistema baseado em estereótipos: É um dos componentes do módulo de aquisição e utiliza uma técnica muito popular quando a aquisição é feita em domínios onde as características dos agentes são divididas em classes. $\mathrm{O}$ sistema implementado no TAGUS permite a definição de uma taxonomia de estereótipos e dos mecanismos de ativação utilizando para isso uma linguagem. $\mathrm{O}$ dispositivo 
de inferência interpreta essa linguagem e gera as hipóteses a serem incluídas no MUA.

- O subsistema de diagnóstico: Determina a melhor hipótese para explicar um comportamento não esperado. Em termos gerais, esse sistema cria hipóteses sobre o agente baseadas em respostas "erradas" da parte deste último.

- $\quad$ meta - argumentador: Interpreta o conteúdo do modelo e realiza raciocínios dentro dele. Portanto, se o modelo inclui regras de inferência, o meta argumentador as executa para simular o raciocínio do agente.

- O AMMS: É um módulo auxiliar que é usado para manter as justificativas para o conteúdo do modelo. Toda vez que um novo fato é incluído no modelo, o AMMS é ativado e muda uma estrutura de dados interna que representa as dependências entre os fatos no modelo.

- As interfaces: A interface com o mundo exterior pode ser feita de duas maneiras: Uma com a aplicação que é feita através de um conjunto de mensagens; e a outra, com um usuário especial, que fornece alguns serviços para utilizar o modelo, mudá-lo, simulá-lo e testar algumas técnicas. $\mathrm{O}$ "usuário" neste caso đeve ser alguém que tenha conhecimentos sobre modelagem.

\subsubsection{Representação do conhecimento de modelagem de usuário e do conhecimento do dominio}

A representação do MUA no TAGUS permite a descrição de alguns tipos de atitudes dos usuários e estudantes, chamadas entidades e são definidas por meta-operadores sobre fórmulas do cálculo de predicado de primeira ordem.

\subsection{Conhecimentos e crenças de usuários e estudantes}

As crenças e conhecimentos dos agentes são representados seguindo a abordagem SMLLE onde um modelo é dividido em quatro níveis: o nível de crenças, o nível de argumentação, o nível de monitoramento e o nível de reflexão.

- No nível de crenças, os fatos em que o agente crê estão representados como atitudes de crença a respeito de uma sentença.

- No nível de argumentação, os mecanismos para solução de problemas são apresentados como regras de inferência. Uma regra é chamada argumento e determina como o agente pode argumentar em uma dada situação. 
- No nível de monitoramento, é representado o controle que o agente tem sobre a maneira com que ele executa tarefas, como por exemplo, a tática usada para solucionar um tipo de problema, ou uma regra para dizer quando desistir de tentar resolver certo problema.

- $\quad$ O nível de reflexão é um conjunto de mecanismos usados pelo agente como meio de controlar as táticas utilizadas.

\subsection{Açóes do usuário e do aprendiz}

São incluídas no modelo como fatos toda vez que a aplicação detecta uma ação do usuário ou aprendiz.

\subsection{Características do usuário e do aprendiz}

São propriedades específicas do aprendiz, como, por exemplo, a idade do usuário, sua nacionalidade e até mesmo quantas vezes ele utilizou uma mesma regra.

\subsection{Objetivos}

É importante em aplicações que disponibilizam um ambiente para a resolução de problemas onde as ações do agente são executadas a fim de alcançar objetivos. Os objetivos são também utilizados no argumentador e no monitor.

\subsection{Mudanças}

$O$ agente muda durante a interação com o sistema, principalmente se for um sistema de aprendizado. Quando essas mudanças são detectadas pelo sistema também são guardadas no modelo.

\subsubsection{Aquisição do Modelo de Usuário e a manutenção da consistência no TAGUS}

Os mecanismos de aquisição e manutenção são ativados toda vez que a aplicação manda uma mensagem ao TAGUS, que pode também implicar em novas informações sendo incluídas no modelo. O sistema identificará alguns mecanismos de aquisição para serem aplicados e através da execução destes métodos, o modelo é modificado. A aquisição é baseada nesta 
informação, chamada Observação, que é uma ação do aprendiz especificada na linguagem do TAGUS. O ciclo básico de aquisição no TAGUS toma essas observações e executa todas as inferências diretas possíveis a partir delas, modificando o modelo. Então, a partir do modelo modificado, é iniciado o mecanismo de aquisição indireta até que o modelo se torne estável.

Os mecanismos utilizados devem ser definidos de maneira que um modelo estável seja obtido. Isto é garantido pela maneira que o modelo é mantido e pelas justificativas também mantidas pelo AMMS.

O TAGUS mantém os modelos providenciando um conjunto de funções de manutenção de núcleo, como por exemplo: addFact, addBelief, deleteFact. Esses mecanismos básicos de armazenamento de informação no modelo foram extendidos para suportar a manutenção de justificativas (pelo AMMS). Então, com o AMMS, uma outra camada de funções de manutenção foi construída, entre elas reviseBelief, expandBelief, contractReasoner, etc. Toda vez que o processo de aquisição de conhecimento faz uma nova inferência, as funções do núcleo são utilizadas para adicionar essas informações ao modelo e o AMMS para manter as justificativas para a inferência que foi feita.

\subsubsection{Comparação entre os Shells}

Como visto nas sessões anteriores, tanto o BGP como o Tagus são exemplos de shells bastante complexos. Para melhor visualização de suas possibilidades, encontra-se abaixo uma tabela de comparação:

Tabela 5: Comparação das características básicas dos shells: BGP x TAGUS

Interface

\begin{tabular}{|l|l|l|}
\hline Características & \multicolumn{1}{|c|}{ TAGUS } & \multicolumn{1}{|c|}{ BGP-MS } \\
\hline Número de interfaces & $\begin{array}{l}\text { Duas, uma com a aplicação } \\
\text { (mensagens) e outra com um } \\
\text { "super usuário" para a edição de } \\
\text { perfis. }\end{array}$ & $\begin{array}{l}\text { Três, uma com a aplicação (mensagens), } \\
\text { um editor de partições estereótipos e um } \\
\text { editor de SB - ONE em implementação. }\end{array}$ \\
\hline Interface com a aplicação & $\begin{array}{l}\text { Mensagens seguindo o padrão } \\
\text { SMILE. }\end{array}$ & $\begin{array}{l}\text { Mensagens em BGDL (Belief and Goal } \\
\text { Description Languagc). }\end{array}$ \\
\hline Interface com "super usuário" & $\begin{array}{l}\text { Permite a adição de novas regras } \\
\text { de aquisição de conhecimento ao } \\
\text { modelo de usuário corrente. }\end{array}$ & $\begin{array}{l}\text { Permite a edição da hierarquia de } \\
\text { partiçóe por intermédio de um editor } \\
\text { gráfico (desenhos) e permite a edição de } \\
\text { esterétipos, como, por exemplo, } \\
\text { adicionar ou remover regras de } \\
\text { conhccimento e regras para a ativação e } \\
\text { retração de estereótipos. }\end{array}$ \\
\hline
\end{tabular}


Modelo de usuário

\begin{tabular}{|c|c|c|}
\hline Características & TAGUS & BGP-MS \\
\hline Número de agentes modelados & Uma única pessoa. & Uma única pessoa ou grupos de pessoas. \\
\hline Modelo estático / dinâmico & Dinâmico. & Dinamico. \\
\hline Curto Prazo/Longo Prazo & $\begin{array}{l}\text { Longo prazo (visando } \\
\text { reutilização). }\end{array}$ & Longo prazo (visando rcutilização). \\
\hline Aquisiçăo implícita/ explícita & $\begin{array}{l}\text { Aquisição implícita (ações e } \\
\text { conteúdo pré-existente do modelo, } \\
\text { estereótipos). }\end{array}$ & $\begin{array}{l}\text { Aquisiçã̃o explícita (questionário) e } \\
\text { implicita (açoses e conteúdo pré-cxistente } \\
\text { do modelo, estereótipos). }\end{array}$ \\
\hline Origem dos dados & $\begin{array}{l}\text { Comunicação com o sistema } \\
\text { através de mensagens (açöes do } \\
\text { usuário), estereótipo. }\end{array}$ & $\begin{array}{l}\text { Comunicação com o sistema através de } \\
\text { mensagens (açôes do usuário), entrevistas } \\
\text { com o usuário, conhecimento do } \\
\text { estereótipo. }\end{array}$ \\
\hline Verificação de consistência & $\begin{array}{l}\text { Utiliza o AMMS para a } \\
\text { verificação de inconsistências no } \\
\text { modelo, as quais são guardadas } \\
\text { numa "coleção de erros" do } \\
\text { usuário. Guarda as dependências } \\
\text { entre as inferências. }\end{array}$ & $\begin{array}{l}\text { Verifica a inconsistência através de } \\
\text { inferências bidirecionais, guardando as } \\
\text { dependências entre as inferências (parte } \\
\text { desse módulo está em desenvolvimento). }\end{array}$ \\
\hline
\end{tabular}

Representação de conhecimento

\begin{tabular}{|l|l|l|}
\hline Características & \multicolumn{1}{|c|}{ TAGUS } & \multicolumn{1}{|c|}{ BGP-MS } \\
\hline $\begin{array}{l}\text { Representaç̆o externa } \\
\text { (comunicação) }\end{array}$ & Sistema SMILE de comunicação. & $\begin{array}{l}\text { BGDL (Belief and Goal Description } \\
\text { Languagc). }\end{array}$ \\
\hline $\begin{array}{l}\text { Representaçăo interna } \\
\text { (raciocinio) }\end{array}$ & $\begin{array}{l}\text { Cálculo de Predicado de Primeira } \\
\text { Ordem. }\end{array}$ & $\begin{array}{l}\text { SB-ONE (preferencial) e Cálculo de } \\
\text { Predicado de Primeira Ordem. }\end{array}$ \\
\hline $\begin{array}{l}\text { Representaçăo interna } \\
\text { (armazenamento) }\end{array}$ & $\begin{array}{l}\text { Cálculo de Predicado de Primeira } \\
\text { Ordem. }\end{array}$ & $\begin{array}{l}\text { SB-ONE ou Cálculo de Predicado de } \\
\text { Primeira Ordem. }\end{array}$ \\
\hline Linguagem de programaçăo & Prolog & Lisp \\
\hline
\end{tabular}

\subsection{Modelos de Usuários Internos}

\subsubsection{Modelando os erros dos estudantes no tutor ELECTRE}

Desde o aparecimento da instrução programada, técnicas de aprendizado usando o computador têm sido desenvolvidas. Toda a história de tal ensino foi dirigida para o ensino cada vez mais individualizado. As técnicas de inteligência artificiais (IA) tornaram possível pensar em um ensino no qual existe uma relação entre a máquina e o estudante semelhante a tutores $\mathrm{e}$ aprendizes. Mas para fazer isto, devem ser resolvidos alguns problemas, como a representação do conhecimento a ser ensinado e também a representação do estudante.

O conhecimento de um domínio especifico pode estar em níveis diferentes de sofisticação. O conhecimento do estudante pode ser visto como uma parte, um subconjunto, do conhecimento do especialista [Carr-77], mas também pode ser um conhecimento diferente do especialista. Neste caso, estudantes podem desenvolver noçð̄es errôneas. O assunto é bastante 
diferente em domínios semanticamente ricos, como a fisica, porque o conhecimento em tal domínio não só inclui habilidades processuais. Os resultados de pesquisas de educação em fisica revelam que as dificuldades dos estudantes também vêm de noções erradas desenvolvidas na vida cotidiana. Assim, um modelo do conhecimento do estudante deveria prever a representação dos erros do estudante.

O ELECTRE é um sistema de diagnóstico de erros de estudantes que resolvem problemas em eletricidade básica. Uma vez que os erros foram descobertos, serão dados aos estudantes um treinamento especial para os corrigi-los.

\subsubsection{Esboço do sistema ELECTRE}

ELECTRE é um projeto de multidisciplinar no qual cientistas da computação, psicólogos cognitivos e investigadores de educação em física estão trabalhando. $O$ domínio de física escolhido é eletricidade básica e mais especificamente circuitos de DC. O objetivo do projeto é diagnosticar o estado do conhecimento do estudante depois de resolver um conjunto de problemas que lidam com tensão e/ou corrente. Ao unir os erros feitos por estudantes à análise de diagrama, o sistema ELECTRE propõe três categorias diferentes de tarefas:

- Descrição de diagramas de circuito;

- Cálculos de correntes;

- Cálculos de voltagens.

O sistema ELECTRE vem atrás do ensino de conceitos básicos de eletricidade, testando o conhecimento do estudante e diagnosticando suas deficiências.

Os tipos diferentes de conhecimento na mente do estudante não têm o mesmo estado. Alguns são diretamente utilizáveis, e outros precisam ser processados. Assim a modelagem do estudante tem que levar em conta os diferentes níveis de conhecimento. Qualquer modelagem de estudante deveria ter certas características para ser válidas. Primeiro um modelo de estudante deveria ser pertinente ao assunto. Assim em educação de física, se o objetivo é enfocar os conceitos, que erros devem ser desconsiderados. Também deveria ser pertinente às metas do professor como corrigir os erros mais freqüentes; neste caso o sistema não levará em conta os erros muito raros. Outra característica a ser considerada é sua validade psicológica. Qualquer modelo de estudante, em particular os modelos cognitivos, deveria estar baseado nos mais recentes resultados de psicologia cognitiva, por exemplo, modelos mentais [Gentner-83]. 
Finalmente, o modelo deveria ser geral o bastante para ser aplicado à maioria dos estudantes e não só para alguns, e também para a maioria dos problemas que lidam com o mesmo domínio.

Tecnicamente, o ELECTRE é um sistema baseado em sistemas especialistas. Todas as regras se agrupam em uma base de regras. A administração das regras é executada pelo SNARK, interpretador baseado no cálculo de predicado [Lauriere-83]. Como em qualquer sistema especialista, o interpretador é independente dos dados. Os dados compõem a base de fatos. Cada fato é descrito pelo trio objeto-atributo-valor. A máquina de inferências examina a possível partida entre o estado atual da base de fato e a condição das regras de produção. Uma vez que a regra é escolhida, é disparada. Então o estado atual da base de fatos é modificado.

\subsubsection{Modelo do conhecimento do estudante}

Estudos preliminares [Caillot-85] mostraram que alguns estudantes descrevem esquemas de circuitos e resolvem problemas em circuitos DC depois de terem construído representações de problema baseado nas características da declaração do problema em lugar dos princípios de eletricidade. Em geral estes circuitos são reconhecidos imediatamente por estudantes. A base de conhecimento do estudante novato é organizada ao redor da noção de protótipos [Reed-72] que são unidades muito limitadas e desconectadas de conhecimento. Eles são freqüentemente associados com circuitos canônicos e têm diagramas específicos; assim os resistores que se conectam em série são vistos alinhados e os que se conectaram em paralelo são representados ao longo de linhas paralelas geométricas. Os estudantes menos proficientes só têm este conhecimento de protótipo, considerando que os estudantes mais qualificados têm um conhecimento muito flexível, adaptado a tipos diferentes de circuitos.

Quando os problemas tratam de circuitos diferentes do canônico, os novatos argumentam analogamente e usam heurísticas que os conduz atrás de situações bem conhecidas de circuitos canônicos, mas estas heurísticas são impróprias do ponto de vista de um físico.

Pode-se então criar regras em linguagem natural para simbolizar o circuito:

SE um terminal de um resistor $\mathbf{R} 1$ está conectado a um terminal de um resistor $\mathbf{R} 2$, E SE R1 e R2 estão alinhados no diagrama de circuito, ENTÃo R1 e R2 estão em série no protótipo.

SE estão conectados dois resistor em série no protótipo, ENTÃO a corrente é a mesma ao longo de qualquer ponto da linha diretamente formada pelo arame e pelos resistores. 
Estas duas regras estão corretas, mas elas são muito especificas, muito restritivas. Os estudantes iniciantes podem só resolver a classe de problemas onde os resistores em série estão ao longo de uma linha direta. Pode aparecer um diagrama onde dois resistores estão conectados em série, mas não estão alinhados (veja Figura 6). Assim o conhecimento sobre protótipos está muito limitado.
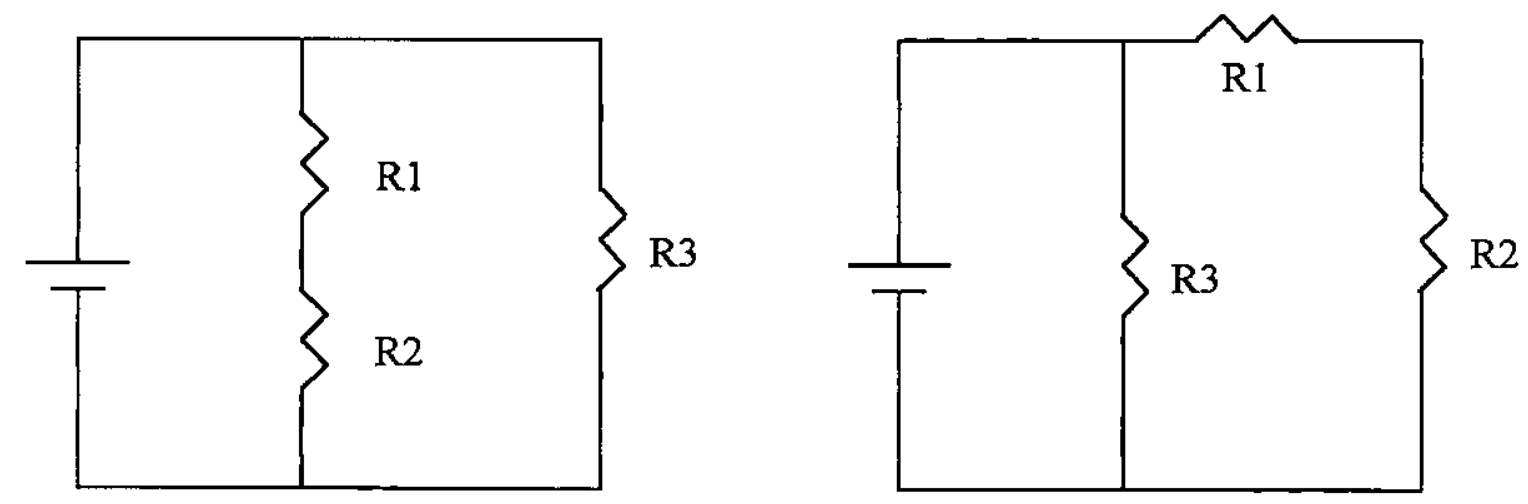

Figura 6: Um diagrama onde dois resistores estão conectados em série

Existe um número aproximado de 100 regras na base que descrevem os circuitos.

O esquema ou frame representa um conhecimento menos específico. Pode-se colocar então valores de variáveis discretas ou contínuas Assim a representação anterior ficaria assim:

Se um terminal de um dispositivo de dois pólos 1 está conectado a um terminal de um dispositivo de dois pólos 2 E SE não há nenbuma junção entre eles, ENTĀO são conectados em série.

O conhecimento esquemático é insuficiente quando os problemas tratam de circuitos mais complexos. Neste caso uma heurística é usada. Os estudantes substituem um determinado problema por sub-problemas ou simplificam o circuito substituindo resistor por um resistor equivalente cuja resistência pode ser calculada ou remove algum componente. Tudo isto é feito para achar um protótipo ou uma situação onde o conhecimento esquemático está disponível. Um exemplo que induz ao erro seria:

SE estão colocados três resistores ao longo de três linhas em T, ENTÃO remova a junção e a linha vertical no meio do circuito. 
3.4.2. Uma interface de banco de dados adaptável

O propósito do sistema adaptável de Benyon [Benyon-96] descrito abaixo simplesmente é selecionar a interface mais apropriada aos usuários para que o sistema possa satisfazer suas exigências de usabilidade, por exemplo, trazendo a taxa de erro de uso do sistema para menos que 1 erro para 12 tarefas e manter o tempo médio de conclusão de tarefa (TMCT) para menos de 25 segundos para quem usa a interface de comando e menor que 35 segundos para quem usa a interface de menu.

\subsubsection{Modelo do Domínio}

O modelo do domínio pode ser dividido em três partes. Cada uma possui seus atributos e valores, como mostra a Tabela 6 .

Tabela 6: Modelo do Domínio.

\begin{tabular}{|c|l|c|c|}
\hline \multirow{2}{*}{ Intencional } & $\begin{array}{l}\text { Uma tarefa de uma query é } \\
\text { completada com sucesso }\end{array}$ & tarefas & $\{1 \ldots \mathrm{N}\}$ \\
\hline \multirow{2}{*}{ Conceitual } & $\begin{array}{l}\text { Um erro é definido como: } \\
\text {-Uma formulação incorreta; } \\
- \text { Um operador perdido ou } \\
\text { incorreto; } \\
\text { - Um comando inapropriado }\end{array}$ & erros \\
\cline { 2 - 5 } & $\begin{array}{l}\text { O tempo médio para completar } \\
\text { uma tarefa é calculado como o } \\
\text { tempo total para completar um } \\
\text { bloco de 12 tarefas dividido por } \\
12\end{array}$ & $\{1 \ldots \mathrm{N}\}$ \\
\hline \multirow{2}{*}{ Físico } & $\begin{array}{l}\text { Uma interface é um estilo } \\
\text { coerente de interação }\end{array}$ & $\{1 \ldots \mathrm{N}\}$ segundos \\
\hline
\end{tabular}




\subsubsection{Modelo do Usuário}

O modelo do usuário contém dados do perfil pessoal do usuário, características cognitivas e o modelo do estudante. O modelo do estudante herda todos os atributos do domínio e é atualizado no registro de diálogo. Um aspecto importante de definir o modelo do usuário é estabelecer como os dados serão obtidos. A Tabela 7 mostra esta relação:

Tabela 7: Modelo do Usuário.

\begin{tabular}{|c|c|c|c|c|}
\hline Modelo & Nome do Atributo & Como Obter & Valores & Valores Iniciais \\
\hline Cognitivo & Habilidade Espacial & $\begin{array}{l}\text { Deduzido da } \\
\text { interação (Inferência) }\end{array}$ & $\begin{array}{l}\text { \{Alto, } \\
\text { Baixo }\}\end{array}$ & Alto \\
\hline Perfil & $\begin{array}{l}\text { Experiência em linguagem } \\
\text { de comando }\end{array}$ & $\begin{array}{l}\text { 1) Perguntando ao } \\
\text { usuário } \\
\text { 2) Inferência }\end{array}$ & $\begin{array}{c}\text { \{Alto, } \\
\text { Baixo, } \\
\text { Nenhum }\end{array}$ & Nulo \\
\hline Perfil & $\begin{array}{l}\text { Freqüência de uso do } \\
\text { computador }\end{array}$ & $\begin{array}{l}\text { Perguntando ao } \\
\text { usuário }\end{array}$ & $\begin{array}{l}\{\text { Freqüente, } \\
\text { Ocasional }\}\end{array}$ & Nulo \\
\hline Estudante & Tarefas & Registro do diálogo & $\{1 \ldots N\}$ & Nulo \\
\hline Estudante & TMCT & Registro do diálogo & $\begin{array}{c}\{1 \ldots \mathrm{N}\} \\
\text { segundos }\end{array}$ & Nulo \\
\hline Estudante & Erros & Registro do diálogo & $\{1 \ldots N\}$ & Nulo \\
\hline Estudante & Interface & Registro do diálogo & $\begin{array}{c}\{\text { Menu, } \\
\text { Comando }\}\end{array}$ & Comando \\
\hline
\end{tabular}

\subsubsection{Modelo da Interação}

O Registro de Diálogo detalha o número de erros feito e o número de tarefas completadas, atualizando o modelo de estudante. Consiste nos seguintes dados: Número de Tarefas, Número de erros. A Base de Conhecimento de interação é composta por várias regras de inferência e adaptação do tipo:

\section{Regra de Inferência 1}

Se interface $=$ comando e erros $>1$ e tarefas $=12$

Então habilidade espacial é baixa e experiência de comando é nenhum. 


\section{Regra de Adaptação 1}

Se habilidade espacial $=$ alto

Então interface $=$ comando.

\section{Regra de Adaptação 2}

Se habilidade espacial $=$ baixo e experiência de comando $=$ baixo $\mathrm{e}$ computando $=$ freqüente

Então interface $=$ comando.

\section{Regra de Adaptação 3}

Se habilidade espacial $=$ baixo e experiência de comando $=$ nenhum $\mathbf{e}$ freqüência de uso de computador $=$ ocasional

Então interface $=$ menu.

\subsection{Considerações Finais}

Como se observou neste capítulo, vários sistemas se beneficiaram do uso de modelos de usuários, por exemplo um ambiente de ensino de eletrônica ou uma interface de banco de dados. O estudo dos principais shells e sistemas de modelagem de usuários, bem como as suas caracteristicas e as ferramentas de ajuda e ensino da escrita foram fundamentais para a modelagem de usuários proposta para o protótipo do sistema adaptativo apresentado no Capitulo 5. No próximo capitulo, apresentaremos os conceitos de agentes, necessários à implementação do sistema de troca de mensagens usado no protótipo. 


\section{Agentes de Software}

Desde o inicio dos tempos, o homem sonhava com um agente não humano. Noções populares de andróides, robôs, humanóides, cyborgues, etc, sempre estiveram em nossa cultura. Quem nunca assistiu aos desenhos dos "The Jetsons", onde um robô substituía a empregada doméstica e todos os aparelhos tinham algo de inteligente, como tutores que ensinavam como usar o produto ou um diário que aconselhava a "Judi" sobre sua adolescência? No fundo, as noções de agentes de software sempre estiveram presentes nesses desenhos. Nos dias atuais, essas noções começaram a ganhar importância e forma. Este capítulo apresenta o conceito que será utilizado na arquitetura do ambiente AMADEUS para que as ferramentas sejam integradas: AMADEUS será formado por três agentes se comunicando com um outro agente especial que incorpora o modelo de usuário.

\subsection{O que são Agentes?}

Nos últimos dez anos tem havido um interesse crescente na tecnologia orientada a agentes, porém, não existe nenhuma concordância no que se constitui exatamente um agente. Tentamos neste capítulo trazer várias definições de agentes vindas de vários autores atuantes na área.

Segundo Genesereth em [Genesereth-94] agentes são componentes de software que se comunicam entre si através da troca de mensagens em um esquema de comunicação. Enquanto os agentes podem ser tão simples quanto seqüências de dados, normalmente eles são entidades maiores com algum tipo de controle persistente e autônomo. O que caracteriza um agente é a habilidade para comunicar e cooperar com outros agentes.

Nwana, em [Nwana-96], define um agente como se referindo a um componente de hardware e/ou de software que é capaz de realizar tarefas em nome de seu usuário.

$\mathrm{Na}$ grande área da Computação, a noção de um agente auto-suficiente executando processos de software que encapsula algum estado e que pode se comunicar com outros agentes por mensagem é vista como um desenvolvimento natural do paradigma de programação orientada a objetos [Agha-86; Agha-93]. 
"Um softbot é um agente que interage com um ambiente de software emitindo comandos e interpretando a realimentação do ambiente. Os effectors de um softbot são comandos que mudam o estado do ambiente externo. Os sensores de um softbot são comandos de entrada de informação" [Etzioni-94].

Wooldridge e Jennings, em [Wooldridge-95], definem agentes de dois modos distintos: agentes fracos e agentes fortes. Agentes fracos talvez seja o modo mais geral que o termo agente é usado para denotar um hardware ou, mais normalmente, um sistema de computador baseado em software que desfrute das seguintes propriedades:

- Autonomia: agentes operam sem a intervenção direta de humanos ou outros, e tem algum tipo de controle em cima de suas ações [Casteifranchi-95];

- Habilidade social: agentes interagem com outros agentes (e possivelmente com os humanos) por algum tipo de idioma [Genesereth-94];

- Reatividade: agentes percebem o ambiente, (que pode ser o mundo físico, um usuário por uma interface de usuário, uma coleção de outros agentes, ou a combinação destes), e interagem com este;

- Ativos: agentes não só reagem em resposta ao ambiente, mas eles podem exibir comportamento meta-dirigido tomando a iniciativa.

Agentes fortes é um outro lado de como ver agentes. Para alguns pesquisadores, o termo 'agente' tem um significado mais forte e específico que o esboçado acima. Para estes, agente é um sistema de computador que, além de ter as propriedades identificadas acima, é concebido ou implementado usando conceitos que são aplicados normalmente aos humanos. Por exemplo, é bastante comum um agente que usa noções de conhecimento, crença, intenção, e obrigação [Shoham-93]. Alguns pesquisadores foram mais adiante, e consideram os agentes emocionais [Bates-92; Bates-94]. Outro modo de dar aos agentes atributos humanos é representa-los visualmente, talvez usando um caricatura ou uma face animada [Maes-94].

Às vezes são discutidos vários outros atributos no contexto de agência. Por exemplo: -

- Mobilidade é a habilidade de um agente se mover em uma rede de computadores [White94];

- Veracidade é a suposição que um agente não comunicará falsa informação conscientemente [Galliers-88];

- Benevolência é a suposição que os agentes não têm metas contraditórias, e que todo agente tentará, então, sempre fazer o que é esperado dele [Rosenschein-85]; e 
- Racionalidade é a suposição que um agente agirá para alcançar suas metas e não irá agir de tal forma a evitar que suas metas sejam alcançadas. [Galliers-88].

\subsection{Porque agentes?}

Graças à IA Distribuída (DAI), os agentes de software herdaram os beneficios de modularidade, velocidade (devido a paralelismo) e confiabilidade (devido à redundância). Nwana, em [Nwana-96], propôs o conceito de agentes como sendo um objeto auto-suficiente, interativo e executado concorrentemente. Este objeto poderia responder às mensagens de outros objetos semelhantes.

A lista das empresas e universidades que procuram a tecnologia de agentes é bastante longa e está sempre crescendo. Inclui nomes como Carnegie Mellon University (CMU), Massachusetts Institute of Technology (MIT), Alcatel, Apple, AT\&T, BT, Daimler-Benz, DEC, HP, IBM, Lotus, Microsoft, Oracle, Sharp.

\subsection{Tipos de Agentes}

Nwana, em [Nwana-96], criou uma tipologia de agentes baseada em três características: autonomia, aprendizado e cooperação. Autonomia se refere ao princípio que agentes podem operar por si próprios sem a necessidade de intervenção humana. Cooperação com outros agentes é a razão de se ter múltiplos agentes no lugar de somente um. Para cooperar, agentes precisam interagir com outros e também com humanos via uma linguagem de comunicação. Para que agentes sejam realmente inteligentes, eles precisam aprender à medida que reagem e/ou interagem com o meio externo. $O$ aprendizado pode também tomar forma de um aumento de desempenho com o passar do tempo. A Figura 7 descreve essas três características formadoras da tipologia de Nwana. 


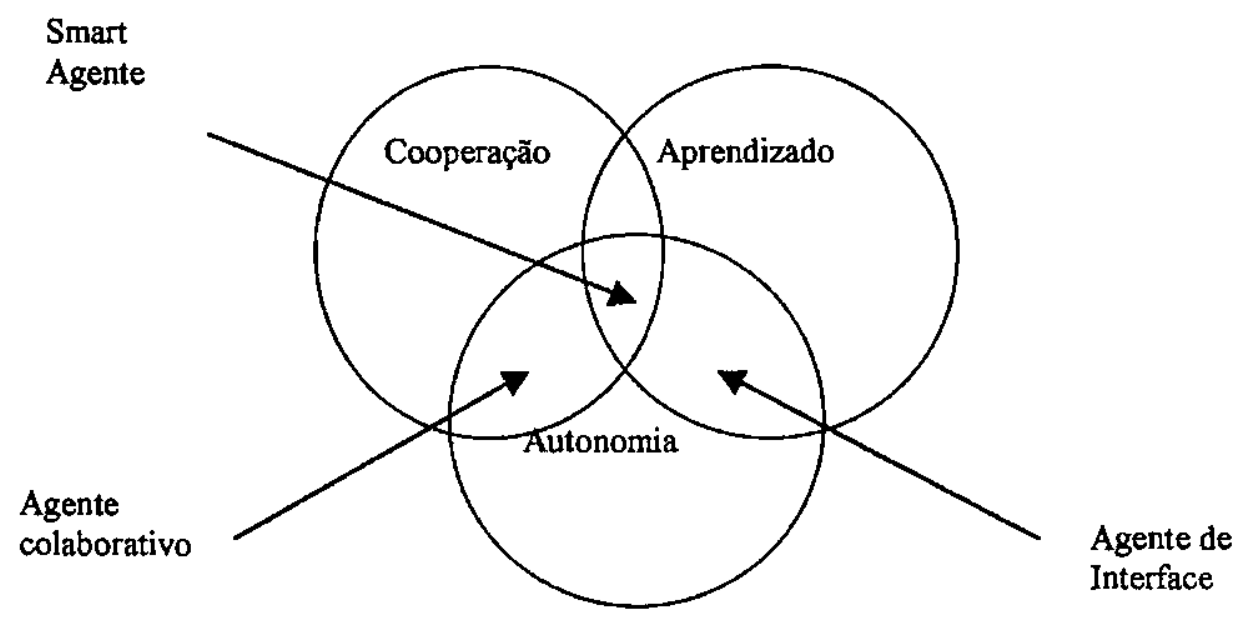

Figura 7: Tipologia de agentes segundo Nwana.

A Figura 8 apresenta a tipologia de agentes. Há algumas aplicações que combinam os agentes de duas ou mais destas categorias, e são referidos como sistemas de agentes heterogêneos.

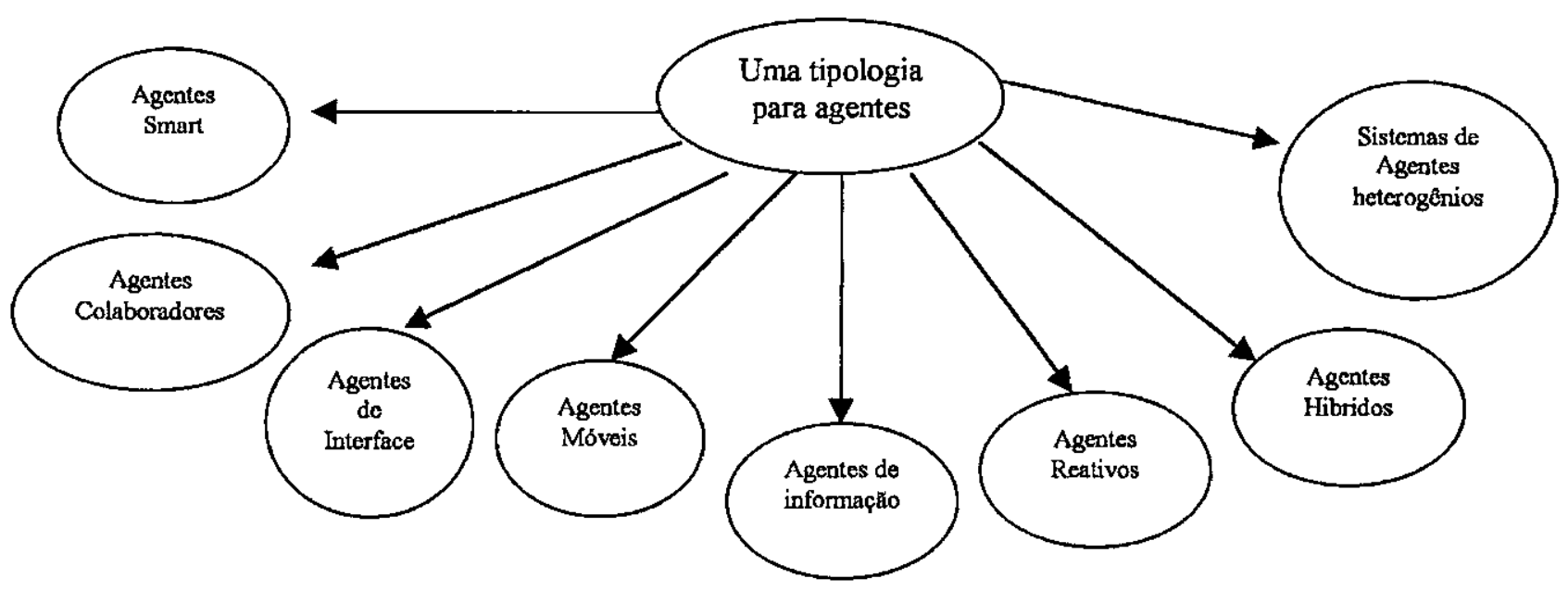

Figura 8: Classificação de Agentes de software. 
A Tabela 8 resume as principais características de cada tipo de agente apresentado acima.

Tabela 8: Principais características de cada tipo de agente

\begin{tabular}{|c|c|c|c|c|c|c|c|c|}
\hline & Colaborativo & Interface & Móvel & Informação & Reativo & Áfbrido & Heterogêneo & Smart \\
\hline Autonomia & 6 & $\theta$ & $\theta$ & & 0 & & & $\theta$ \\
\hline Cooperação & 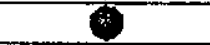 & & ( & & & & & 8 \\
\hline $\begin{array}{l}\text { Habilidades } \\
\text { sociais (interagem } \\
\text { através de uma } \\
\text { linguagem de } \\
\text { comunicação) }\end{array}$ & (i) & & & & & & & \\
\hline Responsiveness & 9 & & & & & & & \\
\hline $\begin{array}{l}\text { Proactivos } \\
\text { (Tomam a } \\
\text { iniciativa) }\end{array}$ & $\theta$ & & & & & & & \\
\hline Aprendizado & & (2) & & 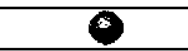 & & & & 9 \\
\hline $\begin{array}{l}\text { Interface com o } \\
\text { usuário }\end{array}$ & & 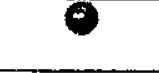 & & & & & & \\
\hline Executam em rede & & & 霖 & $\bar{C}$ & & & & \\
\hline $\begin{array}{l}\text { Gerenciam e } \\
\text { manipulam } \\
\text { informação } \\
\text { distribuída }\end{array}$ & & & & e & & & & \\
\hline $\begin{array}{l}\text { Resposta a } \\
\text { estimulos }\end{array}$ & & & & & Q & & & \\
\hline $\begin{array}{l}\text { Não existe uma } \\
\text { representação } \\
\text { simbólica } \\
\text { explicita }\end{array}$ & & & & & $\Phi$ & & & \\
\hline Adaptividade & & & & & 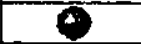 & & & 6 \\
\hline $\begin{array}{l}\text { Várias } \\
\text { arquiteturas de IA } \\
\text { sem uma } \\
\text { preocupação com } \\
\text { formalização }\end{array}$ & & & & & & 9 & & \\
\hline $\begin{array}{l}\text { Conjunto } \\
\text { integrado de dois } \\
\text { ou mais diferentes } \\
\text { classes de agentes }\end{array}$ & & & & & & & 6 & \\
\hline
\end{tabular}

\subsection{Considerações finais}

Esta seção apresentou as várias definições de agentes encontradas na literatura. Também apresentou as características de cada agente da tipologia de Nwana em [Nwana-96]. Embora Nwana observa que agentes verdadeiramente inteligentes (Smart agentes) não existam, este projeto de mestrado tentará alcançar várias das características que definem este tipo de agente no projeto do modelo do usuário. Assim, estaremos buscando autonomia, cooperação, proactividade, interface com o usuário e adaptatividade. 


\section{Modelando o Usuário em}

\section{um Sistema de Auxílio à Escrita Técnica em Inglês}

Como foi visto no Capitulo 3 , muitos dos sistemas computacionais atuais não satisfazem completamente as exigências dos usuários. Os sistemas deveriam, então, se adaptar às tarefas e aos usuários específicos, baseando-se na observação das atitudes enquanto estes utilizam o sistema.

Um sistema capacitado a se adaptar está baseado na suposição de que o mesmo pode se adaptar aos desejos e as tarefas do usuário. Existem três maneiras distintas para se implementar a adaptação:

- Os sistemas são adaptáveis, isto é, permitem que o usuário mude certas características manualmente;

- Os sistemas podem conter suporte para adaptação aprovada pelo usuário;

- Os sistemas podem mudar seu comportamento automaticamente.

Decidimos usar a adaptação automática e controlada combinadas, pois o usuário recebe adaptação automática da interface (as ferramentas são alteradas automaticamente), porém ele recebe sugestões, que poderá aceitar ou rejeitar, durante toda a interação. A adaptação automática prevalece entretanto, como mostrado no decorrer do capítulo, podendo se dizer que o sistema implementado é adaptativo.

\subsection{O modelo do usuário}

$\mathrm{Na}$ comunicação entre seres humanos, os participantes podem adaptar-se de acordo com as características do outro. Este processo de comunicação enriquece e refina o conhecimento de ambos, permitindo assim aumentar a satisfação com interação. 
Como visto no Capítulo 3, para que um sistema possa interagir eficientemente com outras pessoas, ele precisa saber alguma coisa sobre elas. Além da complexidade dos sistemas atuais, devemos levar em conta o fato de que diferentes usuários não têm os mesmos problemas.

Modelar um usuário significa, então, adquirir e representar as suposições sobre os usuários de um sistema computacional, conseguindo assim um sistema individualizado. De uma forma geral, todos os sistemas possuem um modelo de usuário. Este pode estar representado implicitamente no sistema ou explicitamente. Para este projeto, foi adotada uma modelagem de usuário explícita, seguindo a tendência atual, em que o conhecimento sobre o usuário é explicitamente representado e modificável, sendo que o sistema possui mecanismos para explorar esta informação e adaptar-se ao usuário.

O modelo do usuário adotado possui quatro critérios básicos: ele é canônico, isto é, o sistema pode ter múltiplos modelos para mesmo usuário, dinâmico, isto é, pode ser alterado durante a interação, de curto prazo e de aquisição implícita.

Devemos observar o fato que um modelo de usuário só é útil quando a quantidade e o tipo de informação que contém são relevantes para aplicação.

As informações para o modelo de usuário provêm das três ferramentas do AMADEUS, juntamente com as ações dos usuários. O modelo proposto chama-se SMUA (Sistema de Modelagem de Usuários para o Amadeus) e contém informações sobre o usuário, a troca de mensagens entre o usuário e qualquer das ferramentas, a avaliação do usuário feita pelas ferramentas em um dado momento, a pontuação e o nível atual do usuário.

Cada estereótipo do usuário possui várias condições de ativação, que podem ser definidas pelo usuário.

\subsection{A arquitetura multiagentes utilizada}

Como parte de uma dissertação de mestrado já apresentada no Instituto de Ciências Matemáticas e da Computação da USP (ICMC) [Silva-99], foi desenvolvido um sistema que suporta adequadamente a colaboração entre diversos agentes, possivelmente heterogêneos e distribuídos, para servir de plataforma à ferramenta de ensino de escrita técnica em Inglês (LEGO). Esse sistema resulta da articulação de alguns módulos: 
a) Lego Meeting Server, o subsistema de comunicação inter-agentes, compreendendo o servidor de broadcast e uma pilha de protocolos para difundir primitivas de transformação estrutural e emissão de opiniões;

b) Lego Workbeanch, um ambiente gráfico que trabalha em torneio no qual um usuário pode funcionar confortável e efetivamente com colaborador;

c) Lego Prolog Agent, um arcabouço para agentes artificiais a serem programados em Prolog, munidos de poderes plenos e expressivos, com sensibilidade a ações de seus colaboradores e predicados para reconhecer padrões na estrutura em construção e quantificar a similaridade desta com as preexistentes. Basicamente, todas as ferramentas estão baseadas neste agente, mudando o seu enfoque. A seguir são apresentadas estas ferramentas com mais detalhes.

\subsubsection{O Lego Meeting Server}

Como visto anteriormente, o Lego Meeeting Server pode ser visto como a central de comunicação multiagentes do sistema (Agente de Informação, capaz de executar em rede), pois sem ele não a troca de mensagens.

Todas as ferramentas (Suporte, Referência e Crítica), o sistema de interface com o usuário (Lego Workbeanch), o sistema de modelagem de usuário (SMUA) e qualquer outra ferramenta que for desenvolvida deverá possuir esta funcionalidade de comunicação, para que possa existir a troca de mensagens.

Para que agentes humanos e artificiais possam colaborar no desenvolvimento de um projeto, é necessário que eles sejam capazes de construir e manter uma concepção compartilhada do mesmo projeto. No jargão de computação, isso equivale a dizer que, sempre que um número de colaboradores procurar saber simultaneamente o estado atual de um projeto compartilhado, eles devem obter representações semanticamente equivalentes. Nos referimos a essa caracteristica como compartilhamento de projeto.

No caso do protótipo Lego, buscando a independência de plataforma, maior simplicidade e flexibilidade no que diz respeito à implementação dos possiveis agentes, o compartilhamento do projeto não é implementado como uma estrutura de dados única; em vez disso, o sistema permite que cada um dos agentes mantenha uma representação individual (estrutura privada) do projeto em andamento, semanticamente equivalente às representações dos seus colaboradores. Esse modelo, inspirado nos bate-papos (chats ou mais especificamente IRC - Internet Relay Chat) da Internet é ilustrado pela Figura 9 e descrito a seguir. 


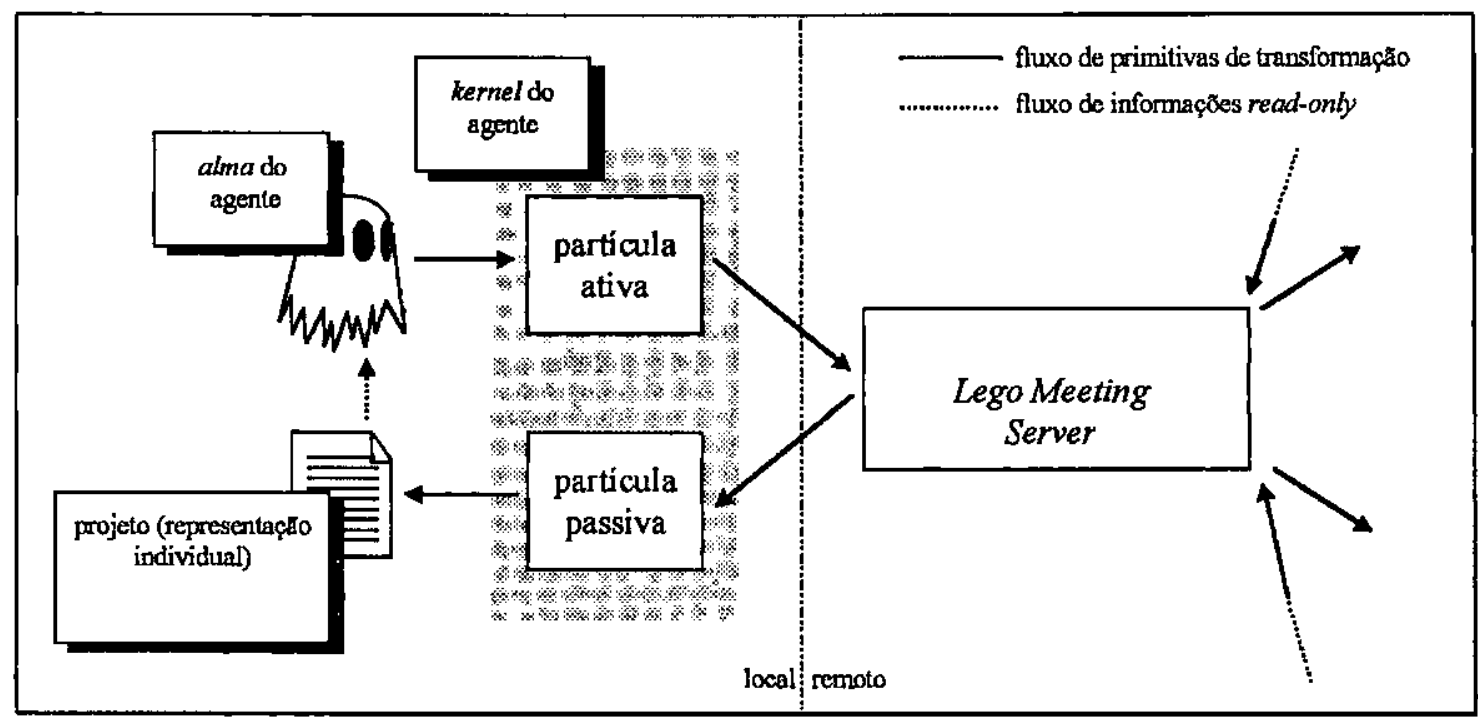

Figura 9: Modelo de Compartilhamento de Projetos

O núcleo (kernel) da implementação da entidade "agente" foi bipartido em uma partícula ativa e outra passiva. A partícula ativa é manipulada diretamente pela "alma do agente" (um ser humano ou um programa que possa ordenar mudanças no projeto, a partir do estado atual de sua representação individual) e transmite as ordens desta para uma instância, possivelmente remota, de Lego Meeting Server. Este concentra as mensagens enviadas por diversos agentes. Cada mensagem recebida referente ao projeto será retransmitida, na mesma ordem de chegada, a todos os agentes colaboradores desse projeto, inclusive ao emissor original da mensagem. As mensagens enviadas pelo Meeting Server para um agente são recepcionadas pela "partícula passiva" de seu kernel, que efetua as ações correspondentes. Dentre essas ações, estão operações de transformação sobre a estrutura de dados privada com que o agente em questão representa o projeto compartilhado. Os agentes reagem ao estado atual de sua representação individual do projeto, fechando o ciclo.

De acordo com as especificações atuais, uma instância de Lego Meeting Server só suporta o compartilhamento de um único projeto. Além disso, todos os agentes devem estar conectados antes que se insira o primeiro vocábulo, e ainda, não se pode retomar um projeto interrompido.

\subsubsection{Lego Workbench}

Lego Workbench é um ambiente que permite a criação de estruturas no formato de árvore, apoiando-se em um arquivo de especificação de vocabulário (extensão .voc). Esse 
arquivo contém, além da especificação do vocabulário com que o usuário quer trabalhar, um conjunto de regras, fornecido pelo criador do vocabulário em questão, para racionalizar a tarefa de codificação.

Basicamente, o Lego Workbench é o "front-end" com o usuário, pois todas as mensagens são reportadas ao usuário através desta interface ao mesmo tempo em que toda as ações do usuário são transmitidas a central de comunicação (Lego Meeting Server).

A aparência atual deste módulo pode ser visualizada na Figura 10. Nela podemos ver as funcionalidades que este pode proporcionar aos colaboradores, como a interface gráfica de fácil utilização. Para inserir componentes da estrutura de uma introdução, por exemplo, o usuário precisa apenas arrastá-los da palette à esquerda para a área de trabalho à direita. Outras operações naturalmente necessárias, como a exclusão ou a troca da posição de componentes, são realizadas de forma intuitiva para usuários acostumados ao uso de aplicações como o Windows Explorer.

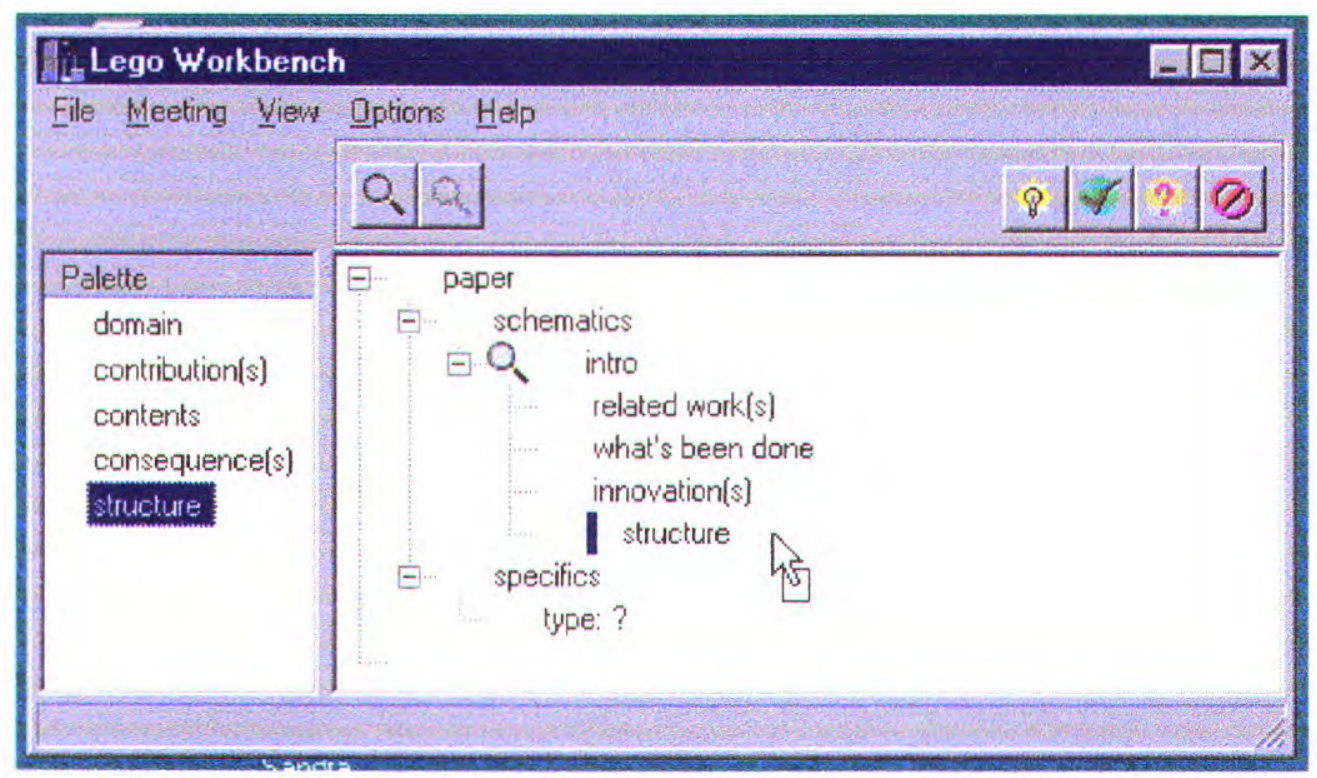

Figura 10: Interface Gráfica do Lego Workbench

A codificação em uma linguagem de árvore, dois são os pontos que representam a maior carga de dificuldade para o usuário comum:

a) Sintaxe: apesar de serem tarefas muito familiares, a construção e, em especial, a manutenção de uma árvore pode se tornar árduas e sujeitas à alta probabilidade de erro caso o autor esteja trabalhando num ambiente puramente textual. Para tornar o ambiente de composição mais agradável, a hierarquia e a ordem entre os nós são representadas por meio de uma estrutura gráfica, como mostra a figura abaixo. 


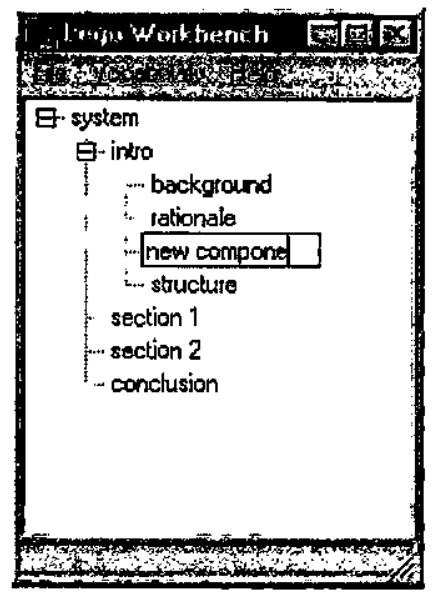

Figura 11: Apoio Gráfico à Construção de Árvores

b) Vocabulário/semântica: sem dúvida, a carga cognitiva representada pela aquisição de um novo vocabulário e seu uso correto (compreensão da semântica) é bastante grande, tanto para o usuário novato quanto para o experiente. Para evitar que o usuário seja obrigado a memorizar cada um dos possiveis vocabulários, estes ficam disponíveis na forma de uma palette, isto é, uma lista cujos elementos (vocabulos) podem ser arrastados pelo usuário para a área de composição, como mostra a Figura 12:

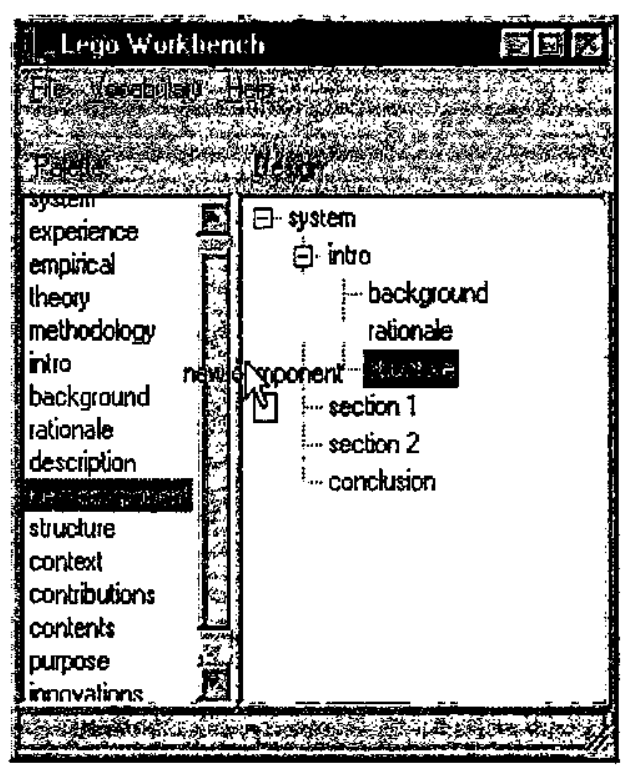

Figura 12: Aliviando a Memória com a Adição de uma Palette

No intuito de evitar que muitos componentes sejam mostrados simultaneamente, ocasionando o uso incômodo da barra de rolagem, existem dois mecanismos para agrupar os vocabulários em conjuntos significativos: 
- A palette dinâmica: na especificação de um vocabulário de árvore, é muito freqüente que alguns vocábulos só façam sentido quando inseridos como filhos de um vocábulo-pai em específico. Quando isso for verdade, é interessante que aqueles só se tornem disponíveis na palette quando o usuário estiver refinando o projeto. Para que o sistema possa conhecer onde a atenção do usuário está voltada a cada momento, existe uma operação de focalização. A Figura 13 ilustra o funcionamento desse mecanismo: no primeiro screemdump de tela (à esquerda) o elemento schematics foi focalizado (clica-se sobre o botão que representa uma lupa e em seguida clica-se sobre o vocábulo a ser focalizado). No próximo screemdump de tela (à direita), o componente intro foi inserido e, na última das telas (abaixo) o componente intro foi focalizado, momento em que os componentes da estrutura esquemática podem ser inseridos.

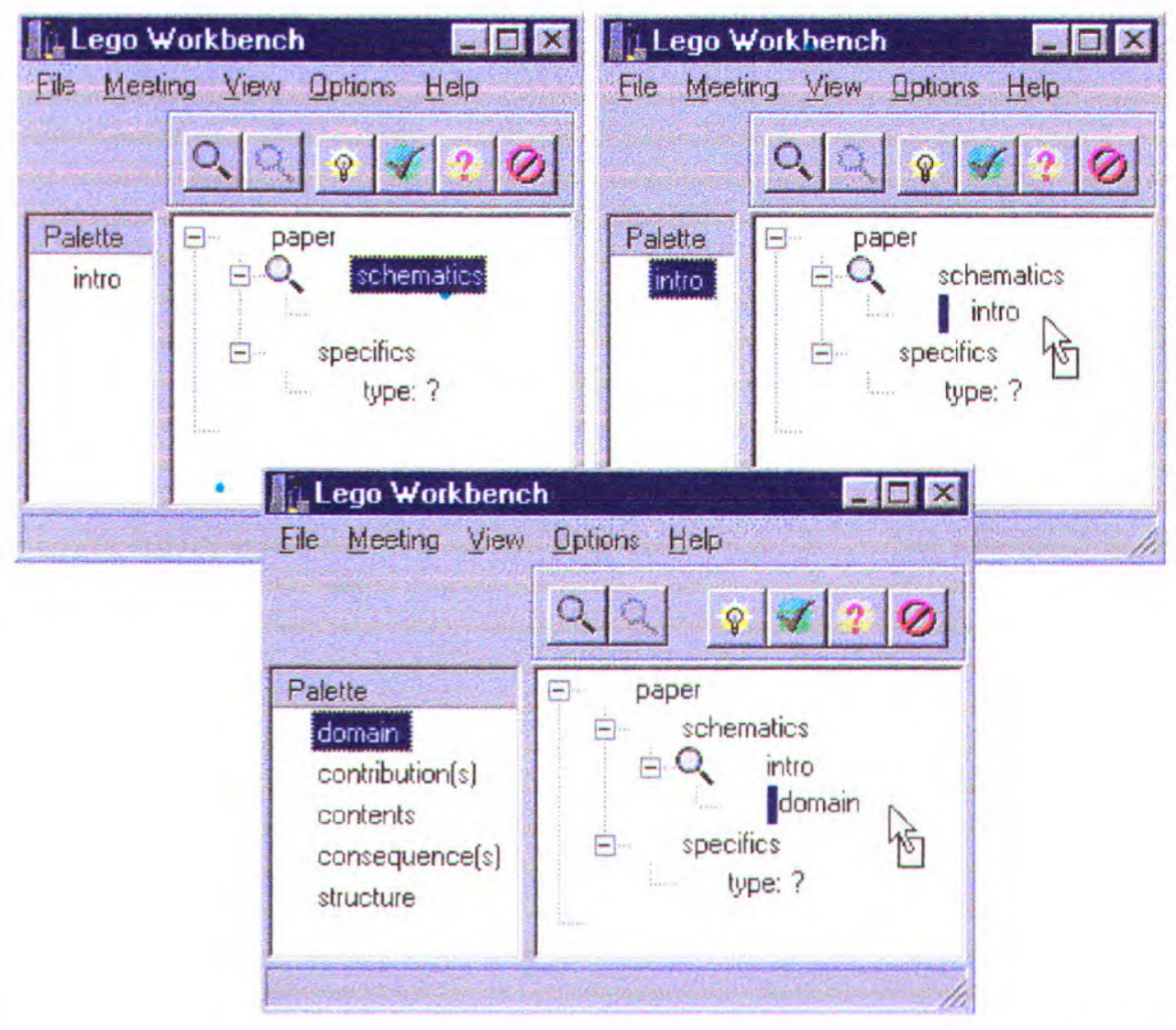

Figura 13: Três Momentos da Palette Dinâmica (Sensível a Contexto) em Ação

- Vocábulos abstratos: é possivel ainda que, mesmo com o uso de uma palette dinâmica, o número de vocábulos disponíveis em um dado momento seja grande. Nesse caso, se pelo menos alguns itens puderem ser agrupados em conjuntos 
devido a algum tipo de semelhança natural, é aplicável a idéia de vocábulos abstratos. Um vocábulo abstrato, quando focalizado ou inserido, requisita sua substituição por um dos elementos de uma palette auxiliar específica (chamada de palette de substitutos do vocábulo em questão). A Figura 14 e a Figura 15 ilustram o funcionamento desse mecanismo.
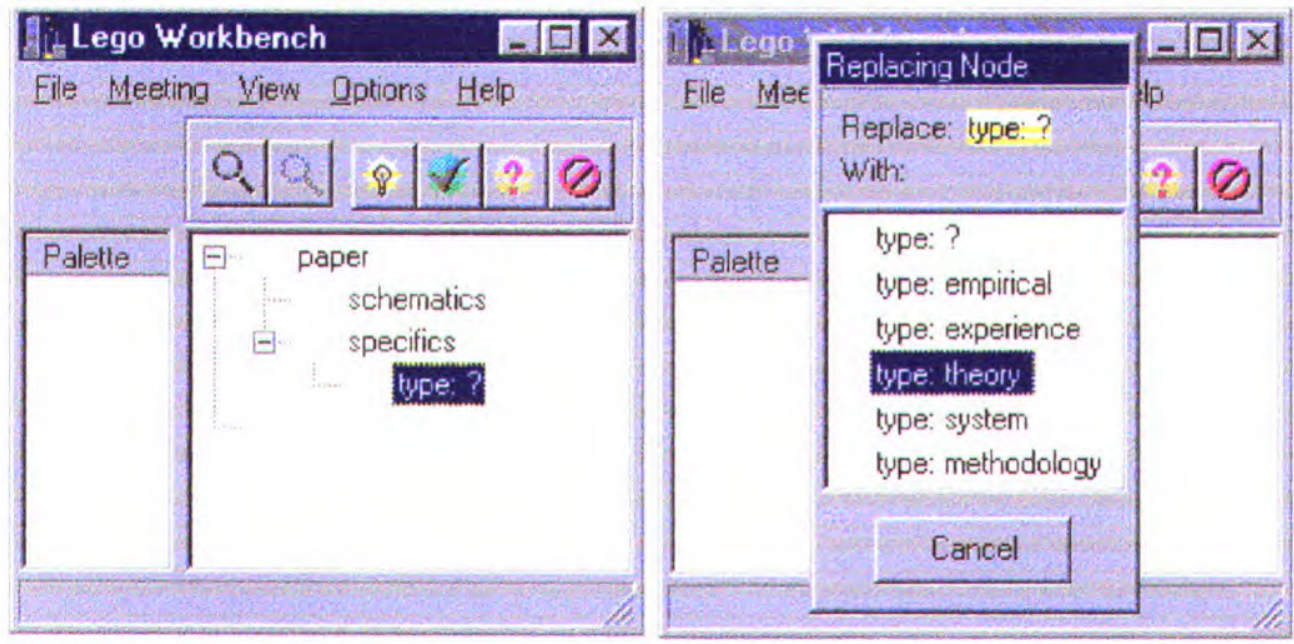

Figura 14: Seqüência da Substituição de um Vocábulo Abstrato Quando de sua Focalização (Theory é um Tipo de Type)

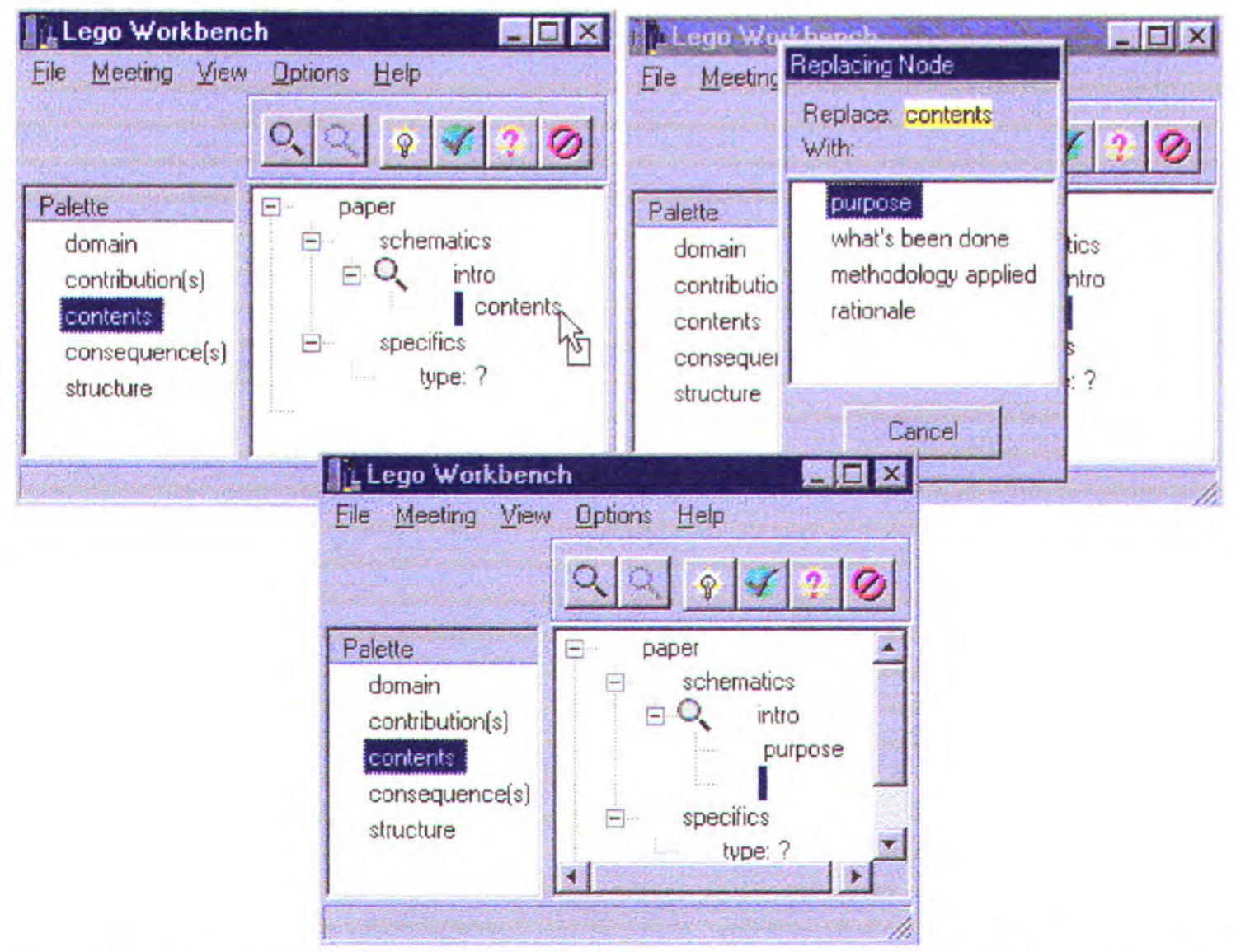

Figura 15: Seqüência da Substituição de um Vocábulo Abstrato quando de sua Inserção. 
Até este momento, deu-se ênfase às capacidades de Lego Workbench relativas ao auxílio na construção de uma estrutura em árvore. No entanto, o Lego Workbench insere um contexto de desenvolvimento colaborativo. Para tal, necessita-se de um meio capaz de possibilitar a comunicação interpessoal. Desta forma, existem três modos diferentes de comunicação interpessoal:

1. Anotações de revisão: uma anotação de revisão consiste de um item de informação inserido num projeto de forma a não influir no significado deste e geralmente sendo associado a um componente (o objeto da anotação). É meio ideal para a emissão de críticas ativas, mas não intrusivas.

2. Notificações: uma notificação é uma comunicação curta, urgente e intrusiva. É usada, por exemplo, para convidar os colaboradores para uma nova discussão, interromper uma atividade ou marcar o início/fim de processos demorados (mecanismos de sincronismo);

3. Discussões: uma discussão tem natureza conversacional: é um fenômeno interativo que se desenvolve no tempo e sobre o qual os diversos participantes devem manter sua atenção, se possivel, do início ao fim.

O usuário do Lego Workbench tem acesso às anotações referentes ao componente correntemente selecionado por meio da janela auxiliar Peer Annotations, como se pode observar na Figura 16. Essas anotações podem ser feitas, tanto pelo crítico artificial, quanto por colaboradores humanos. Além disso, tenta-se chamar a atenção do usuário para a existência de uma ou mais anotações não lidas, por meio da apresentação de f́cones ao lado dos componentes a que se referem às anotações em questão, o que é exemplificado na mesma figura. 


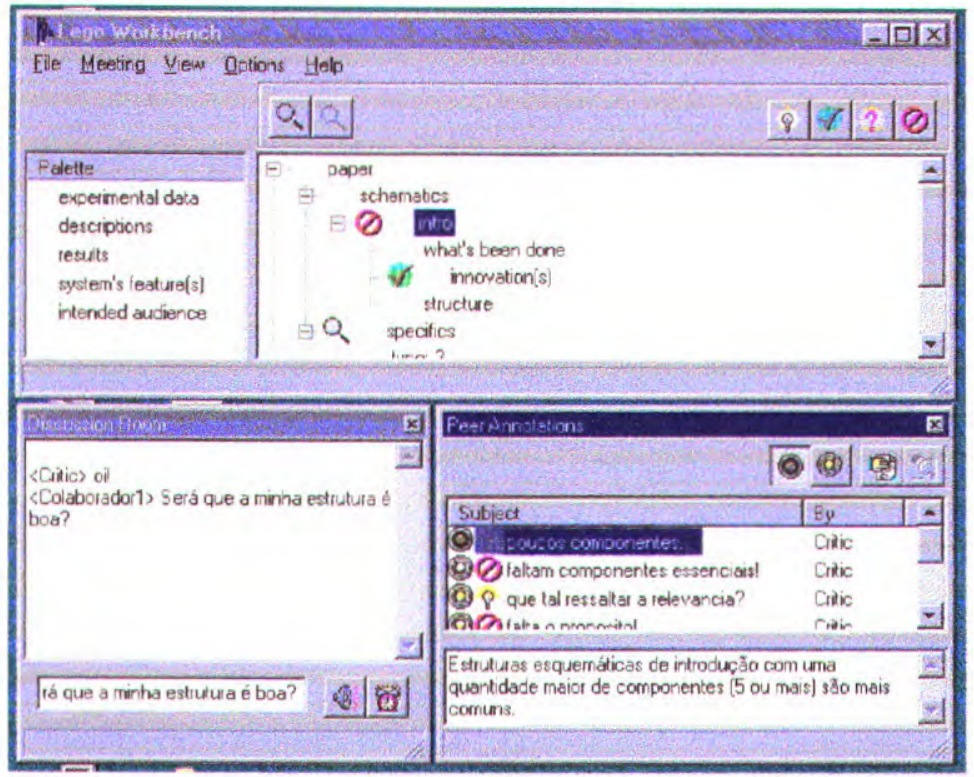

Figura 16: Lego Workbench: Ênfase em Anotações de Revisão

Para que um colaborador humano possa emitir uma crítica, basta que selecione um dos quatro botões posicionados no canto superior direito da janela de Lego Workbench e clique sobre o componente/vocábulo que deseja emitir a crítica. Estes botões estão relacionados às formas de crítica, e podem assim ser definidos:

8 Representa uma crítica do tipo New!. Este tipo de crítica significa idéia e está diretamente relacionada à forma de crítica Sugestões Diretas e Instruções;

- $\forall$ Crítica do tipo Good!. Indica uma crítica positiva e representa a forma de crítica Elogios;

- 2 Crítica do tipo Hum... É a indicação de que o produto pode ser melhorado. Representa a forma de crítica Sugestões Impessoais para Melhorias e Críticas Indiretas.

- Q Crítica do tipo Bad!. Este ícone significa que o produto apresentado possui sérios problemas e deve ser reestruturado; está associado à forma de crítica Críticas Diretas.

Além de anotações de revisão, Lego Workbench suporta também notificações. Para o colaborador a chegada de uma notificação representa inevitavelmente a interrupção de suas atividades correntes, como exemplificado na Figura 17. 
O colaborador pode ainda tomar parte de discussões por meio da janela auxiliar Discussion Room, que funciona à maneira de um "Chat" convencional. Como exemplo, na Figura 16 visualizamos a tentativa de comunicação de um colaborador com os demais.

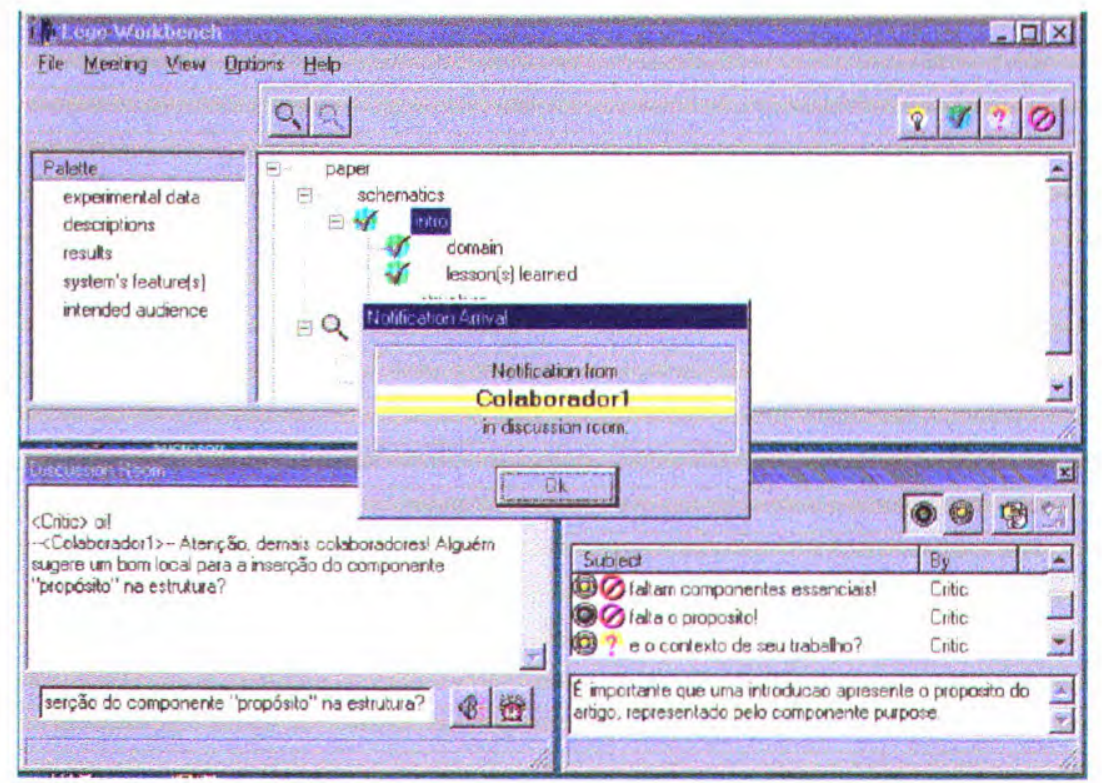

Figura 17: Lego Workbench: Ênfase em Notificações

\subsubsection{Lego Prolog Agent}

Lego Prolog Agent é o módulo que, ao ser executado, carrega um programa Prolog compilado num servidor de lógica embutido (AMZI! Logic Server) e, em seguida, conecta-se a uma seção com uma das ferramentas disponíveis, que compartilham a mesma estrutura de mensagens padrões pré-definidas. A partir desse momento, passam a ser executados, no servidor de lógica, predicados especiais, chamados operadores passivos ou eventos, correspondentes às mensagens recebidas do Lego Meeting Server.

Quando ocorre um evento não só ocorre a manutenção automática da representação interna da árvore em desenvolvimento, como também chama a totalidade dos predicados de reação que se aplicam ao evento em questão.

A condição de prova de um predicado de reação, por sua vez, pode conter chamadas a predicados especiais, chamados operadores ativos, que desencadeiam a emissão de mensagens de Lego Prolog Agent aos seus colaboradores. Os operadores ativos disponíveis cobrem toda sorte de ações que um agente qualquer pode realizar num projeto Lego.

O Lego Prolog Agent forma um arcabouço comum a todas as ferramentas, pois ele implementa todo um ambiente necessário a implementação das ferramentas, como a troca de 
mensagens e a manutenção de uma estrutura de dados representando o guideline que está sendo construído pelo usuário.

\subsubsection{Mudanças na estrutura das ferramentas para reportarem o score do usuário}

Como o novo shell para modelar o usuário (SMUA) depende de informações para avaliar o usuário, foram efetuadas modificações nas ferramentas para que estas reportassem um valor (Score) para os erros ou acertos. Como o SMUA não tem o conhecimento sobre a avaliação de como um documento está sendo escrito, mas somente as ferramentas, foram introduzidos alguns novos comandos que, ao serem requeridos pelo sistema de qualquer das ferramentas, retornam várias informações sobre o usuário, dentre elas uma avaliação do usuário em um dado instante. A tabela abaixo mostra os novos comandos criados:

Tabela 9: O novo conjunto de instruções das ferramentas

\begin{tabular}{|l|c|c|l|}
\hline \multicolumn{1}{|c|}{ Função } & $\begin{array}{c}\text { Parâmetro } \\
\text { de Entrada }\end{array}$ & $\begin{array}{l}\text { Parâmetro } \\
\text { de Sarda }\end{array}$ & \\
\hline SetScore $(\mathrm{X})$ & $\begin{array}{c}\text { Valor } \\
\text { inicial }\end{array}$ & - & $\begin{array}{l}\text { Zera o Score armazenado em cada uma das } \\
\text { ferramentas (individual para cada uma delas). }\end{array}$ \\
\hline AccScore $(\mathrm{X})$ & Valor & - & Adiciona o valor de X no escore atual do usuário. \\
\hline SendScore & - & Valor & Envia o Score atual para o meeting. \\
\hline
\end{tabular}

Também foram criadas novas mensagens:

Tabela 10: As novas mensagens

\begin{tabular}{|l|c|c|l|}
\hline Mensagem & Entrada & Saida & \multicolumn{1}{|c|}{ Comentario } \\
\hline SendScore & - & - & Pedido para enviar o Score atual para o SMUA \\
\hline FalarSoCom & $\begin{array}{l}<\text { nick do } \\
\text { agente }>\end{array}$ & - & $\begin{array}{l}\text { Comando vindo do SMUA para que a ferramenta } \\
\text { envie somente para ele as mensagens, ignorando o } \\
\text { usuário. }\end{array}$ \\
\hline Who & - & $\begin{array}{l}<\text { nick do } \\
\text { agente }>\end{array}$ & Envia a identificação da ferramenta para o SMUA. \\
\hline broadcast & $\begin{array}{l}<\text { nick do } \\
\text { agente }>\end{array}$ & - & $\begin{array}{l}\text { Comando vindo do SMUA para que a ferramenta } \\
\text { envie as mensagens para todos, inclusive para o } \\
\text { usuário. }\end{array}$ \\
\hline
\end{tabular}

\subsubsection{O sistema de avaliação implementado nas ferramentas}

Foram realizadas pequenas modificações nas ferramentas visando a obtenção de um Score do usuário. Abaixo são mostrados alguns exemplos destas modificações. 
- Pontuação positiva, isto é, uma recompensa por ter realizado uma ação que melhora a redação do texto final. Exemplo:

cycleAnnot(Topicld) :-

assert(cycleAnnoted), accScore (\$1\$),

aAnnot(new, Topicld, \$repetição de componentes pode ser útil.\$, \$A repetição alternada de componentes caracteriza uma estrutura mais refinada. Este recurso é utilizado para montar estruturas cíclicas, que geralmente são úteis para abordar um campo muito ramificado, abrangendo muitos tópicos fracamente relacionados.\$).

\section{$\mathrm{Ou}$}

ifContains(intro, /

([methodology], 1, good, \$Trabalho bem fundamentado!\$, \$Ótimo! Com o componente "methodology" você está fundamentando as afirmações $e$ conseqüentemente validando a hipótese.\$),

([gap, review], 3, good, \$Trabalho com revisão da literatura!\$)].

- Pontuação negativa, isto é, o usuário cometeu algum erro na construção do guideline do texto. Exemplo:

shouldContainl(intro, /

[gap, review], -3, hum, \$E a revisão da literatura ?\$, \$A citação de "review work(s)"/"gap" são essenciais para comparar e contrastar o seu trabalho com a literatura atual.\$),

[[purpose], -3, bad, \$Falta purpose!\$, \$Falta o componente "purpose", e este é essencial em uma Introdução de artigo.\$)

([results], -1, new, \$Faltam conclusões...\$, \$Eu sugiro que os componentes "lesson(s) learned"/"innovation(s)" apareçam para esboçar conclusões.\$), 7).

\subsubsection{Esclarecimentos sobre o projeto Lego}

Maiores informações sobre cada componente do projeto Lego (Lego Workbench, Lego Meeting Server e Lego Prolog Agent), suas funções, a implementação da ferramenta de crítica, bem como a sua correta utilização podem ser obtidas na dissertação já mencionada. A seguir, 
descreveremos a nova arquitetura de modelagem de usuário, baseada no sistema LEGO e na arquitetura do AMADEUS.

\subsection{A nova arquitetura SMUA.}

O principal objetivo deste mestrado é a implementação do AMADEUS como um sistema adaptativo e integrado de ferramentas de auxílio à escrita. Então, a partir deste ponto, descreveremos a nova arquitetura com o shell de modelagem de usuários incorporado.

O SMUA é um shell de modelagem de usuário capaz de capturar informações da aplicação através da observação das ações executadas pelo usuário e fazer deduções a partir destas, usando regras de inferência.

A próxima figura ilustra a troca de mensagens entre os integrantes do novo sistema. Observe que, para o usuário o sistema atua de forma transparente, isto é, ele não tem conhecimento sobre o modelo de usuário e quantas ferramentas existem. Sobre o ponto de vista do usuário, é como se existisse uma única ferramenta que alterasse a sua interface apresentando novas funcionalidades conforme a necessidade.
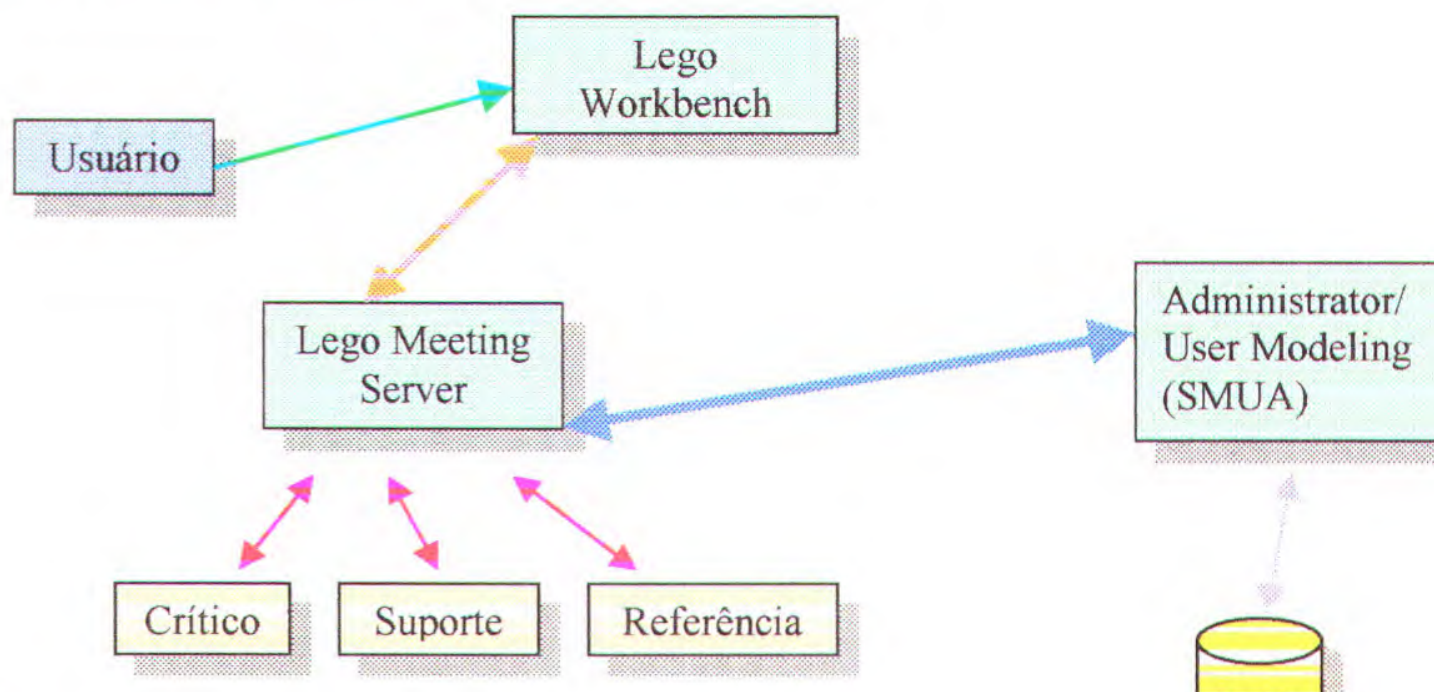

\section{Begende:}

Ações do usuário

Ações do usuário / Mudança de Foco / etc.

Entra ações do usuário e sai comentários / sugestões / críticas

Críticas e sugestões das ferramentas / Modelo Atual

Interação com o modelo atual e demais modelos em busca de novas características.

Figura 18: A nova arquitetura do AMADEUS com o SMUA 
A arquitetura do ambiente LEGO-AMADEUS pode ser vista como sistema multiagente comunicando-se com um agente especial que contém o modelo do usuário. Como foi visto no Capítulo 4, nos últimos anos tem havido um crescente interesse pela tecnologia orientada a agentes. Várias são as definições possíveis de agentes. Tentaremos, então, definir a nossa própria concepção de agente com base nas definições de outros autores:

"Agentes são componentes de software que se comunicam entre si através de troca de mensagens, em um esquema de comunicação, capaz de realizar tarefas em nome de seu usuário".

Wooldridge e Jenning [Wooldridge-95] definiram agentes de dois modos distintos: agentes fracos e agentes fortes. Este último foi bastante utilizado no SMUA por apresentar as seguintes propriedades: autonomia, habilidade social, relatividade, ativos, noções de conhecimento, crenças, interação e obrigação.

Nwana em [Nwana-96] propôs-se o conceito de agentes como sendo um objeto autosuficiente, interativo e executando concorrentemente. Este conceito também foi utilizado pelo SMUA, pois este consegue interagir com as ferramentas e com o usuário através da troca de mensagens, é auto suficiente e executa todas as ferramentas (agentes) de maneira concorrente.

Como visto no Capítulo 4, poderíamos definir o agente utilizado como um agente híbrido, isto é, o agente possui as seguintes características:

- Autonomia;

- Cooperação;

- Habilidades sociais;

- Toma a iniciativa;

- Executa em rede;

- Gerencia e manipula a informação distribuída;

- Possui adaptatividade.

Poderíamos então, representá-los da seguinte forma: 


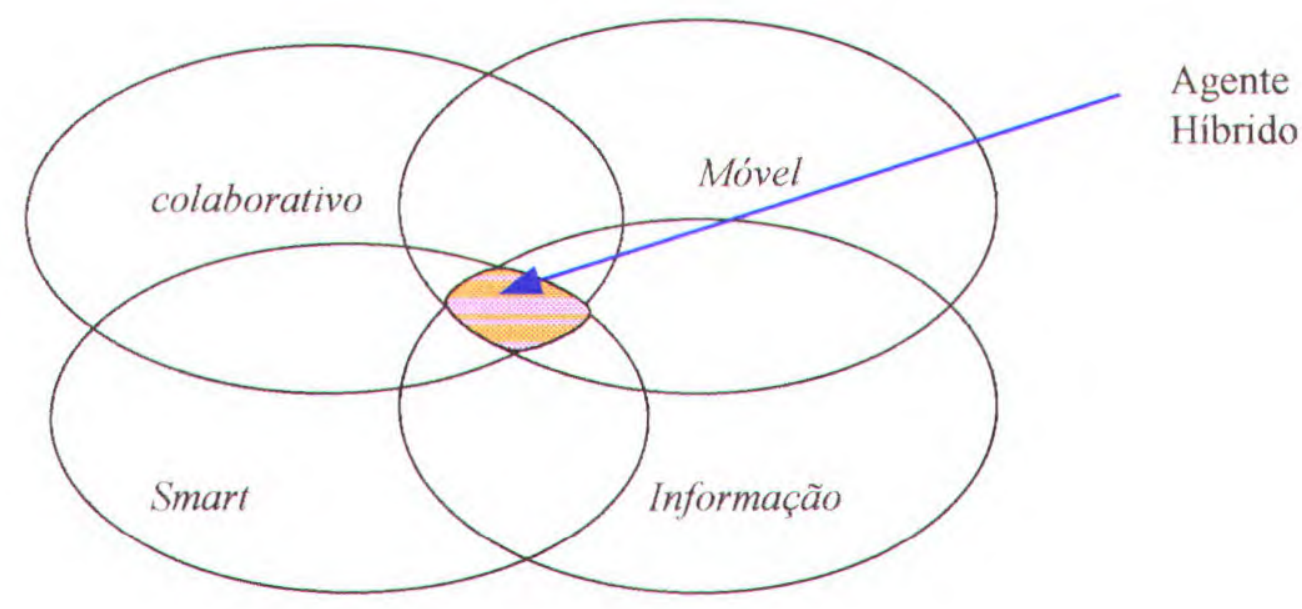

Figura 19: Representação da topologia de agentes híbridos utilizada.

Podemos perceber que o agente híbrido utilizado engloba as principais características de agentes, tornando-se uma solução viável para a comunicação e integração entre as ferramentas. Nas próximas seções veremos a comunicação entre os agentes e a forma como são tratados.

\subsubsection{Fluxo de informações entre a aplicação e o Shell SMUA}

O SMUA é capaz de se comunicar com um sistema de aplicação através da troca de mensagens. Conforme visto na Figura 18, todo o fluxo destas passa obrigatoriamente pelo agente de comunicação, chamado Lego Meeting Server. Entre as mensagens que são informadas ao sistema, podemos destacar as seguintes funcionalidades:

- A aplicação pode informar o SMUA sobre crenças e objetivos observados do usuário.

- $\quad$ A aplicação pode mandar ao SMUA as respostas do usuário.

- $\quad$ A aplicação pode informar o SMUA sobre as ações observadas do usuário.

O SMUA pode sinalizar eventos importantes no modelo do usuário para a aplicação, mesmo quando não solicitado, por exemplo, quando o sistema chega a conclusão que a ferramenta atual não atende todas as necessidades do usuário. 
Quando um usuário está manipulando uma das ferramentas e encontra dificuldades com a mesma, o shell deve ser suficientemente "inteligente" para trocá-la por outra que melhor o auxilie. Mesmo em casos onde o usuário é classificado como especialista, ele pode encontrar problemas especificos em uma determinada área e necessitar que o nível de interação e ajuda sejam alterados para melhor atender às suas necessidades.

Para facilitar a compreensão, o sistema pode ser visto como uma sala, onde se encontram um aluno, vários professores e um coordenador. Quando o aluno (usuário) entra na sala, o coordenador (SMUA) avalia o aluno com base em sua ficha escolar e decide qual o melhor professor para auxiliar o aluno. Cada professor difere em nível de conhecimento e interação com o usuário. Quando o coordenador toma a decisão de quem irá ensinar o aluno, ele comunica a todos os professores. A partir deste momento o professor selecionado começa a auxiliar o aluno, mas os outros professores estarão observando o aluno. Se qualquer um deles achar que existe algum erro grave e que o professor atual deve deixar de auxiliar o aluno, ele comunica o fato ao coordenador que decide se deve ou não afastar o professor atual e colocar outro. Se a decisão for favorável, o professor atual é informado que a partir daquele momento ele não estará mais auxiliando o aluno e irá ficar apenas observando, e o novo professor assume o seu lugar.

\subsubsection{Inferências baseadas nas ações do usuário.}

O shell é capaz de realizar suposições sobre o usuário, através da observação do mesmo. Em geral, as regras são especificas do domínio, mas existem também algumas regras independentes, feitas quando o usuário realiza algumas ações na aplicação. Um exemplo disso é a correta utilização de um dos objetos. Pressupõe-se então que o usuário conhece o objeto e sabe como utilizá-lo. O conhecimento necessário para que o SMUA possa avaliar a correta construção do texto está disponível nas ferramentas, isto é, quem avalia o conhecimento do usuário são as ferramentas. Esta avaliação é repassada ao sistema através de troca de mensagens.

\subsubsection{A base de Informação e a troca de mensagens}

Como o shell SMUA observa as mensagens do usuário e das ferramentas para auxiliar o processo de tomada de decisão, existe a necessidade de criar-se um módulo capaz de guardar informações sobre os vários usuários através do tempo. Este módulo será capaz de identificar o usuário, as ações e o tempo decorrido entre cada uma destas ações. Com base nestas informações, o sistema poderá criar um estereotipo individualizado e "customizado" do usuário, conforme a necessidade. Assim, com o passar do tempo, o sistema armazenará informações relevantes a respeito do usuário, podendo melhor avaliá-lo. 
A Figura 20 apresenta a relação entre as diversas bases de dados e as mensagens vindas do Lego Meeting Server.

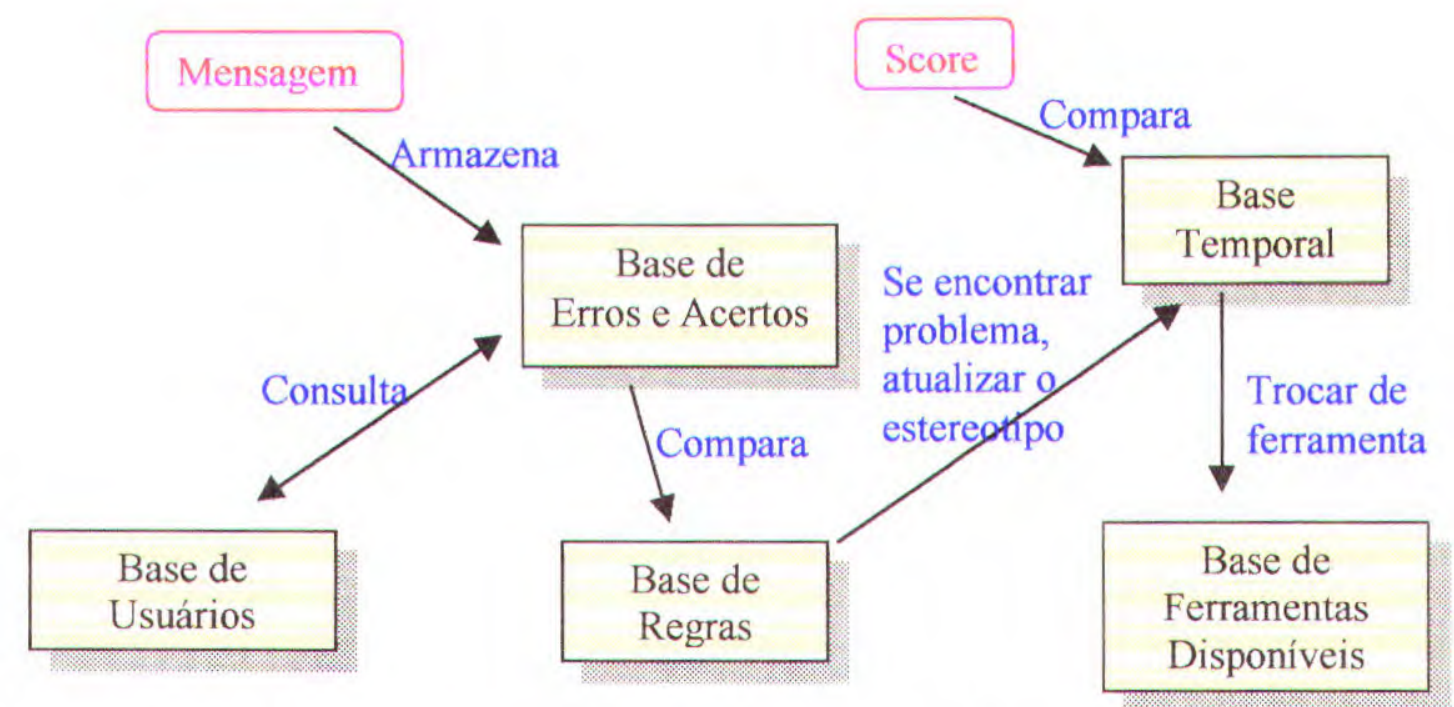

Figura 20: Representação do fluxo das mensagens

Independente de quem enviou, toda mensagem de anotação (mensagem gerada pelas ferramentas (como críticas, sugestões, etc...)) é armazenada na base de erros e acertos, pois esta mantém um histórico do desempenho do usuário e as críticas enviadas ao sistema. Nesta base são armazenados o nome do usuário (estereotipo), a data e a hora que a mensagem chegou, o tipo da crítica (sugestão, boa, ruim, novidade), a pontuação da mensagem (esta pontuação não é o Score, mas sim um número para representar o quanto esta mensagem é importante, definida pelas ferramentas), a mensagem propriamente dita e que gerou a mensagem (autor).

Após o armazenamento da mensagem, está é decodificada e aplicada na base de regras de inferência do domínio para verificar se alguma delas pode tirar proveito desta informação. Esta base contém o nome do modelo e as regras a serem aplicadas. Como o usuário pode mudar de classificação com o passar do tempo (ex.: leigo -> expert), o estereotipo individual do usuário (Base de Usuários) guarda o nome do usuário (Estereótipo) e o modelo de usuário atual a ser aplicado (qual conjunto de regras deverá ser aplicado).

A base de dados temporal armazena o nome do usuário, a data da atualização, a pontuação (Score) atual do usuário e a classificação deste (leigo, expert, etc.). Esta base pode ir crescendo pois, com o passar do tempo, o usuário pode evoluir e deixar de ser um usuário leigo e tornar-se expert ou vice-versa. Com isto, temos uma base de dados com informações sobre a evolução de um usuário, no que diz respeito a sua classificação (estereotipo atual). 
Após aplicar as regras, o SMUA solicita das ferramentas o envio de uma avaliação (Score) do usuário (Individual para cada ferramenta). Com base nas regras, Score e nas informações gravadas na base temporal, o sistema toma a decisão, se deve ou não mudar a ferramenta. Se a conclusão for positiva, ele verifica quais das ferramentas disponíveis que melhor auxiliam o usuário.

\subsection{Avaliando o Usuário}

O usuário pode ser avaliado de duas formas distintas. A primeira diz respeito à pontuação enviada pela ferramenta (Score) e a segunda é o conjunto de regras pré-definidas.

Como o sistema de modelagem de usuário não possui o conhecimento para avaliar se o usuário está escrevendo um bom texto (funcionalidade cabível às ferramentas), a ferramenta ativa pode ser requerida a enviar uma avaliação do usuário. Se a avaliação for satisfatória, a ferramenta ativa pode permanecer, desde não exista nenhuma regra que a impeça. Caso contrário, o sistema irá avaliar se deve ou não mudar para outra ferramenta com base em um conjunto de informações especificadas abaixo: 


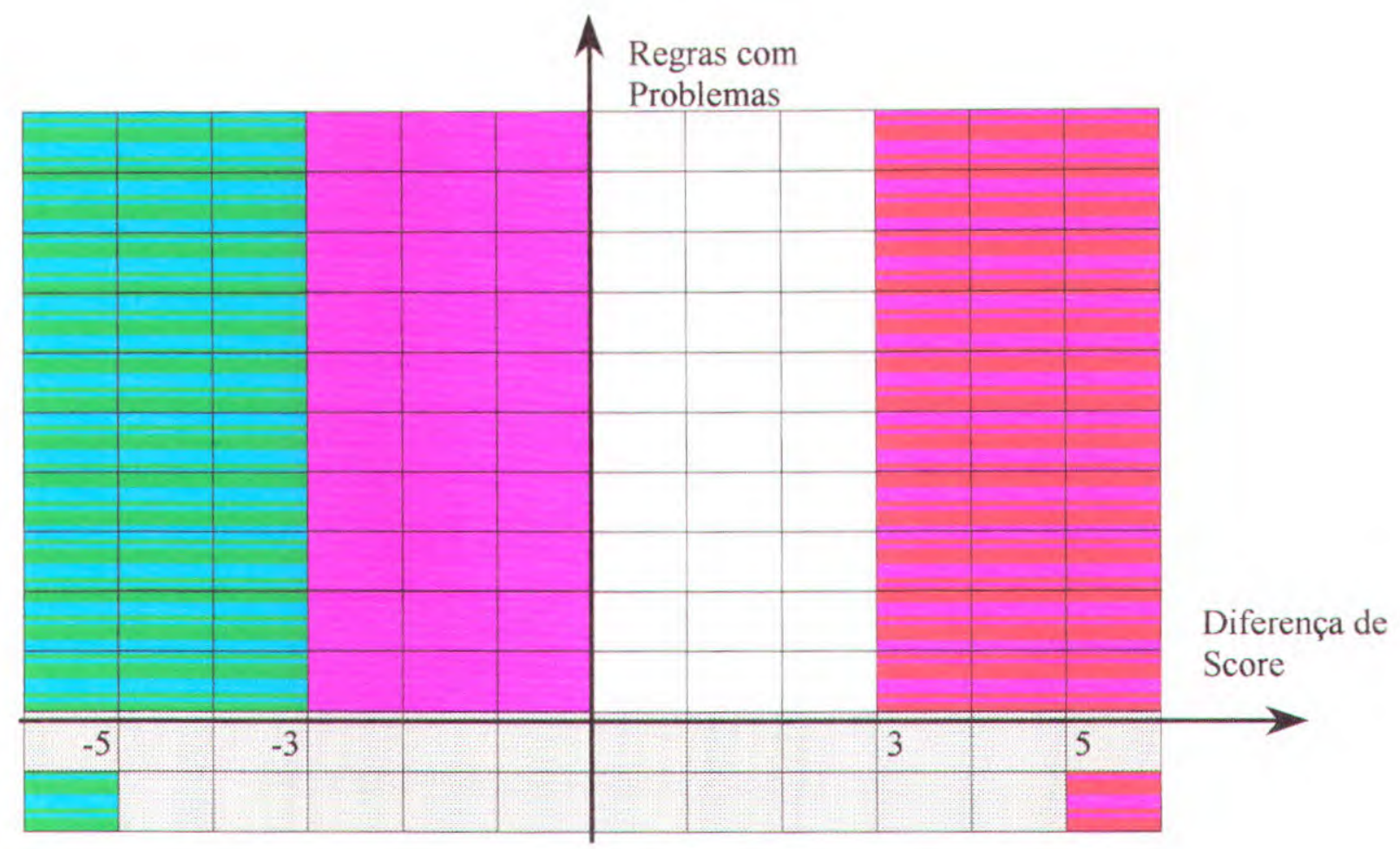

Muda automaticamente para um ferramenta com maior nível de auxilio.

Verifica se deve ou não mudar para uma ferramenta com maior nível de auxilio.

Verifica se deve ou não mudar para uma ferramenta com menor nivel de auxilio.

Muda automaticamente para um ferramenta com menor nível de auxilio.

Figura 21: Gráfico ilustrando os tipos de decisões

Quando o limite inferior de tolerância é rompido (representado no gráfico pelo verde), seja pela diferença entre o Score atual da ferramenta e o anterior, ou pelas regras, o sistema muda automaticamente para uma ferramenta que melhor auxilie o usuário, pois a ferramenta atual já não o satisfaz. O mesmo se aplica se o limite superior é rompido (representado no gráfico pelo vermelho), só que o sistema mudará para uma ferramenta com menor auxilio ao usuário.

Existe também a possibilidade de existir um erro, mas o limite ainda não foi rompido. Neste caso o sistema irá avaliar o usuário de uma maneira diferenciada. Vale ressaltar que os limites podem ser definidos no modelo do domínio (regras). 


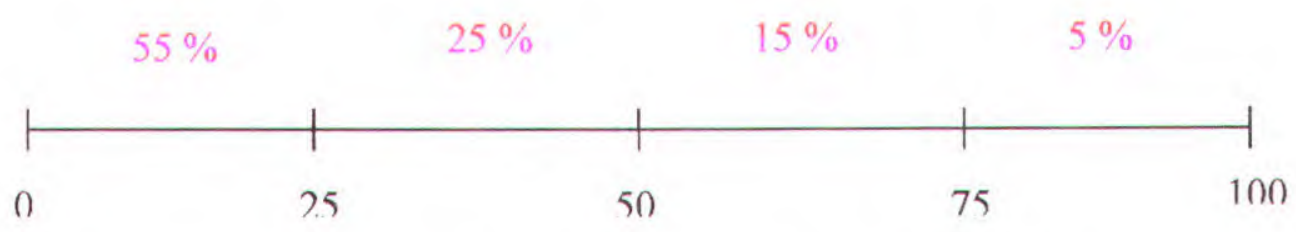

Figura 22: Avaliação do usuário usando a base temporal

O processo de avaliação de troca do usuário é simples. Para um usuário (estereótipo), procuramos na base de dados temporal a primeira classificação do usuário e a última. Calculamos a diferença entre as datas (e horas) e dividimos o intervalo em 4 partes iguais.

Feita a divisão, pesquisamos na base as classificações que o usuário já possuiu. Com esta informação, para cada classificação procuramos todos os casos em que o a data registrada está no intervalo final (75 a 100), isto é, são as classificações mais antigas do usuário. Para cada ocorrência, é somado 1 ponto a uma variável acumulativa. Com o número de ocorrência registrado, multiplica-se pelo peso de $5 \%$, isto é, vai influir em $5 \%$ na decisão. O mesmo se aplica ao demais intervalos.

Com os cálculos feitos, soma-se as pontuações obtidas e armazena na classificação do usuário. Depois comparamos qual a classificação obteve a melhor pontuação (qual o estereótipo permaneceu por mais tempo). Se esta classificação for a mesma da atual, então o sistema não troca de ferramenta. Caso contrário, deve trocar.

Assim, o sistema toma as decisões baseado-se nas ações do passado, porém considerando o fato de que as avaliações mais recentes pesam mais na avaliação do usuário.

\subsection{Módulo de criação de Regras de Decisão.}

Uma das grandes preocupações deste projeto diz respeito a sua facilidade de uso. Para tornar esta uma realidade, foi desenvolvida uma ferramenta para ajudar o usuário na criação e manutenção de regras, com a qual o sistema poderá modelar o usuário.

Cada linha da base de regras de uma determinada ferramenta é aplicada a um sistema que interpreta a mesma como condição para um "IF". As condições podem retornar verdadeiro ou falso.

Abaixo podemos observar uma figura ilustrando a criação de uma regra. 


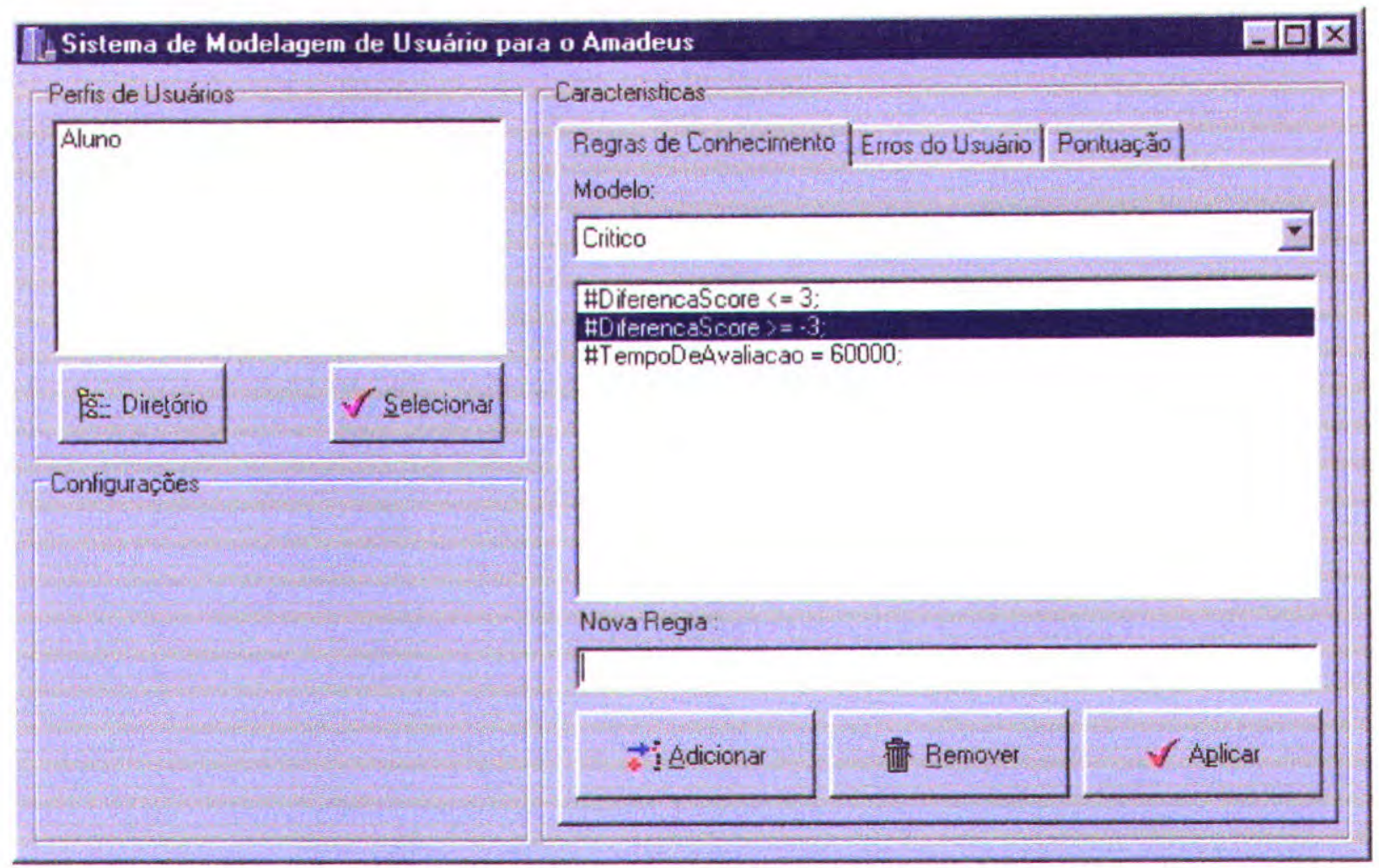

Figura 23: A Interface de criação de regras do modelo de usuário para cada ferramenta

Para cada nova ferramenta adicionada ao sistema, deve-se criar um conjunto de regras correspondente à mesma (conjunto de regras de ativação). A sintaxe de criação de regras nesta ferramenta pode ser vista a seguir.

\subsubsection{Variável}

Qualquer variável armazenada na base de dados pode ser acessada por esta funcionalidade. A sintaxe é:

(a) $<$ nome da base de dados $>$.<nome do campo $>$

\subsubsection{Funções Pré-definidas:}

\subsubsection{DiferencaScore}

Esta função calcula a diferença entre a última avaliação e a atual pontuação (Score) retornada pela ferramenta desde a última avaliação e a atual, isto é, pode-se definir uma regra em 
que a diferença entre a avaliação anterior e a atual não passe de um patamar. As operações disponíveis são: $>,<,<=,>=, !=,=$. A sintaxe é apresentada abaixo:

\#DiferencaScore <operador $><$ valor $>$;

\#DiferencaScore < operador > $(<$ função $>$ );

\#DiferencaScore <operador>@< $><$ variável>;

Ex:

\#DiferencaScore $>=-3$;

\subsubsection{TempoDeAvaliacao}

Esta função estipula de quanto em quanto tempo o sistema irá efetuar a avaliação do usuário. Isto é importante para evitar que o sistema ocupe muitos recursos do usuário (tempo de processamento). O valor para este tempo é em milisegundos. A única operação disponível é a atribuição $(=)$. Se esta função não for declarada, o valor padrão será de 60.000 milisegundos (1 minuto). A sintaxe é apresentada abaixo:

\section{\#TempoDeAvaliacao = <valor $>$; \\ \#TempoDeAvaliacao = $(<$ função $>$; \\ \#TempoDeAvaliacao=@< $<$ variável $>$;}

Ex:

\#TempoDeAvaliacao $=60000 ; \quad$ *avaliação de cada 60 segundos.

\subsubsection{TempoUltimaMensagem}

Esta função calcula o tempo decorrido desde a ultima mensagem, em segundos. Isto é relevante, pois o usuário pode não saber usar a ferramenta e se não forem efetuadas modificações no projeto durante um certo tempo, o sistema pode alterar o nível de auxilio. As operações disponíveis são: $>,<,<=,>=, !=, \equiv+,-, /, *$, quando combinados com o uso de parênteses. A sintaxe é apresentada abaixo:

\#TempoUltimaMensagem <operador $><$ valor $>$;

\#TempoUltimaMensagem <operador $>(<$ função $>)$;

\#TempoUltimaMensagem <operador>@< < variável>;

<variavel ou função> <operador> (\#TempoUltimaMensagem <operador aritmético> $<$ valor $>$ );

Ex: 
\# TempoUltimaMensagem $>=-3$;

@ Tempo >= (TempoUltimaMensagem*2);

\subsubsection{Funções de Manipulação da avaliação do usuário}

Estas funções estipulam os limites no momento em que o sistema for avaliar o usuário através do Score. As funções são:

- ProblemaRegraDiferencaInferior (Quando uma das regras for violada e o sistema terá que decidir, usando o Score, se deve ou não mudar para um estereotipo que ajude mais o usuário, qual será o limite inferior da avaliação);

- ProblemaRegraDiferecaSuperior (Quando uma das regras for violada e o sistema terá que decidir, usando o Score, se deve ou não mudar para um estereotipo que interfira menos nas atitudes do usuário, qual será o limite inferior da avaliação);

- ProblemaRegraVerificaInferiorl (Quando uma das regras for violada e o sistema terá que decidir, usando o Score, se deve ou não mudar para um estereotipo que ajude mais o usuário, qual será o limite inferior da do intervalo de avaliação);

- ProblemaRegraVerificaInferior2 (Quando uma das regras for violada e o sistema terá que decidir, usando o Score, se deve ou não mudar para um estereotipo que ajude mais o usuário, qual será o limite superior do intervalo de avaliação);

- ProblemaRegraVerificaSuperiorl (Quando uma das regras for violada e o sistema terá que decidir, usando o Score, se deve ou não mudar para um estereotipo que interfira menos nas atitudes do usuário, qual será o limite inferior do intervalo de avaliação);

- ProblemaRegraVerificaSuperior2 (Quando uma das regras for violada e o sistema terá que decidir, usando o Score, se deve ou não mudar para um estereotipo que interfira menos nas atitudes do usuário, qual será o limite superior do intervalo de avaliação);

- SemProblemaRegraDiferencaInferior (Quando nenhuma regra for violada, mas o Score ultrapassar o limite inferior, o sistema deverá mudar para um estereotipo que ajude mais o usuário);

- SemProblemaRegraDiferencaSuperior (Quando nenhuma regra for violada, mas o Score ultrapassar o limite superior, o sistema deverá mudar para um estereotipo que ajude mais o usuário); 
Exemplo:

\#SemProblemaRegraDiferencaSuperior $=5$;

\subsection{Considerações Finais}

Neste Capítulo abordamos as decisões de projeto tomadas para a construção do protótipo do shell de Modelagem de Usuários para a Escrita Técnica em Inglês.

Foram detalhados todos os passos do desenvolvimento, desde as modificações nas ferramentas já existentes, o sistema de troca de mensagens e o sistema de avaliação do usuário.

A descrição do protótipo construído constitui uma etapa extremamente importante para que o leitor/pesquisador compreenda um pouco mais sobre o funcionamento do protótipo e as razões das escolhas. 


\section{Conclusões}

Neste trabalho abordamos o desenvolvimento de um shell de modelagem de usuários, destinada a um sistema de auxílio à escrita já existente conhecido como LEGO-AMADEUS.

As atividades principais da pesquisa foram a construção do protótipo de modelagem de usuários (SMUA) e a tarefa de adaptar as ferramentas de Suporte e Referência para o novo esquema de trabalho apresentado através da troca de mensagens, descrito no Capitulo 5.

\subsection{Contribuições}

Para a concretização deste trabalho, várias etapas foram necessárias. Inicialmente, foi realizada uma ampla revisão de literatura sobre modelagem de usuários, interfaces de usuários adaptativas, shells e agentes de software.

Após esta fase, houve um estudo sobre as ferramentas já implementadas: Suporte, Referência e a ferramenta de Crítica (LEGO). Observou-se que as interfaces das ferramentas eram incompativeis entre si e que existiria a necessidade de adaptar as ferramentas Referência e Suporte para o esquema de troca de mensagens proposto no ambiente LEGO. Algumas funcionalidades da ferramenta Suporte foram perdidas por não serem aplicáveis a nova realidade do projeto LEGO. Modificar a interface destas duas ferramentas para que fossem similares à ferramenta de critica já existente, se constitui, assim, na primeira contribuição deste trabalho de mestrado.

Além disto, as bases de dados divergiam entre si. A base de dados das ferramentas Suporte e Referência referiam-se a artigos de Física, e a do LEGO à Computação e o esquema de anotação dos artigos, isto é, a estrutura esquemática, era incompatível. Houve, então, um processo de modificação e adaptação da base de conhecimento das ferramentas já existentes, principalmente das ferramentas de Suporte e Referência, atualizando-as para a nova realidade do LEGO. O estudo e a adaptação da nova base de dados constituiu a segunda contribuição deste trabalho de mestrado.

Finalmente, a nossa terceira e última contribuição consiste na especificação da arquitetura e a implementação do protótipo de modelagem de usuários. Essas duas tarefas foram amplamente abordadas, pois é neste momento que a proposta do trabalho de mestrado realmente se concretiza. 


\subsection{Limitações}

A ferramenta de Crítica trabalha como uma estrutura dual: a de componentes esquemáticos e a de componentes específicos. No que diz respeito à estrutura de componentes específicos, as ferramentas de Suporte e Referência não possuem qualquer mecanismo que possa tirar proveito destas informações.

Os casos anotados também poderiam servir para a extração de regras heurísticas a serem aplicadas nos modelos computacionais dos usuários, utilizando algum tipo de algoritmo de aprendizado de máquina, porém esta estratégia de obtenção de conhecimento não foi utilizada neste trabalho.

Outra limitação do sistema diz respeito ao compartilhamento das informações em um projeto. Quando vários usuários estão trabalhando em um mesmo documento, o sistema avalia o grupo como um todo, podendo penalizar, de forma injusta, o grupo pelo erro de um único individuo pertencente ao mesmo. Isto ocorre pelo fato de existir apenas uma única cópia de cada ferramenta rodando e somente uma delas pode estar ativa em um determinado momento. Quando um erro grave é cometido por um usuário e o sistema decide por trocar de ferramenta ativa, todo o grupo será penalizado e a nova ferramenta estará ativa para todos os membros do grupo.

\subsection{Trabalhos futuros}

Devido às limitações do Lego Meeting Server, não pudemos trabalhar com vários usuários ao mesmo tempo e tratá-los individualmente. Poderia-se modificar o Meeeting para manter estruturas de dados separadas para cada usuário.

Vale lembrar que esta modificação na estrutura do Lego Meeting Server não é trivial, podendo acarretar erros na estrutura das ferramentas, pois estas não foram projetadas visando a manutenção de várias estruturas em árvore dos trabalhos. Considerando este fato, deve-se fazer um estudo do impacto nas ferramentas já implementadas e no SMUA.

Um módulo de manutenção de raciocínio poderá ser implantado no SMUA, empregando estratégias para resolução de conflitos, pois atualmente isto não é realizado. Muitos do Shells estudados propõem este módulo, mas nem mesmo o BGP-MS já o possui implementado, devido ao custo de implementação.

Um sistema de entrevista inicial e avaliação do usuário poderia ser construído, para que todas as vezes que um novo usuário entrasse no sistema, este já estivesse classificado em uma dada categoria, evitando aborrecimentos para o usuário. 


\section{Referências e Bibliografia}

[Agha-86]

[Agha-93]

[Aluísio-95a]

[Aluísio-95b]

[Aluísio-95c]

[Aluísio-97a]

[Aluísio97b]

[Andeweg-92]

[Barbosa et al.-97]

[Bates-92]

[Bates-94]
Agha, G. ACTORS: A Model of Concurrent Computation in Distributed Systems. The Mit Press : Cambridge, MA, 1986.

Agha, G., Wegner,P., and Yonezawa, A. Research Directions in Concurrent Object-Oriented Programming. The Mit Press : Cambridge, MA, 1993.

Aluísio, S.M. Ferramentas para Auxiliar a Escrita de Artigos Científicos em Inglês como Língua Estrangeira. Tese de Doutorado, IFSC-USP, agosto de 1995.

Aluísio, S.M. and Oliveira Jr, O.N. A Case-Based Approach for Developing Writing Tools Aimed at Non-native English Users, Lecture Notes in Artificial Intelligence 1010, p. 121-132, 1995.

Aluísio, S.M. and Oliveira Jr, O.N. Developing Corpus-Based Writing Tools Aimed at Non-Native Users of English. Proceedings of The Eighth Annual Conference on Writing and Computers, 1995.

Aluísio, S.M. and Gantenbein, R.E. "Educational Tools for Writing Scientific Papers". VIII Simpósio Brasileiro de Informática na Educação. ITA, pp. 239-253, São José dos Campos, 18 a 20 de novembro de 1997.

Aluísio, S.M. and Gantenbein, R.E. Towards the Application of Systemic Functional Linguistics in Writing Tools, In: Proceedings of International Conference on Computers and their Applications, pp. 181-185, Arizona, USA, 1997.

Andeweg, B.A. et al. Hypertext Adventures: Computer-Assisted Teaching of Technical report Writing in Deft. Instructional Science, Vol 21, N 1-3, 1992.

Barbosa, S.D.J.; Cara, M.P.; Cereja, J.R.; Cunha, C.K.V.; de Souza, C.S. Interactive Aspects in Switching between User Interface Language and End-User Programming Environment: A Case Study. In Proceedings of WOMH'97, São Carlos, Brazil, 1997.

Bates, J., Bryan Loyall, A., and Scott Reilly, W. An architecture for action, emotion, and social behaviour. Technical Report CMU-CS-92-144, School of Computer Science, Carnegie-Mellon University, Pittsburgh, PA, 1992.

Bates, J. The role of emotion in believable characters. Communications of the ACM 37 (7), 122-125, 1994. 
[Beeken-92]

[Benyon - 87]

[Benyon - 96]

[Blandford-94]

[Bolt-91]

[Bos-94]

[Brajnik-92]

[Branting-96a]

[Branting-96b]

[Brusilovsky-96]
Beeken, J.; Geerts, G. and van Belle, W. The CONST-Project: Computer Instructed Writing. In Computers and Writing - State of the Art, P. O'Brian Holt \& N.Williams (eds), Kluwer Academic Publishers, Dordrecht, pp. 337-354, 1992.

Benyon, D., Innocent, P. and Murray,D. System Adaptivity and the Modelling of Stereotypes. In Bullinger, H.J. and Shackel, B. (Eds.), Human-Computer Interaction: INTER-ACT'87. North Holland, Amsterdam, 1987.

Benyon, D. Intelligent Interface Technology. HCI Tutorial 10. Human Computer Interaction'96. London.

Blandford, A.E. Teaching Through Collaborative Problem Solving. Journal of Artificial Intelligence in Education 5 (1), p.51-84, 1994.

Bolt, P. eL: A Computer-Based System for parsing and Correcting Written English. CALL, Vol 4(3), p.173-182, 1991.

Bos, E. and Van de Plassche, J. A Knowledge-Based, English Verb-Form Tutor. Journal of Artificial Intelligence in Education, 5 (1), p.107-129, 1994.

Brajnik, G. and Tasso, C. A Flexible Tool for Developing User Modeling Application with Nonmonotonic Reasoning Capabilities. In Andre, E., Cohen, R.,Graf, W., Kass, R., Paris, C. and Wahlster, W. (Eds.), U92 Thirth International Workshop on User Modeling. Deutsches Forschungszentrum fur Kunstliche Intelligenz, Saarbrucken.

Branting, L.K. and Lester, J.C. A Framework for Self-Explaining Legal Documents. In: Proceedings of the Ninth International Conference on Legal Knowledge-Based Systems (JURIX-96), Tilburg University, the Netherlands, December 1996.

Branting, L.K. and Lester, J.C. Justification Structures for Document Reuse. In: Proceedings of the Third European Workshop on Case-Based Reasoning (EWCR-96), Lausanne, Switzerland, the Netherlands, November 1996.

Brusilovsky, P. Methods and techniques of adaptive hypermedia. User Models and User Adapted Interaction, 6, 1996.

Burton, M. et al. Splitting the Collaborative Atom: How to Support Learning about Collaboration. Artificial Intelligence in Education, B. du Boulay and R. Mizoguchi (Eds.), IOS Press, p.135-142, 1997. 
[Caillot-85]

[Carr-77]

[Castelfranchi-95]

[Cherry-82]

[Chin-89]

[Chin-93]

[Cohen-91]

[Dale-90]

[Deyes-82]

[Edmonds-87]

[Eller-91]

[Etzioni-94]

[Finin - 89]

[Fischer-91]
Caillot, M. Problem representations and problem solving procedures in electricit. In Aspects of Understanding Electricity(eds R. Duit, W. Juan and C. von Rhoneck), IPN-Arbeitsberitchte, Kiel, 1985.

Carr, B. and Goldstein, I. Overlays: a theory of modeling for computeraided instruction. Technical Report A. I. Memo 406, Cambridge, MA: MIT, 1977.

Castelfranchi, C. Guarantees for autonomy in cognitive agent architecture. In Wooldridge, $M$. and Jennings, N. R., editors, Intelligent Agents: Theories, Architectures, and Languages (LNAI Volume 890), pages 56-70. Springer-Verlag: Heidelberg, Germany, 1995.

Cherry, L. Writing Tools. IEEE Transactions on Communications, 30 (1), 100-105.

Chin, D. N. Knome: Modeling what the User Knows in UC. In Kobsa, A. and Wahlster, W. (Eds.), User Models in Dialog Systems. Springer Verlag, London.

Chin, D.N. Acquiring User Models. In: Artificial Intelligence Review 7, 185-197,1993.

Cohen, R., Song, F., Spencer, B. and van Beek, P. Exploiting Temporal and Novel Information from the User in Plan Recognition. User Modeling and User-Adapted Interaction 1 (2), 125-148, 1991.

Dale, R. A Rule-Based Approach to Computer-Assisted Copy-Editing, CALL Journal, Vol 2, 1990, pp. 59-67.

Deyes, T. Discourse, Science and Scientific Discourse (The Raw Material of Comprehension in ESP). Working Paper 6, Brazilian ESP Project, Pontificia Universidade Católica de São Paulo, São Paulo.

Edmonds, E. Adaptation, response and knowledge . Knowledge Based Systems 1, 3-10, 1987.

Eller, R., and Carberry, S. A Meta-Rule Approach to Flexible Plan Recognition in Dialogue. User Modelling and User-Adapted Interactin1 (4), 1991.

Etzioni, $\mathrm{O}$ and Weld, D. A softbot-based interface to the internet. Communications of the ACM 37, 72-76, 1994.

Finin, T. W. GUMS - A General User Modeling Shell. In Kobsa, A. and Wahlster, W. (Eds.), User Models in Dialog Systems. Springer Verlag, London. 1989

Fischer, G. et al. Critics: An Emerging Approach to Knowlwdge-Based Human-Computer Interaction. International J. of Man-Machine Studies 35, p.695-721, 1991. 
[Fischer-93]

[Fischer-95]

[Fischer-96]

[Fontana-91]

[Fontana-93]

[Galliers-88]

[Garcia-93]

[Genesereth-94]

[Gentner-83]

[Goodfellow-95]

[Grunst-96]

[Guha-94]

[Hayes -81]
Fischer, G. et al. Embedding Computer-Based Critics in the Contexts of Design. Conference on Human Factors in Computing Systems, Amsterdam, p.157-164, 24-29 April/1993.

Fischer, G. Rethinking and Reinventing Artificial Intelligence from the Perspective of Human-Centered Computacional Artifacts. Lecture Notes in Artificial Intelligence 991, p. 1-11, 1995.

Fischer, G. Making Learning a Part of Life Beyond the "Gift Wrapping" Approach to Technology. In: Proceedings of NSF Symposium "Learning \& intelligent Systems", 1996.

Fontana, N. e Oliveira Jr., O.N. O Texto Acadêmico em Inglês como Língua Estrangeira -Dificuldades e Perspectivas. Atas do IX Simpósio Nacional de Ensino de Física, São Carlos, SP, pp. 571-576, 1991.

Fontana, N.; Caldeira, S.M.A,; De Oliveira, M.C.F. and Oliveira Jr., O.N. Computer Assisted Writing--Aplications to English as a Foreign Language. CALL, Volume 6(2), p. 145-161, 1993.

Galliers, J. R.. A Theoretical Framework for Computer Model of Cooperative Dialogue, Acknowledging Multi-Agent Conflict. Phd thesis, Open University, UK, 1988.

Garcia Neto, A.; De Oliveira, M.C.F.; Fortes, R.P.M.; (Caldeira) Aluísio, S.M. and Oliveira Jr. O.N. A Software Architecture for a Computer-Aided Writing Environment. In Proceedings of the 5th HCI International, p. 204, 1993.

Genesereth, M.R. and Ketchpel, SP. Software Agents. Communications of the ACM 37 (7), 48-53, 1994.

Gentner, D and Stevens, A. Metal Models. Erlbaum, Hillsdale, N. J., 1983.

Goodfellow, R. A Review of the Types of Call Programs for Vocabulary Instruction, CALL, Vol 8, N.2-3, p.205-226, 1995.

Grunst, Gernoth; Oppermann, Reinhard; Thomas, Christoph G. Adaptive and adaptable systems. In Hoschka, P. (Ed.): Computers As Assistants - A New Generation of Support Systems. Hillsdale: Lawrence Erlbaum Associates, 1996. S. 29-46. ISBN 0-8058-2187-2.

R.V. Guha, R.V. and Lenat, D.B., "Enabling Agents to Work Together," Communications of the ACM, Vol. 37, No. 7, July 1994, pp. 127-142.

Hayes, P.; Ball, E. ; Reddy, R. Breaking the Ma-machine Communication Barrier. IEEE Computer, 3-30, 1981. 
[Huckin-91] Huckin, T.N. and Olsen, L.A. Technical Writing and Professional Communication for Nonnative Speakers of English. McGraw-Hill, In. 1991.

[James-84] James, K. The Writing of Theses by Speakers of English as a Foreign Language: The Results of a Case Study, ELT Documents: 117, in Common Ground: Shared Interests in ESP and Communication Studies, Williams et al (eds.), Pergamon Press.

[James-89] James, C. Foreign Language Learning, Lecture Notes, Department of Linguistics, University of Wales, Bangor (UK).

[Kass-88] Kass, R. and Finin, T. Modeling the User in Natural Language Systems. Computational Linguistics (Special issue on user modeling), 5-22, 1988.

[Kay-90] Kay, J. um: A Toolkit for User Modelling. In Proceedings of the Second International Workshop on User Modeling, Honolulu, Hawaii.

[Kintsch-78] Kintsch,W. and van Dijk, T.A. Toward a model of text comprehensionand production. Psychological Review, 85, pp. 363-394.

[Kobsa-89a] Kobsa, A. A Taxonomy of Beliefs and Goals for User Models in Dialogue System. In Kobsa, A. and Wahlster, W. (Eds.), User Models in Dialog Systems. Springer Verlag, London.

[Kobsa-89b] Kobsa, A. and Wahlster, W.(Eds.), User Models in Dialog Systems. Springer Verlag, London.

[Kobsa-90] Kobsa, A. Modelling the User's Conceptual Knowledge in BGP-MS, a User Modelling Shell System. Computational Intelligence 6 (4), University of Saarbrucken, pp.193-208.

[Kobsa-92] Kobsa, A. Towards Inferences in BGP-MS : Combining Modal Logic and Partition Hierarchies for User Modeling. In Andre, E., Cohen, R.,Graf, W., Kass, R., Paris, C. and Wahlster, W. (Eds.), U92 - Thirth International Workshop on User Modeling. Deutsches Forschungszentrum fur Kunstliche Intelligenz, Saarbrucken.

[Kobsa-94] Kobsa, A. User Modeling and User-Adapted Interaction. Tutorial Notes, CHI'94. WWW: http://www.acm.org/sigchi/chivas/kobsa.html.

[Kobsa-95] Kobsa, A. and Pohl, W. The User Modeling Shell System BGP-MS. User Modeling and User-Adapted Interaction4 (2), 59-106. (Gzipped PostScript, 50 pages, 164816 bytes). 1995 .

[Kok-91] Kok, A. J. A Review and Synthesis of User Modelling in Intelligents Systems. The Knowledge Engineering Review, 21-47. 
[Lauriere-83]

Lauriere, J. L. SNARK: à moteur d'inferences pour systèmes experts en logique du premier ordre. Report 431, Institut de Programmation, Université Paris 6, 1983.

[Maes-94]

[Mantaras-95]

Maes, P. Agents that reduce work and information overload. Communications of the ACM 37 (7): 31-40, 1994.

Mantaras, R.L. and Plaza, E. Case-Based Reasoning. In The Newsletter of the European Network of Excellence in ML, pp. 29-37, Special Issue, September, 1995.

[Maybury-93] Maybury, M. T. (Ed.) Intelligent Multimedia Interfaces. Boston: AAAI Press/Mit Press, 1993.

[McLoughlin-87] McLoughlin, H. B. Personae : Models of Stereotypical Behaviour. In Reilly, R.(Ed.), Communication Failure in Dialogue and Discourse. North Holland, Amsterdam, 1987.

[McTear-89] Mctear, Michael F. User Modelling and Human-Computer Interaction. The Iris Journal of Psychology, 333-552, 1989.

[McTear-93] Mctear, Michael F. User modelling for adapttive computer systems. Artificial Intelligence Review 7, 157-184, 1993.

[Mitchell-86] Mitchell, T.M.; Keller R. M.; and Kedar-Cabelli, S.T.. Explanation-Based Generalization: A Unifying View. Machine Learning 1 (1):47-80, 1986.

[Moreira-95] Moreira, D.A., Agents: A Distributed Client/Server System for Leaf Cell Generation, Thesis submited to the University of Kent at Canterbury in the subject of Electronic Engineering for the degree of Doctor of Philosophy, Canterbury, United Kingdom, September 1995.

[Nwana-96] Nwana, Hyacinth S. Software Agents: an overview. The Knowledge Engineering Review, vol. 11:3, 205-244,1996.

[Norcio-89] Norcio, A. F. and Staley, J. Adaptative Human-Computer Interfaces: A Literature Survey and Perspective. IEEE Transactions on Systems, Man, and Cybernetics 19, 399-408, 1989.

[Oliveira-92] Chusaurus: A Writing Tool resource for Non-Native Users of English. In: Computer Science: Research and Application (eds.) Ricardo Baeza-Yates and Udi Manber, Plenum Press, New York, p.63-72, 1992. (with O.N. Oliveira Jr.; N. Fontana).

[Oliveira-91] Oliveira, Jr. O.N.; (Caldeira), Aluísio S.M. and Fontana, N. Chusaurus: A Writing Tool Resource for Non-Native Users of English, In Proceedings of the XI International Conference of The Chilean Computer Science Society, pp. 59-70, 1991. Aparece também: In Computer Science: Research and Applications, R. Baeza-Yates and U. Manber (eds), Plenum Press, N.Y. pp. 63-72, 1992. 
[Paiva-94]

[Paris-88]

[Paris-93]

[Pemberton-96]

[Pohl-96]

[Pohl-97]

[Quilici-89]

[Rankin-93]

[Reed-72]

[Renié-95]

[Rich-79]

[Rich-83]

[Rich-89]

[Ritter-97]
Paiva, A. and Self, J. TAGUS : A User and Learner Modeling System. In Proc. of the Fourth International Conference on User Modeling, pages 4349, Hyannis, MA, 1994.

Paris, C.L. Tailoring Object Descriptions to a User's Level of Expertise. Computational Linguistics, Vol 14, No. 3, pp. 64-78, 1988.

Paris, C.L. User Modelling in Text Generation. Pinter Publishers, 1993.

Pemberton, L. et al. Motivating the Design for a Computer Assisted Environment for Writers in a Second Language. In Diaz, Arantza, Fernandez, Isabel (eds): Computer Aided Learning and Instruction in Science and Engeneering, Berlin: Spring-Verlag, pp. 141-148, 1996.

Pohl, Wolfgang. Learning About the User - User Modeling and Machine Learning. In : Hermann, J.; Moustakis, V. (Hrsg.): ICML'96 Workshop Machine Learning meets Human-Computer Interaction, Bari, pp. 29-40, 1996.

Pohl, Wolfgang. Labour-Machine Learning for User Modeling. In: Salvendy, G. (Hrsg.): Proceedings of HCl'97, Elsevier Science Publishers, 1997.

Quilici, A. Detecting and Responding to Plan-Oriented Misconceptions. In Kobsa, A. and Wahlster, W. (Eds.), User Models in Dialog System. Springer - Verlag, Berlin, pp. 108-132, 1989.

Rankin, I. Natural Language Generation in Critiquing. The Knowledge Engineering Review, Vol. 8:4, pp. 329-347, 1993.

Reed S. K. Pattern recognition and categorization. Cognitive Psychology, 3, 382-407, 1972.

Renié, D. and Chanier, T. Collaboration and Computer-Assisted Acquisition of a Second Language. CALL Journal, Vol.8, No.1, p.3-29, 1995.

Rich, E. User Modelling via Stereotypes. Cognitive Science3, 329-354, 1979.

Rich, E. User as Individuals:Individualizing User Model. International Journal of Man-Machine Studies, 199-214. 1983.

Rich, E. Stereotypes and User Modeling. In Kobsa, A. and Wahlster, W.(Eds.), User Models in Dialog Systems. Springer Verlag, London.

Ritter, Frank E., Young, Richard M. (March, 1997). Introduction to Psychological Soar Tutorial Ver 11. WWW: http://www.psychology.nottingham.ac.uk/staff/Frank.Ritter/pst/psttutorial.html 
[Rosenbloom-93] Rosenbloom, P. S., Laird, J. E., and Newell, A. (1993). The Soar Papers: Research on Integrated Intelligence, MIT Press, Cambridge, Ma.

[Rosenschein-85] Rosenschein, J.S. and Genesereth, M. R. Deals among rational agents. In Proceedings of the Ninth Internatioinal Joint Conference on Artificial Intelligence (IJCAI-85), pages 91-99, Los Angeles, CA, 1985.

[Rosenschein-94] Rosenschein, J.S. and Zlotkin, G. Rules of Encounter: Designing Conventions of Automated Negotiation amoung Computers, Mit Press, 1994.

[RSI-92]

[Segalowitz-95] Segalowitz, N. Automaticity and Lexical Skills in Second Language Fluency: Implications for Computer Assisted Language Learning. CALL, vol 8, N 2-3, p.129-149, 1995.

[Sharples-90] Sharples, M. and Pemberton, L. Starting from the Writer: Guidelines for the Design of User-Centred Document Processors. In Computer Assisted Language Learning Journal, Vol. 2, pp. 37-57, 1990.

[Sharples-94] Sharples, M.; Clutterbuck, A. and Goodlet, J. A Comparison of Algorithms for Hypertext Notes Network Linearisation, International Journal of Human-Computer Studies, 1994, 40 (4) pp. 727-752.

[Shoham-93] Shoham,Y. Agents-oriented programming. Artificial Intelligence 60 (1), 51-92.

[Shurville-97] Shurville, S. et al. The Composer System: a Genre-Based Writing Environment for Non-Native writrs of Academic English. Proceedings of Writing and Computers 10, University of Brighton, UK, p. 122-124, 1997.

[Silva-99]

[Silverman-92] Silverman, B.C. Survey of Expert Critiquing Systems: Practical and Theoretical Frontiers. CACM, Vol. 35, No. 4, pp. 107-127, 1992.

[Smith-86] Smith, J.B. et alli. WE: A Writing Environment for Professionals. TR86025, University of North Carolina at Chapel Hill, 1986.

[Smith-88] Smith, J.B. and Lansman, M. A Cognitive Basis for A Computer Writing Environment. Technical Report, University of North Carolina at Chapel Hill, 1988.

[Smith-91] Smith, J. et alli. Automated Protocal Analysis: Tools and Methodology. TR91-034, Universidade da Carolina do Norte em Chapel Hill, 1991. 
[Sparck-89]

Sparck Jones, K. Realism about User Modeling. In Kobsa, A. and Wahlster, W.(Eds.), User Models in Dialog Systems. Springer Verlag, London.

[Specht-96] Specht, M. and Weber, G. Episodic Adaptation in Learning Environments. EC on AI in Education (EDS) Paul B., Paiva, A. and Self J., Lisboa, Portugal, 1996.

[Tambe-95] Tambe, Milind, et all. (1995). Intelligent Agents for Interactive Simulation Environments, IA Magazine, Spring, pag 15 a 39.

[Trimble-85] Trimble, L. English for science and technology: a discourse approach. Cambridge University Press, 1985.

[Vergara-94] Vergara,H. PROTUM: A Prolog Based Tool for User Modeling. WIS Memo 10, WG Knowledge-Based Information Systems, Department of Information Science, University of Konstanz, Germany, 1994.

[White-94] White, J.E. Telescript technology: The Foundation for the eletronic marketplace. White paper, General Magic, Inc., 2465 Latham Street, Mountain View, CA 94040, 1994.

[Wolfson-89] Wolfson, N. Perspectives: Sociolinguistics and TESOL, Newbury House Publishers, N.Y., 1989.

[Wooldridge-95] Wooldridge, Michael and Jennings, Nicholas R. Intelligent Agents: Theory and Practice. Knowledge Engineering Review, 10 (2): 115-152, 1995.

[WTG-91] Writing Tool Group, Inc. Using Correct Grammar for Windows. Writing Tools Group, Inc. Sausalito, California, USA, 1991.

[Yazdani-91] Yazdani. M. The Linger Project - An Artificial Intelligence Approach to Second-Language Tutoring. CALL, Vol 4 (2), p.107-117, 1991. 


\section{Apêndice - Como utilizar o Sistema Adaptativo}

Este apêndice visa esclarecer ao leitor os procedimentos comuns iniciais que todo usuário deve executar para trabalhar com o novo Sistema AMADEUS que trabalha agora com o shell SMUA.

Sendo uma ferramenta colaborativa com uma arquitetura do tipo cliente/servidor, existe a necessidade de se executar o Lego Meeeting Server para carregar os agentes de comunicação para a troca de mensagens. A Figura 24 ilustra a execução deste agente.

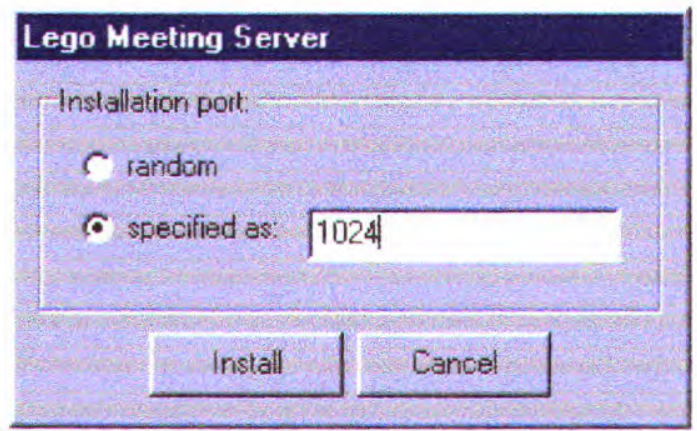

Figura 24: Instalação do Lego Meeting Server

Após a instalação do Meeting, é necessário a execução de todas as ferramentas que irão participar do projeto, para que estas possam se conectar ao sistema central de troca de mensagens (Meeeting Server).

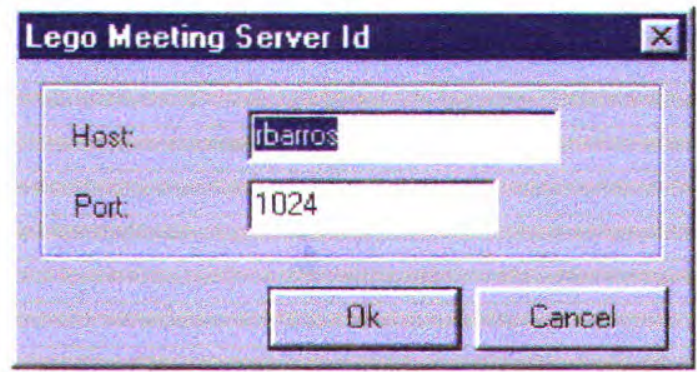

Figura 25: Execução das ferramentas 
Um fato importante é que cada ferramenta, bem como o estereótipo a ser modelado (no SMUA) e o nome do usuário que está usando o Lego Workbench deverá informar o seu Nike (nome pelo qual ele será identificado). A próxima figura ilustra esta situação:

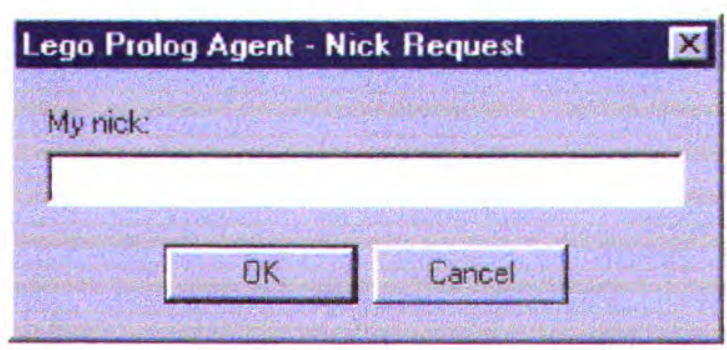

Figura 26: Entrando com o Nike

Após conectar as ferramentas, o passo seguinte é carregar o Workbench e o arquivo de vocabulário, que informa ao sistema quais serão os componentes disponíveis e sua hierarquia.

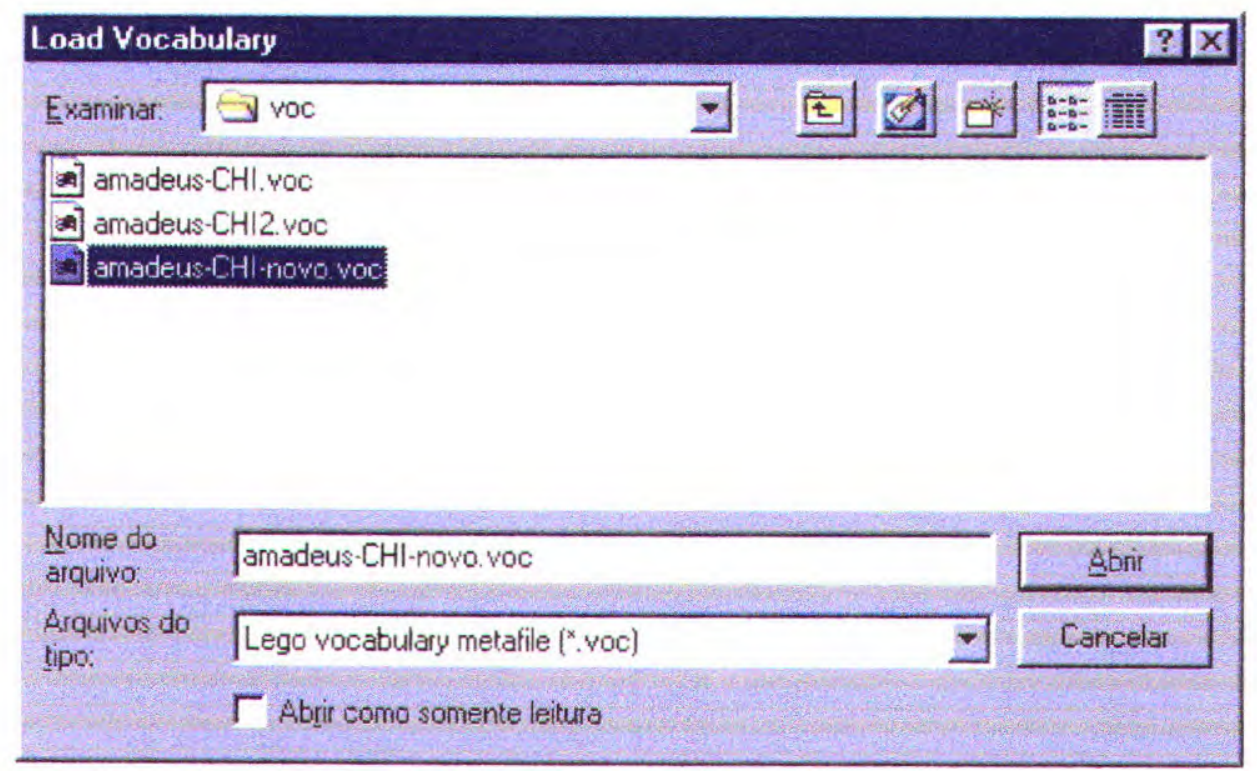

Figura 27: Carregando o arquivo de vocabulário

Para iniciar a execução do protótipo da ferramenta SMUA, o usuário deverá informar o seu Nick (nome pelo qual ele será identificado durante o processo de modelagem do usuário. Vale ressaltar que se o nome já existir (Estereotipo), então o modelo irá assumi-lo e continuará a partir do posto em que parou. Caso contrário, será criado um novo estereotipo padrão. A figura abaixo mostra a tela inicial, lembrando dos procedimentos necessários 


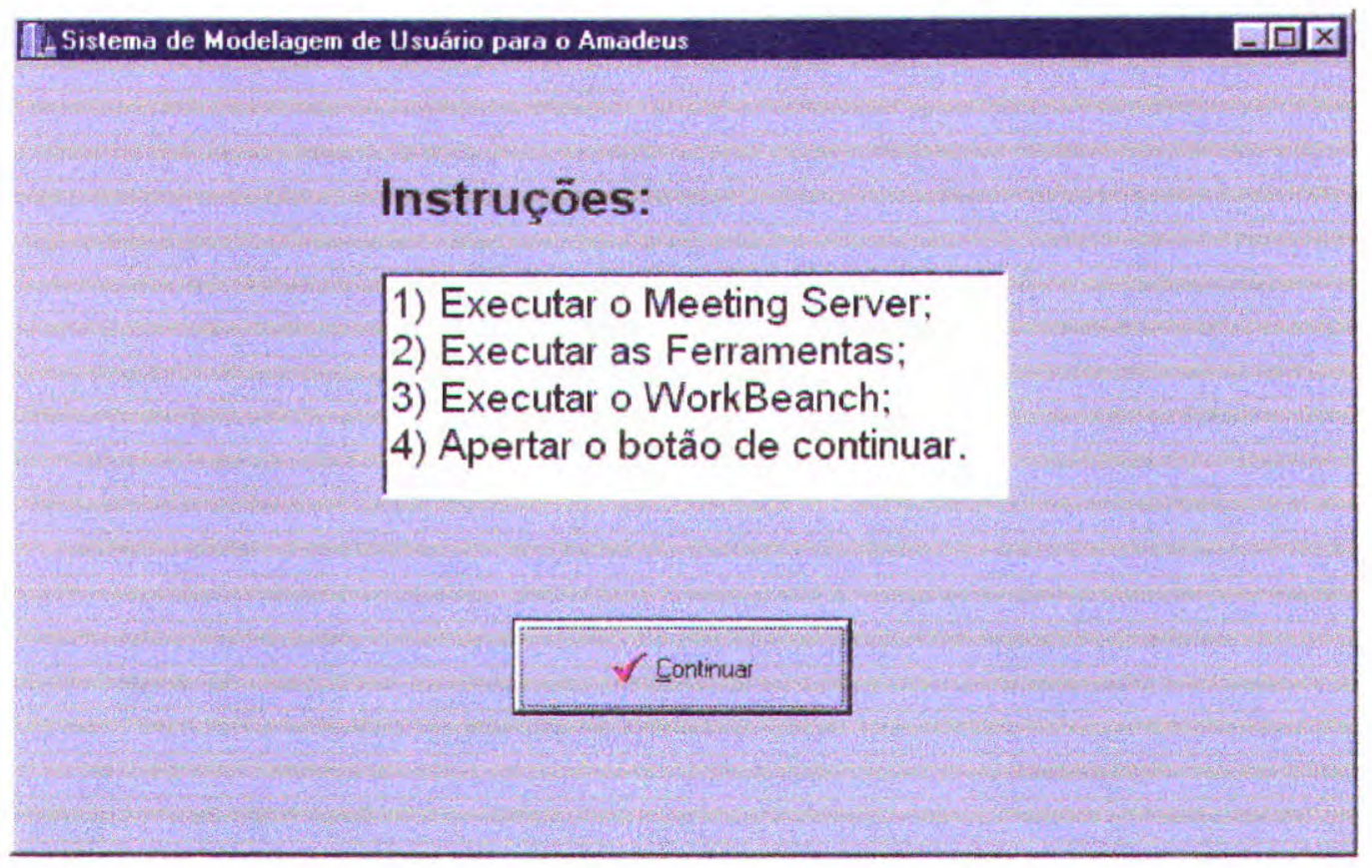

Figura 28: Tela de abertura do SMUA.

Depois de iniciar todas as ferramenta e já ter carregado o Lego Workbench com o arquivo de vocabularios, é necessario acionar o botão de continuar. Após isto deverá aparecer uma tela parecida com a mostrada abaixo: 


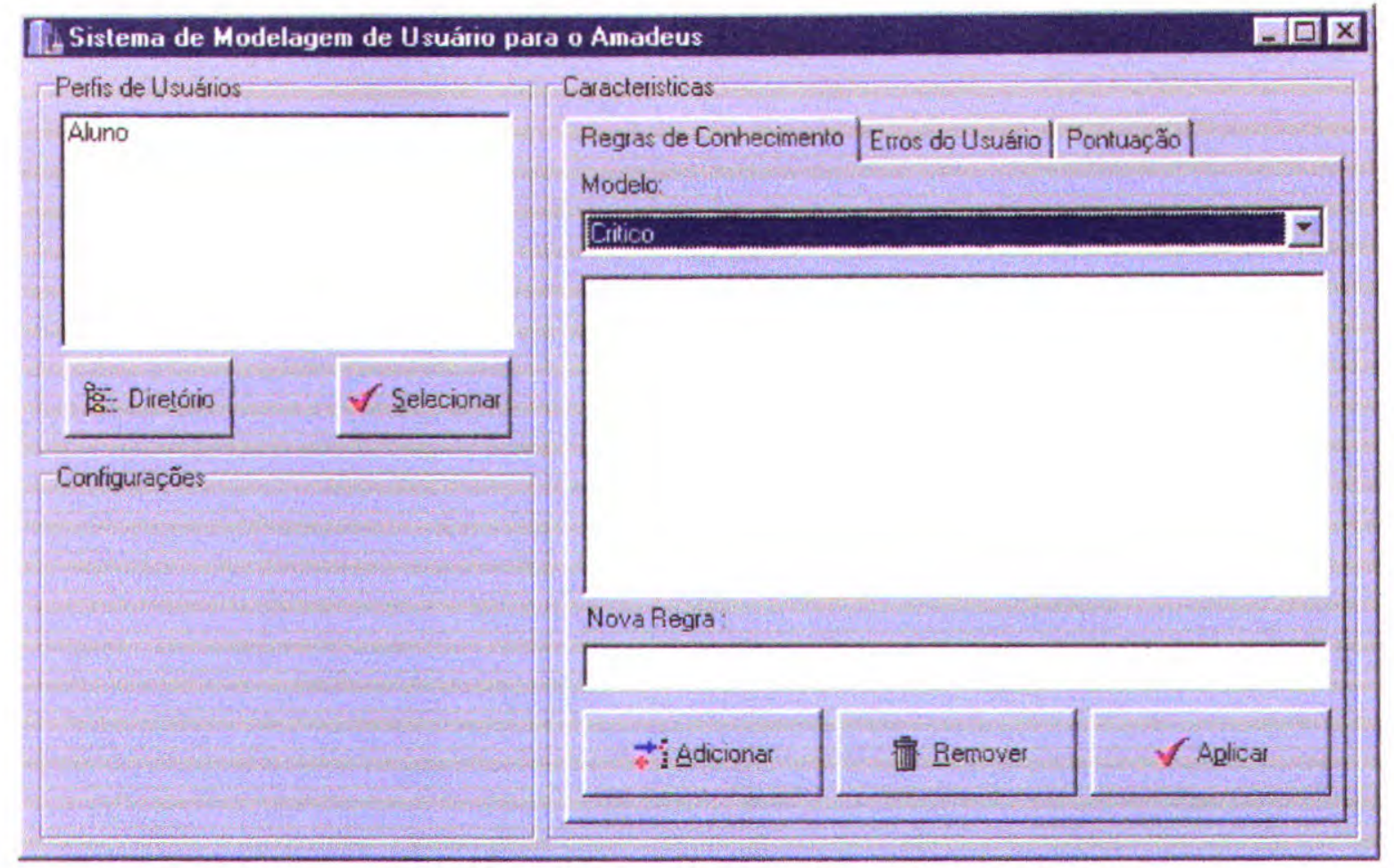

Figura 29: Tela inicial do SMUA

Para o usuário, o SMUA age de forma transparente. A ferramenta de interface é o Lego Workbench, que é mostrado abaixo.

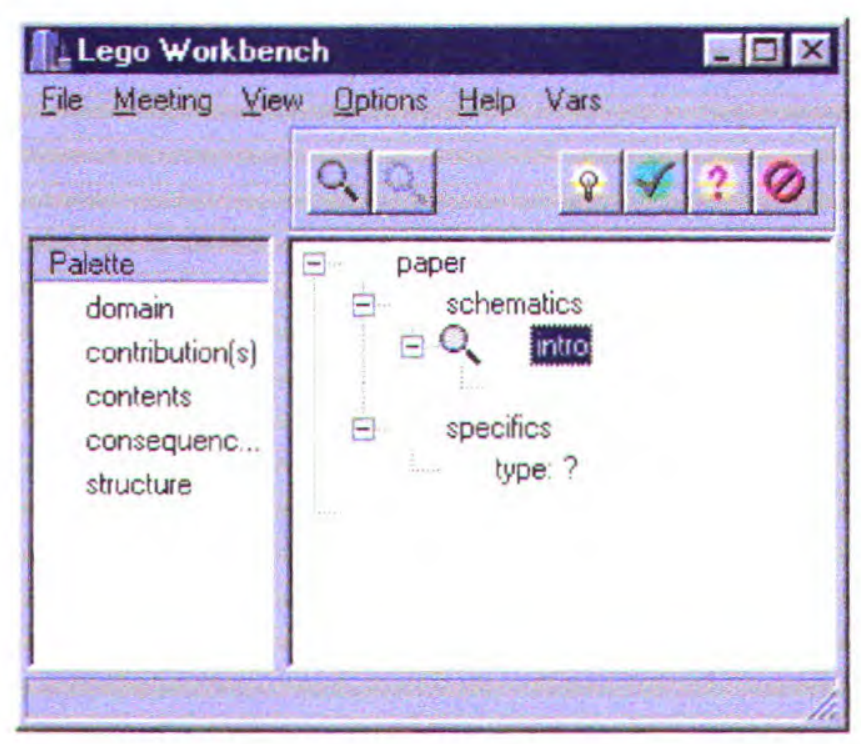

Figura 30: Iniciando a construção de um projeto.

O SMUA possui um sistema pelo qual o usuário ou um "professor" poderá criar as regras de inferência do domínio, bem como criar regras especificas de um estereotipo, 
verificando, por exemplo, o nome do usuário atual e comparando com um valor e se coincidir, aplicar alguma pontuação. A figura abaixo mostra o sistema de criação das regras:

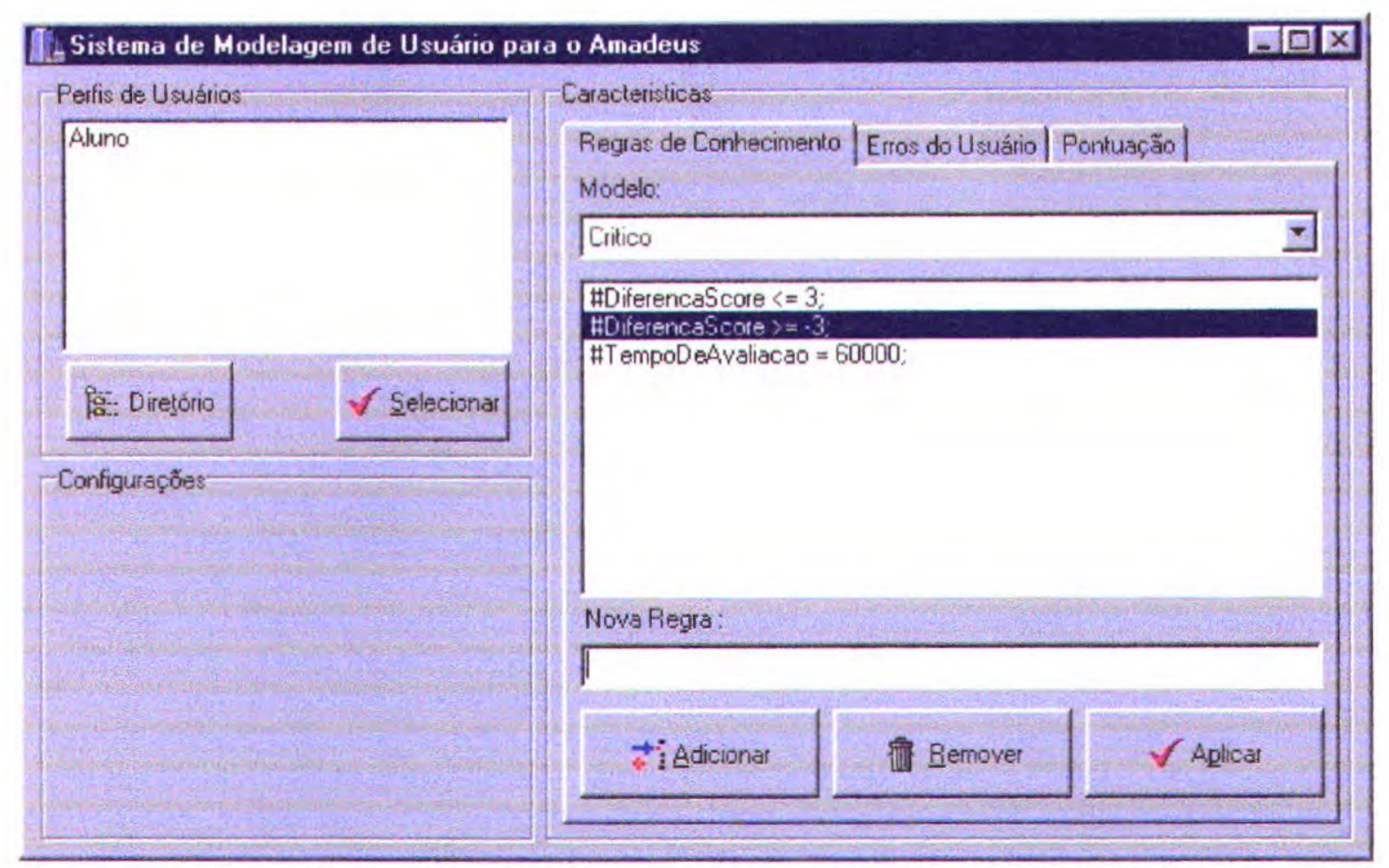

Figura 31: Criação de regras no SMUA.

Com o estereotipo já formado, a ferramenta poderá agir, mapeando as ações do usuário. A figura seguinte ilustra a criação de um outline por um usuário leigo: 


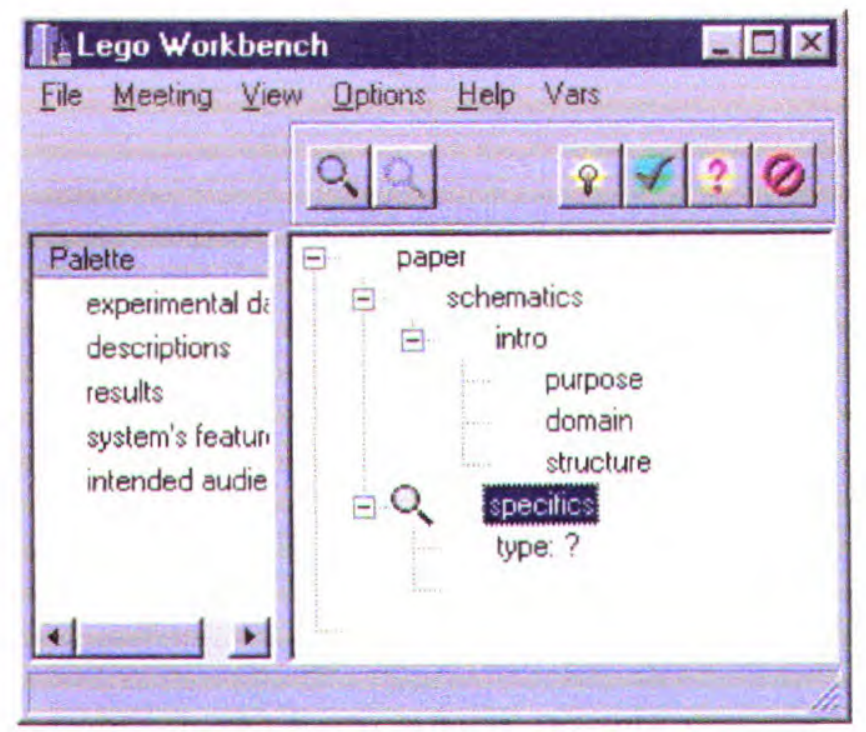

Figura 32: Um usuário leigo criando um outline.

De posse destas ações o sistema inicia o processo de modelagem de usuários, com as informações vindas das ferramentas. A figura abaixo ilustra a passagem de um usuário Leigo para Expert, após reconstruir o outline e obter um boa pontuação.

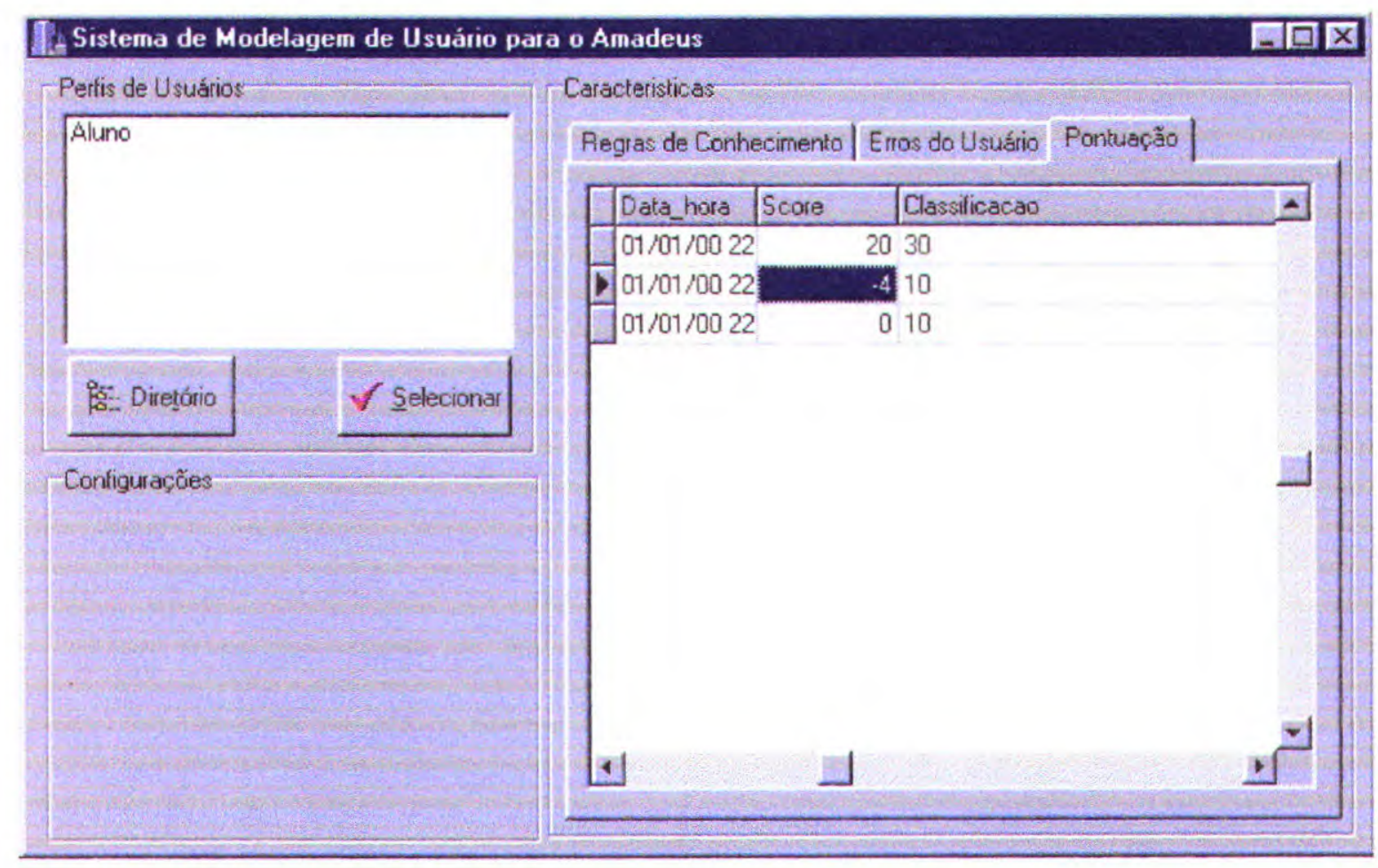

Figura 33: Mudança de perfil. 
Observe que a classificação é numérica, onde números maiores representam um usuário especialista, enquanto números menores representam um usuário leigo. Esses valores são informados pelas ferramentas, isto é, cada ferramenta envia a sua própria avaliação do usuário.

O sistema também armazena os erros e os acertos dos usuários. A Figura 34 ilustra alguns erros armazenados em uma base de teste.

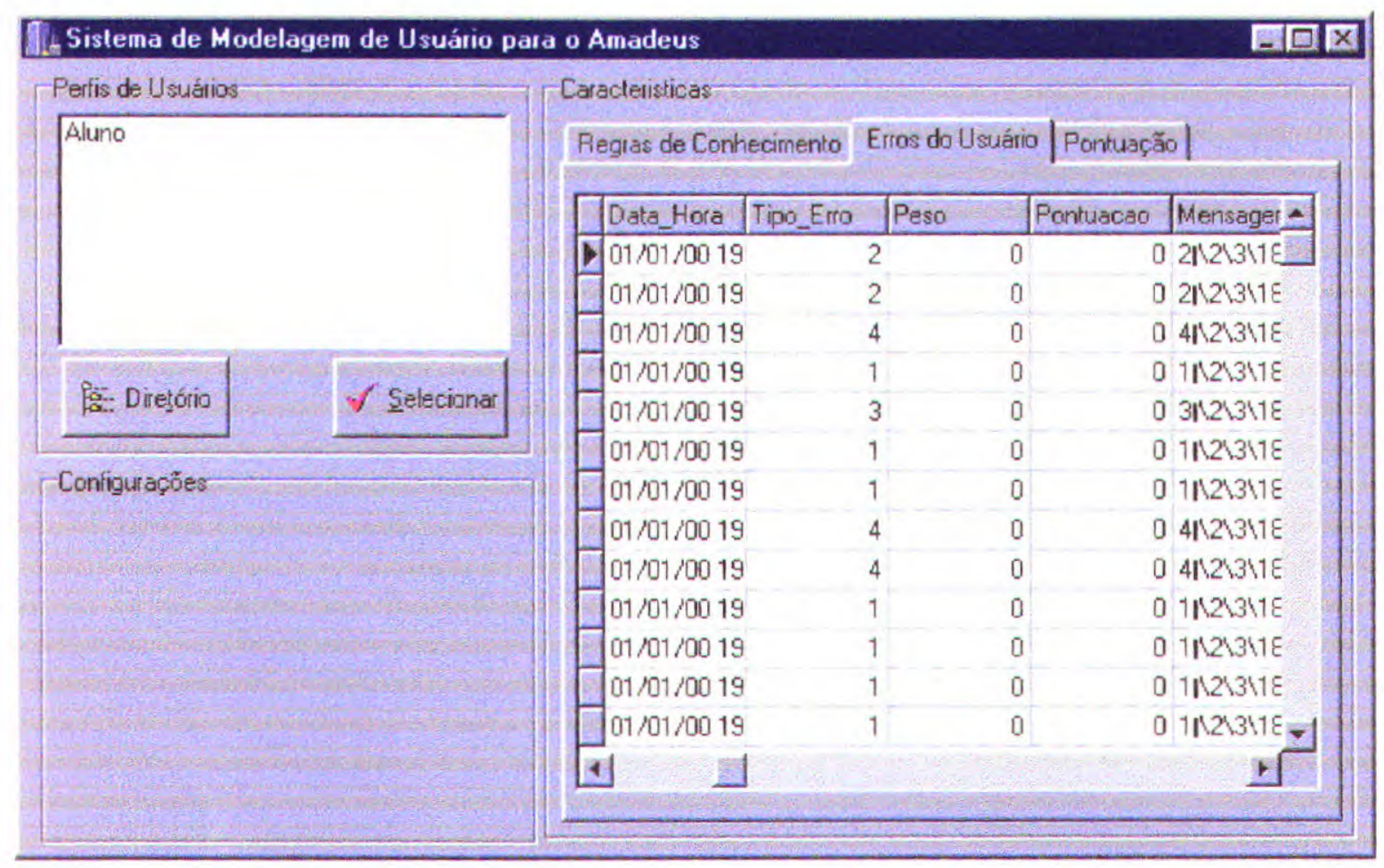

Figura 34: Erros e acertos do usuário reportados pelas ferramentas. 